\title{
Functional Analysis of E3 Ubiquitin Ligases in Developing Neurons
}

\author{
Dissertation \\ for the award of the degree \\ "Doctor rerum naturalium" \\ at the Georg-August-Universität Göttingen
}

within the doctoral programme Molecular Physiology of the Brain of the Georg-August University School of Science (GAUSS)

submitted by

Öyküm Kaplan

from Ankara, Turkey

Göttingen, 2019 


\section{Thesis advisory committee}

Prof. Dr. Nils Brose, Department of Molecular Neurobiology Max Planck Institute for Experimental Medicine, Göttingen

Prof. Dr. Thomas Dresbach, Department of Anatomy and Embryology, Göttingen University Medical Center

Prof. Dr. Tiago Fleming Outeiro, Department of Experimental Neurodegeneration, Göttingen University Medical Center

\section{Members of the Examination Board}

Referee: Prof. Dr. Nils Brose, Department of Molecular Neurobiology Max

Planck Institute for Experimental Medicine, Göttingen

$2^{\text {nd }}$ referee: Prof. Dr. Thomas Dresbach, Department of Anatomy and Embryology, Göttingen University Medical Center

Prof. Dr. Tiago Fleming Outeiro, Department of Experimental Neurodegeneration, Göttingen University Medical Center

\section{Further members of the Examination Board}

Dr. Camin Dean, Trans-synaptic Signaling, European Neuroscience Institute, Göttingen

Dr. Dr. Oliver Schlüter, Department of Psychiatry and Psychotherapy, University Medical Center Göttingen

Prof. Dr. Michael Müller, Department of Neurophysiology and Sensory Biology, University Medical Center Göttingen

Date of the oral examination: $18^{\text {th }}$ June 2019 
Hayatta en hakiki mürşit ilimdir.

Our true mentor in life is science.

Mustafa Kemal Atatürk (1881-1938)

Most people say that it is the intellect, which makes a great scientist.

They are wrong: it is character.

Albert Einstein (1879-1955)

Annem ve babama.

To my parents. 


\section{TABLE OF CONTENTS}

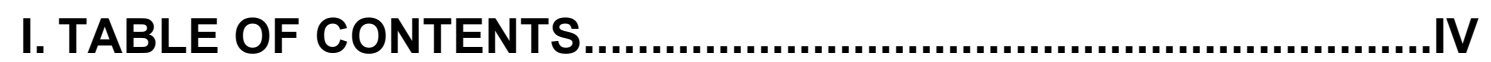

II. LIST OF ABBREVIATIONS ....................................................VII

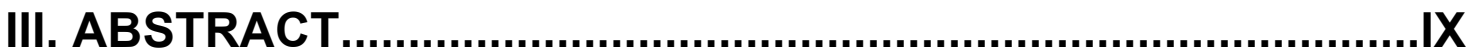

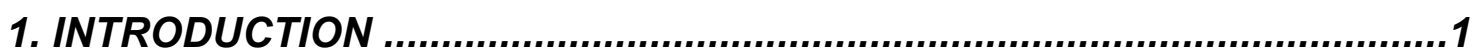

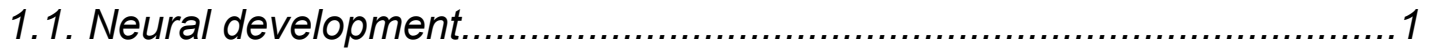

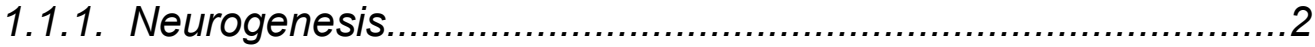

1.1.2. Neural migration......................................................................

1.1.3. Neuritogenesis: formation of axon and dendrites..................... 4

1.1.4. Synaptogenesis and synapse elimination............................. 5

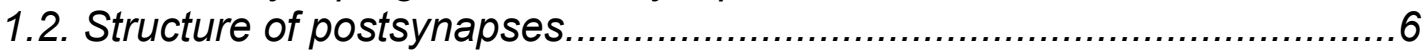

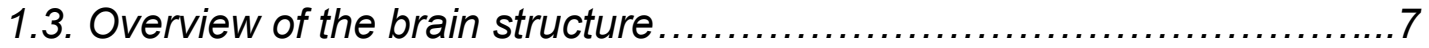

1.3.1. Structure of the hippocampus........................................

1.4. Roles of hippocampus in memory formation ..............................9

1.5. Ubiquitination .......................................................... 10

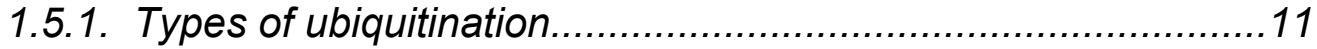

1.5.2. Nedd4 family E3 ligases............................................... 13

1.5.3. Nedd4 ligases in brain.........................................................14

1.5.4. Ubiquitination and memory formation.................................16

1.6. Aims of the study ...................................................... 17

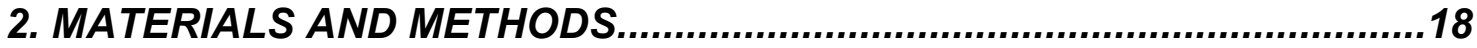

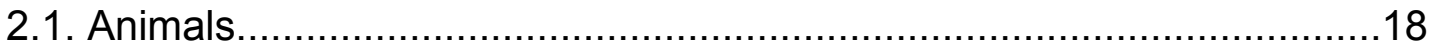

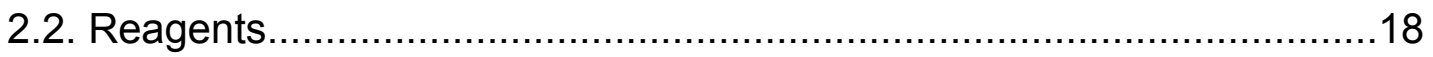

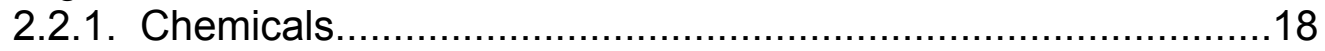

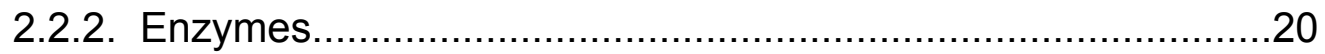

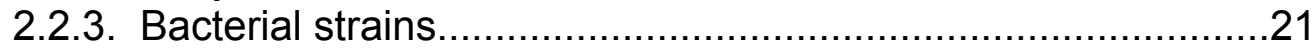

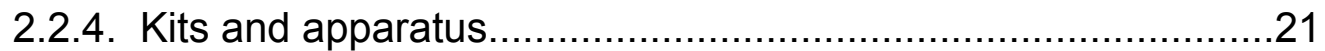

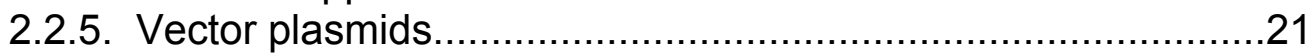

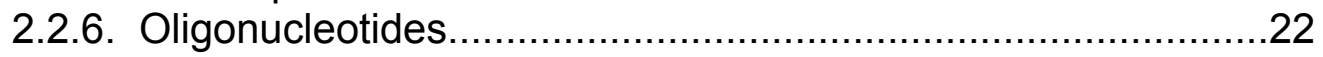

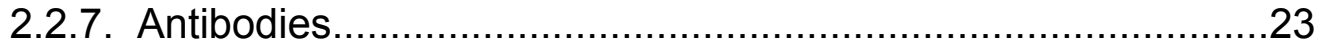

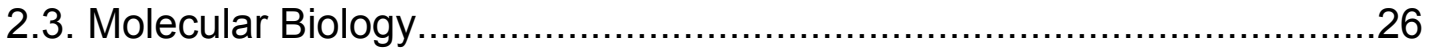

2.3.1. Bacterial transformation of plasmid DNA ..............................26

2.3.1.1. Chemical transformation........................................26

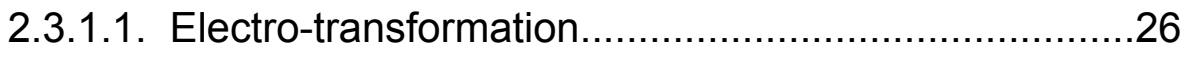

2.3.2. Glycerol stock preparation...................................27

2.3.3. Plasmid DNA purification....................................27

2.3.4. Determination of DNA concentration ...........................27

2.3.5. DNA sequencing............................................... 28

2.3.6. DNA digestion with restriction endonucleases...................28

2.3.7. Agarose gel electrophoresis.................................. 28

2.3.8. Gel extraction ....................................................

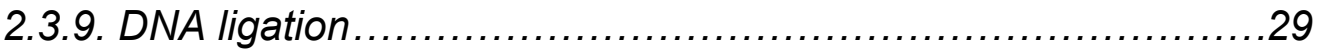

2.3.10. Polymerase chain reaction (PCR) ..........................29

2.3.11. TOPO-TA subcloning .......................................... 30

2.3.12. Site-directed mutagenesis. ................................... 30 
2.3.13. Isolation of genomic DNA from mouse tail biopsies..............31

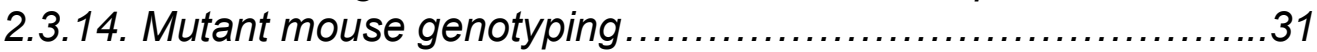

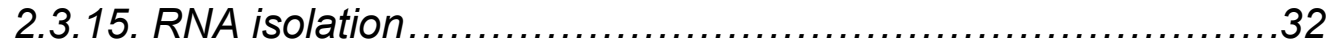

2.3.16. Measuring RNA concentration .................................32

2.3.17. cDNA synthesis...............................................32

2.3.18. Real time quantitative reverse transcription PCR (qRT-PCR)...33

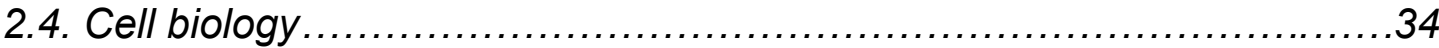

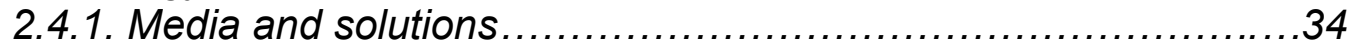

2.4.2. Treatment of coverslips for culturing primary neurons..............34

2.4.3. Primary mouse neuron culture preparation ...........................35

2.4.4. HEK293FT cell line ................................................. 36

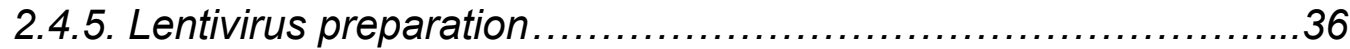

2.4.6. Lentiviral infection of neurons ................................... 37

2.4.7. Immunocytochemistry ..........................................

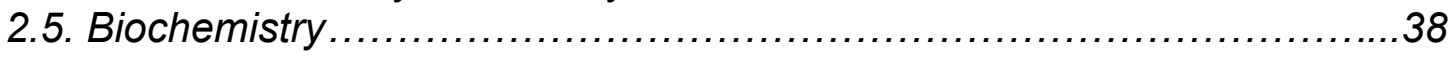

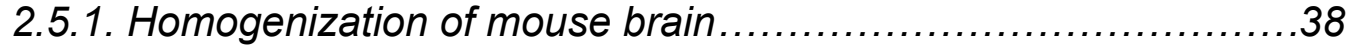

2.5.2. Harvesting neuron culture .......................................38

2.5.3. Estimation of protein concentration ...............................38

2.5.4. Sodium dodecyl sulfate polyacrylamide gel electrophoresis (SDS-

PAGE)............................................................... 39

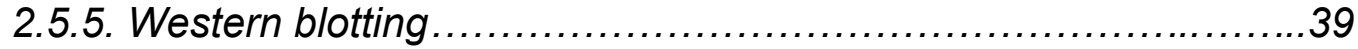

2.5.6. Purification of recombinant GST-fused proteins...................40

2.5.7. Protein extraction from HEK293FT cells..........................41

2.5.8. In vitro binding assay ...........................................42

2.5.9. In vivo ubiquitination assay....................................42

2.5.10. Biotinylation assay in primary cultured neurons..................43

2.5.11. Subcellular fractionation of mouse brain .........................44

2.6. Histology ................................................................ 45

2.6.1 In utero electroporation (IUE) ................................45

2.6.1.1 Preparation of glass capillaries..........................45

2.6.1.2 Preparation of plasmid DNA for IUE ....................45

2.6.1.3. Procedure................................................45

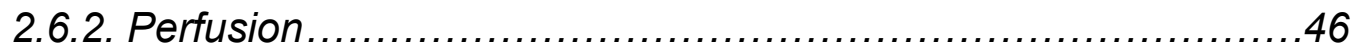

2.6.3. Immunohistochemistry ....................................... 47

2.7. Behavioral analysis .................................................... 47

2.7.1. Animals and housing conditions ...............................47

2.7.2. Elevated plus-maze.............................................48

2.7.3. Open field..................................................... 48

2.7.4. Hole board................................................... 49

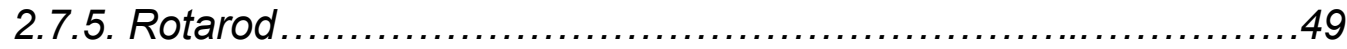

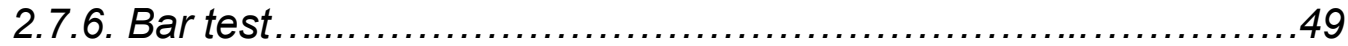

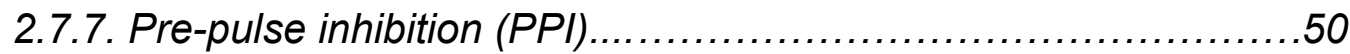

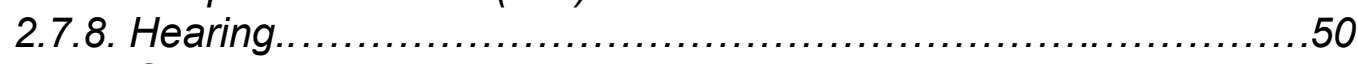

2.7.9. Grip strength..................................................... 50

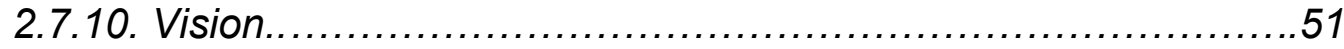


2.7.11. Morris Water Maze and reversal.................................51

2.8. Electrophysiology ................................................ 52

2.9. Live imaging of primary cultured neurons..............................53

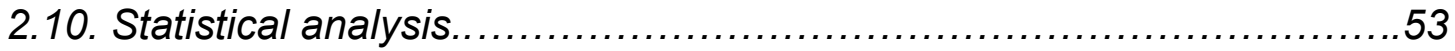

3. RESULTS............................................................................

3.1. Role of Nedd4s in postsynaptic density................................54

3.1.1. Localization of Nedd4-2 in the neuron ..........................54

3.1.2. Identification of proline-rich protein 7 (Prr7) in proteome screening

of Nedd4-1;Nedd4-2 substrates.............................................55

3.1.3. Neuronal N4-2 as a relevant E3 ligase gene for the regulation of

Prr7 protein level.............................................................56

3.1.4. Increased surface expression of Prr7 in N4-2 KO hippocampal neurons.

3.1.5. E3 ligase activity-dependent regulation of Prr7 by N4-2 ..........59

3.1.6. Ubiquitination of Prr7 by N4-2..................................61

3.1.7. First and second WW domain-binding PY motifs of Prr7 as responsible regions for N4-2-binding and for N4-2-dependent ubiquitination..62

3.1.8. Subcellular localization of Prr7...............................64

3.1.9. N4-2 regulates spine size and leads to emergence of bifurcated spines 65

3.1.10. Improved memory formation and re-learning ability in N4-2 KO mice ........................................................................67

3.1.11. No change in postsynaptic density proteins in hippocampal tissue of N4-2 KO mice subjected to behavior analysis..........................75

3.1.12 Electrophysiology ............................................. 79

3.1.13. Intact levels of p-CaMKIla and CaMKIla in stimulated hippocampal tissue of N4-2 KO mice......................................... 81

3.2. Cell autonomous and non-cell autonomous regulations of excitotoxicity by N4-2..

3.2.1. N4-2 KO neurons are resistant to neural death upon NMDA treatment....................................................................... 83

3.2.2. Astroglial protein Connexin-43 as a substrate of Nedd4-2 E3

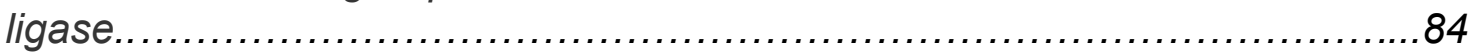

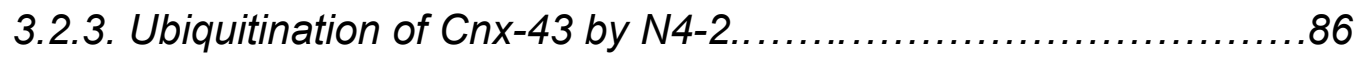

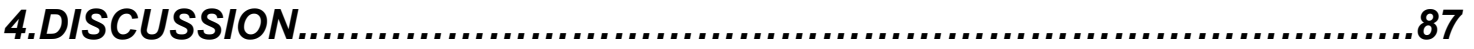

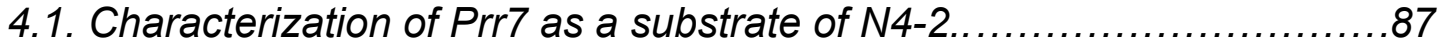

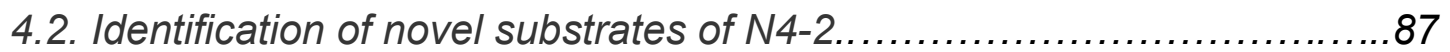

4.3. Neuronal N4-2 enhances spatial reversal learning .......................90

4.4 Neuronal N4-2 as a regulator for L-LTP...............................92

4.5. Roles of N4-2 in neuronal apoptosis..................................93

4.6. Multiple layers of the regulation of Prr7 level.............................99

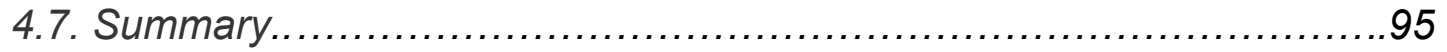

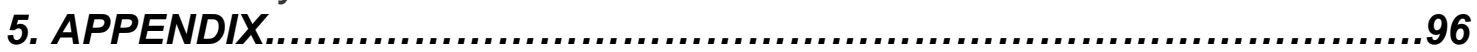

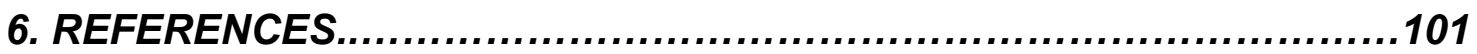

7. ACKNOWLEDGEMENTS ..............................................118

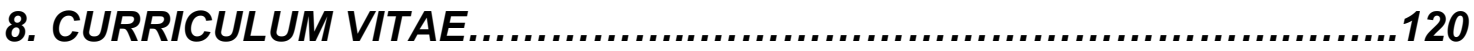




\section{LIST OF ABBREVIATIONS}

\begin{tabular}{|l|l|}
\hline AMP & Adenosine-5'-monophosphate \\
\hline AMPAR & a-amino-3-hydroxy-5-methyl-4isoxazolepropionic acid receptor \\
\hline ATP & Adenosine triphosphate \\
\hline BSA & Bovine serum albumin \\
\hline CA1, 2, 3 & Cornu Ammonis 1, 2, 3 \\
\hline Cre & Cre recombinase \\
\hline cKO & Conditional knockout \\
\hline dcKO & Double conditional knockout \\
\hline DIV & Day in vitro \\
\hline DNA & Deoxyribonucleic acid \\
\hline DUB & Deubiquitinase \\
\hline E1 & Ubiquitin activating enzyme \\
\hline E1, 2, 3... & Embryonic day 1, 2, 3... \\
\hline E2 & Ubiquitin conjugating enzyme \\
\hline E3 & Ubiquitin ligase \\
\hline EMX1 & Empty spiracles homolog 1 \\
\hline E-LTP & Early phase LTP \\
\hline EPSC & Excitatory postsynaptic current \\
\hline GFP & Green fluorescent protein \\
\hline GST & Glutathione S-transferase \\
\hline HA & Hemagglutinin \\
\hline
\end{tabular}




\begin{tabular}{|l|l|}
\hline HECT & Homologous to E6-AP C-terminus \\
\hline IP & Immunoprecipitation \\
\hline IUE & In utero electroporation \\
\hline kDa & Knockout \\
\hline L-LTP & Kilo Dalton \\
\hline LTD & Late phase LTP \\
\hline LTP & Long term potentiation \\
\hline N-terminal & Amino-terminal \\
\hline Nedd4 & $\begin{array}{l}\text { Neural precursor cell expressed developmentally down-regulated } \\
4\end{array}$ \\
\hline NEX1 & Neurogenix differentiation factor 6 \\
\hline NMDAR & N-methyl-D-aspartate receptor \\
\hline P1, 2, 3... & Postnatal day 1, 2, 3... \\
\hline PPR & Paired Pulse Ratio \\
\hline Prr7 & Proline rich protein 7 \\
\hline PSD & Postsynaptic density \\
\hline RGC & Radial glial cell \\
\hline SDS-PAGE & Sodium dodecyl sulfate-polyacrylamide gel electrophoresis \\
\hline Ub & Ubiquitin \\
\hline WB & Western blotting \\
\hline
\end{tabular}




\section{ABSTRACT}

Neuronal development starts after the closure of the neural tube when neural stem cells begin to divide asymmetrically at the ventricular zone of the forebrain. Newborn neurons then migrate vertically from the ventricular zone to the cortical plate to reach their destinations and start generating axons and dendrites. After completing neuronal migration, neurons further extend and branch axons and dendrites. In the final step of neuronal development, neurons establish neuronal networks by forming and refining chemical synapses through synaptogenesis and synapse elimination. These four developmental steps are spatially and temporarily regulated by multiple signaling pathways. Ubiquitination, which is a regulatory posttranslational modification, is one of the most crucial processes necessary for such complex synaptic formation. In this study, we demonstrate the roles of Nedd4 family E3 ubiquitin ligases in nerve cells and characterize substrate proteins contributing to the current understanding of molecular and cellular pathologies in neurological diseases. 


\section{INTRODUCTION}

The human brain is composed of $\sim 10^{12}$ neurons, each of which is connected with other neurons through 1000 synapses on average. Neuronal networks, composed of $\sim 10^{15}$ synapses, play essential roles in the regulation of complex brain functions, including motor and cognitive functions. Neurons have a structure like none of the other cells in the body, with an extended axon and highly branched dendrites and are connected via synapses to other neurons. Thus creating uninterrupted neural connectivity, which makes the nervous system unique (Brose, 1999; Alberts et al., 2002). Addition of a small globular protein called ubiquitin to a substrate protein is named ubiquitination. It is a posttranslational modification, one of the most critical processes required for such complex synaptic formation. In this thesis, I explain how specific protein ubiquitination pathways regulate brain development and function.

\subsection{Neural development}

Development of neurons starts after the closure of the neural tube when neural stem cells begin to divide asymmetrically at the ventricular zone of the forebrain. Newborn neurons migrate vertically from the ventricular zone to the cortical plate to reach their destinations and start projecting axons and dendrites. After completing neuronal migration, neurons further develop arborization of axons and dendrites. In the final step of neuronal development, neurons establish neuronal networks by forming and refining chemical synapses through synaptogenesis and synapse elimination (Figure 1.1) (Kawabe and Brose, 2011). 


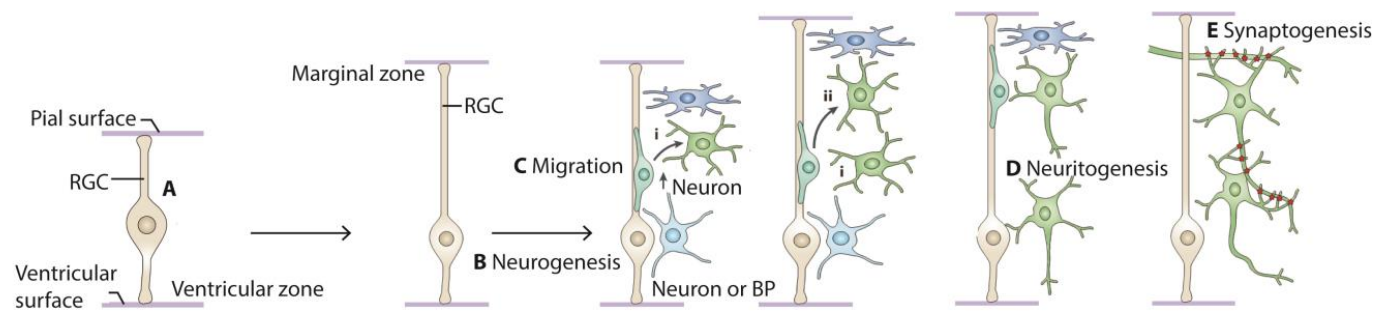

Figure 1.1. Neural development steps in mammalian brain. (A) The extension of in the basal protrusion of radial glial cells (RGCs) in the developing cortex. RGCs have the potential to turn into premature neurons, intermediate progenitors (IPs) and glial progenitors (oligodendrocytes and astrocytes). (B) RGCs produce premature neurons or basal progenitor (BP) cells upon asymmetric division. (C) As newly generated neurons migrate along RGC processes they receive a signal from Cajal-Retzius cells (shown in dark blue). Then they distribute throughout the cortical plate (i), and start to differentiate (ii). (D) Generation of the immature axon and immature dendrites. (E) Extension of the processes of neurons and generation of networks by synaptogenesis and synapse elimination (Modified from Kawabe and Brose, 2011, with license number 4575271327304).

\subsubsection{Neurogenesis}

The neural plate and neural tube are made up of a single layer of cells called neuroepithelial cells, which produce the neuroepithelium. During the cell cycle, interkinetic nuclear migration, the phenomena of up-and-down migration of nuclei inside neuroepithelial cells through the apical-basal axis occurs. Because of this process, the neuroepithelium looks like it is layered (pseudostratified). Neuroepithelial cells carry typical epithelial features and are polarized along their apical-basal axis. Tight junctions and adherence junctions are found at the apical end of the lateral plasma membrane. Specific transmembrane proteins such as prominin-1 (CD133) are selectively found in the apical plasma membrane, as well as receptors for basal lamina constituents like integrin that attaches to the basal lamina. 
Generation of neurons leads to the transformation of the neuroepithelium into a tissue with several cell layers. With the start of neurogenesis, neuroepithelial cells downregulate specific epithelial features followed by the appearance of astroglial markers. After that, neuroepithelial cells differentiate to radial glial cells. These cells exhibit both neuroepithelial and astroglial properties. Radial glial cells have more fate-restricted progenitors compared to neuroepithelial cells, and a big population of neurons in the brain originate from radial glial cells either directly or indirectly.

Another type of neuronal progenitor called the basal progenitor originates from the mitosis of neuroepithelial and radial glial cells. Basal progenitors carry different characteristics from neuroepithelial and radial glial cells as they express different genes such as the non-coding RNA, SVET1, and genes encoding the transcription factors TBR2, CUX1, and CUX2 (Götz \& Huttner, 2005).

\subsubsection{Neural migration}

Similar to other motile cells, migration of neurons occur in three steps; (i) leading edge extension, (ii) nuclear translocation, also known as nucleokinesis, and (iii) retraction of the trailing process. Migration starts with the extension of leading edges of the cell by filopodia and lamellipodia that explore the microenvironment. It is followed by nucleokinesis, which refers to transfer of nucleus to the leading process, which is critically regulated by microtubule cytoskeleton. Nucleokinesis is followed by retraction of the trailing process. Compared to the other cell types, only neurons produce defined cell patterns at the end of migration, which could be named as the fourth and final step of neuronal migration (Rouvroit \& Goffinet, 2001).

Reelin is synthetized in early-generated Cajal-Retzius cells in the marginal zone, and has been identified as a crucial protein for the correct alignment of cortical neurons (Honda et al., 2011). Neurons are generated close to lateral ventricle, and then migrate until they pass the marginal zone. Since 
recently produced neurons go through the same pathway, they end up closer to the marginal zone, and it leads to the formation of in an "insideout" pattern. In the end, firstly generated neurons settle at a deeper position and recently generated neurons are placed in a superficial position in the cortical plate. This migration process is determined by the Reelin signaling pathway. It has been shown that this alignment is completely altered in reeler mutant mouse lacking Reelin protein (Frotscher, 1998).

\subsubsection{Neuritogenesis: formation of axon and dendrites}

After creation and differentiation of neurons, neurons loose their symmetry by producing axons and dendrites, and generate two structurally and functionally distinct compartments. This process starts with generation of small protrusions, called neurites, and then they start polarizing and only one neurite turns to an axon, while the rest of neurites will develop to dendrites.

There are four key steps maintaining neurite extension. 1) Increase in plasma membrane surface amount by vesicle recruitment and fusion. Amount of signaling molecules such as Rho GTPase and phosphatidylinositol 3-kinase (PI3K) are elevated, and they become activated. 2) Population of actin filaments are increased, 3) Then an increase in microtubule assembly. Even a small amount of microtubule growth also triggers an opposite reaction: diminish in microtubule as well as actin filament dynamics and increased endocytosis. 4) An extensionretraction cycle is produced to have balanced positive and negative signals before polarization. When there is a positive cue occurring in this balance, continuous self-activation system (positive feedback loop) is activated, and generation of axon starts. This system also leads to strong negative feedback signals and blocks all other neurites from creating a second axon (Arimura \& Kaibuchi, 2007). 


\subsubsection{Synaptogenesis and synapse elimination}

Synapse formation is the last step in the development of a neuron. Synaptic junctions are asymmetric cell-to-cell contacts, which are composed of three components: presynaptic bouton, synaptic cleft, and postsynaptic spine. The presynaptic bouton has synaptic vesicles filled with neurotransmitters. Those vesicles dock at the presynaptic active zone and fuse with presynaptic plasma membrane to release neurotransmitter into the synaptic cleft. The presynapse is specialized for complex membrane trafficking in order to control neurotransmitter release with spatiotemporal precision. Directly opposed to the presynapse is the postsynaptic plasma membrane. The postsynaptic compartment is scaffolded by an electron-dense structure called the postsynaptic density (PSD) The PSD is responsible for accumulating and anchoring postsynaptic receptors and ion channels at a high density. The postsynapse is specifically developed for signal transduction, containing a complex structure of neurotransmitter receptors, ion channels, and a collection of intracellular signal transduction molecules (Garner et al., 2002).

The complex structure of synapses is established in two steps, synaptogenesis and synapse elimination. Synaptogenesis starts with the initial contact between an axonal growth cone and a target cell. The growth cone targets a certain population of target cells via specific pairs of cell adhesion proteins. Following the initial contact, pre- and postsynaptic protein recruitment starts, and synapse asymmetry is maintained by transsynaptic signaling. After formation of immature synapses, a significant population of synapses is eliminated whereas some others are strengthened during brain development. This balance between synapse elimination and strengthening is regulated by synaptic activity, which plays a critical role for the establishment of proper neuronal networks that mediate learning and memory processes (Brose, 1999). 


\subsection{Structure of postsynapses}

Neuronal communication gives rise to numerous processes from basic to higher-order that are required for regular brain function. This communication is achieved at a specific and compartmentalized site of contact lying between a presynaptic nerve terminal and a postsynaptic neuron: the synapse. The presynaptic terminal transfers information via chemical message with the help of particular receptors in the postsynaptic membrane, where the received message is processed. Synapses are produced from the differential propagation and amount of particular presynaptic and postsynaptic proteins, which leads to explicit organization as well as appropriate function (Scannevin \& Huganir, 2000; Südhof \& Malenka, 2008).

Glutamate is a neurotransmitter responsible for the majority of excitatory neurotransmission in the central nervous system with the help of several glutamate receptors; ionotropic receptors that consist of ion channels, and metabotropic receptors that are coupled to $G$ proteins. lonotropic glutamate receptors consist of three main subtypes depending on their pharmacological and electrophysiological characteristics and sequence homology: $\alpha$-amino-3-hydroxy-5-methyl-4-isoxazole propionate (AMPA), kainate, and $N$-methyl-D-aspartate (NMDA) receptors. AMPA and kainate receptors mainly regulate fast electrophysiological responses to glutamate level. Additionally, NMDA receptors are regulated by calcium through the ion pore, therefore involved with synaptic plasticity (Paoletti et al., 2013). Metabotropic glutamate receptors on the other hand, relate glutamate release to $G$ protein-mediated signaling cascades in the postsynaptic membrane. Moreover, in the postsynaptic density, there are multiple of PDZ domain containing scaffold proteins such as postsynaptic density protein 95 (PSD-95), which coordinates glutamate receptors and related signaling proteins. PDZ domain containing proteins are key regulators controlling protein content and structure at the synapse, which are also affected by protein synthesis and degradation, as well as subcellular distribution and post-translational modification. All in all they assist to create clear-cut 
assembly and construction of the postsynapse (Kim \& Sheng, 2004; Scannevin \& Huganir, 2000).

\subsection{Overview of the brain structure}

The brain can be categorized into three main parts: the hindbrain, midbrain, and forebrain. Among them, the hindbrain is composed of the medulla, pons, and cerebellum, the midbrain is composed of tectum and tegmentum, and the forebrain is comprised of the diencephalon and cerebral hemispheres. Actions related to the cognitive abilities happen mainly in the cerebrum or cortex in the brain. Between the two hemispheres, the cortex can be separated into four anatomically defined lobes named as frontal, parietal, temporal, and occipital lobes. The cortex is the biggest part in the human brain that has been linked with higher brain functions like thought and action (Kandel et al., 2000).

\subsubsection{Structure of the hippocampus}

The hippocampus is located within the medial temporal lobe in the brain, forming the central part of the limbic system. The development and the function of neurons and synapses have been studied in this region, because of its relatively simple and well defined neuronal network pattern, which makes it possible to perform electrophysiological as well as morphological studies.

The hippocampus is composed of the dentate gyrus and the Ammon's horn field carrying four parts of the Cornu Ammonis 1-4 (CA1- 4). The laminar neuronal pathway called the trisynaptic loop is the basis of hippocampal neuronal circuit (Figure 1.2). Sensory information of neurons in layer II of the entorhninal cortex transfer excitatory input to the dendrites of granule cells through the perforant path (PP). Granule cells send projections to the proximal apical dendrite of CA3 pyramidal cells via the mossy fiber pathway. 
Axons of CA3 pyramidal neurons project to ipsilateral CA1 pyramidal neurons by Schaffer collaterals and to contralateral CA3 and CA1 pyramidal cells by commissural connections. CA3 pyramidal neurons also receive direct input from layer II cells of the entorhinal cortex. Layer III cells of the entorhinal cortex excite the distal apical dendrites of CA1 pyramidal neurons (Neves et al., 2008; Deng et al., 2010).

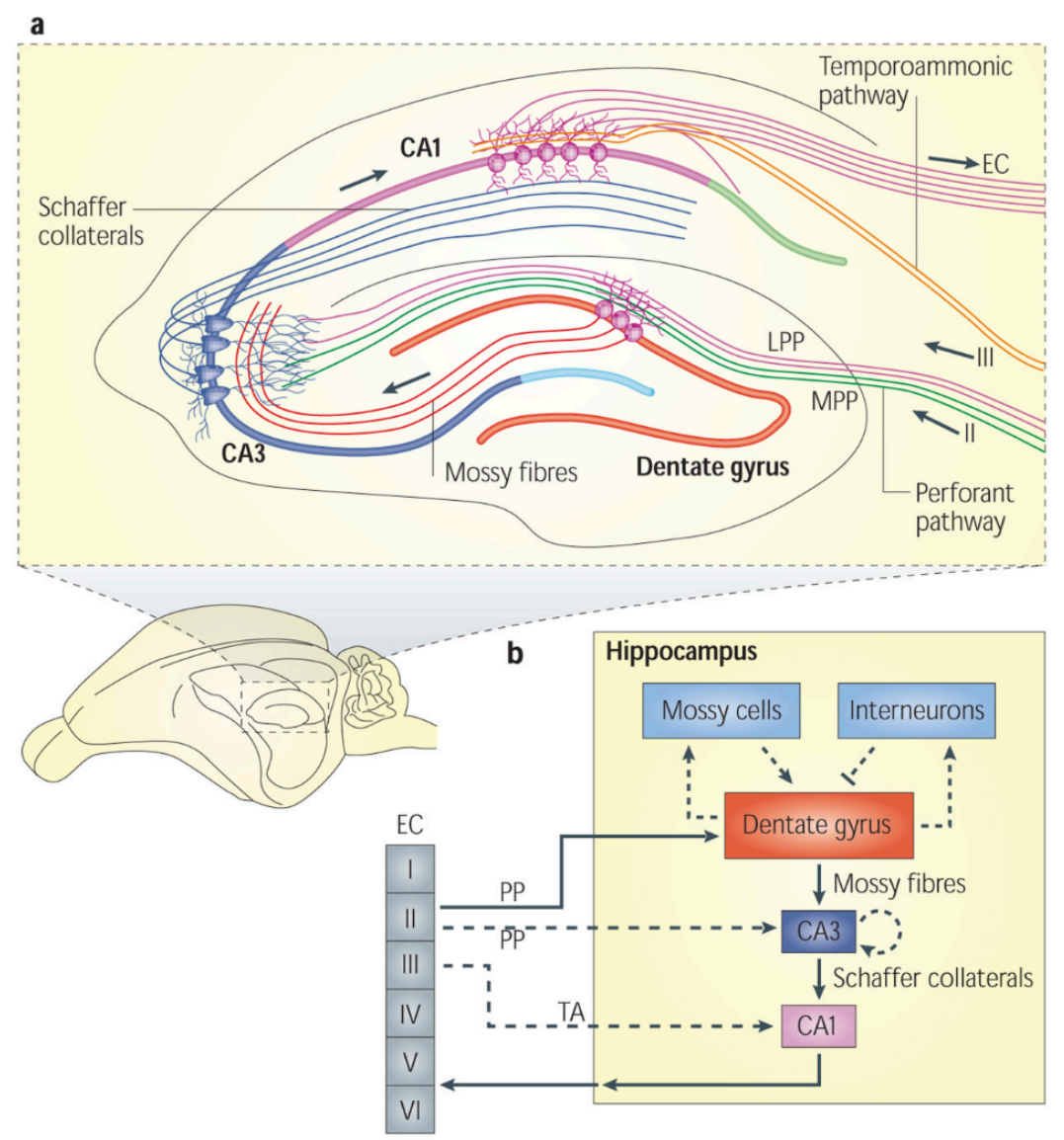

Figure 1.2. Illustration of the rodent hippocampus a. An illustration of the hippocampal circuitry in rodents. b. Scheme of the hippocampal neural network demonstrating excitatory trisynaptic pathway (entorhinal cortex (EC)-dentate gyrus-CA3-CA1-EC) is shown by solid arrows. The axons from layer II neurons in the entorhinal cortex send projections to the dentate gyrus via the perforant pathway (PP), including the lateral perforant pathway (LPP) and medial perforant pathway (MPP). The dentate gyrus projects to the pyramidal cells in CA3 through mossy fibres. CA3 pyramidal neurons transfer information to CA1 pyramidal neurons via Schaffer collaterals. CA1 pyramidal neurons in turn send back-projections into deep-layer neurons of 
the EC. CA3 neurons also receive direct projections from EC layer II neurons via the PP. CA1 neurons receive direct inputs from EC layer III neurons via the temporoammonic pathway (TA). The dentate granule cells also send projections to the mossy cells in the hilus and hilar interneurons, which send excitatory and inhibitory projections back to the granule cells (Deng et al., 2010, with license number 4575280057012).

\subsection{Roles of the hippocampus in memory formation}

In the adult brain, the hippocampus is a primary structure for the formation of specific kinds of memory such as episodic memory and spatial memory. Interactions of hippocampus with different brain structures linked with emotion also affect emotional behavior (Neves et al., 2008; Bird \& Burgess, 2008). Activity-dependent synaptic plasticity has a critical role in the production of synaptic connections, and it has been demonstrated several times that memory formation relies on alterations in synaptic efficiency that enables strengthening and weakening of neuronal connections (Lynch, 2004). Synaptic plasticity is also responsible for the early development of neural circuitry, and disturbances in synaptic plasticity cause numerous neuropsychiatric disorders (Citri \& Malenka, 2008).

Memory formation can be divided into two forms: short-term memory lasting a few minutes, and long-term memory that lasts for some hours, days and even longer. The storage of long-term memory requires gene expression as well as de novo protein synthesis, leading to generation of new synaptic connections at the cellular level (Lynch, 2004). Interestingly, memory acts in parallel with long-term potentiation (LTP), which is a long-lasting change in synaptic strength that can be induced electrically by stimulating hippocampal afferents mimicking neuronal activity. The early phase of LTP (E-LTP) that takes 1-2 hours, is independent of protein synthesis, whereas the late phase or long-lasting LTP (L-LTP) that lasts for several hours in vitro and even weeks in vivo requires synthesis of new proteins. LTP is well 
studied and the most easily observable in the hippocampus, depicting its crucial role in memory acquisition (Lynch, 2004; Bliss et al., 2018).

\subsection{Ubiquitination}

Ubiquitin $(\mathrm{Ub})$ is a small globular protein composed of 76 amino acids. The process of conjugation of the C-terminal glycine residue of $\mathrm{Ub}$ to a lysine residue of the substrate is called ubiquitination. Ubiquitination is a posttranslational modification that results in several outcomes, such as protein degradation, endocytosis, DNA damage response, endoplasmic reticulumassociated degradation, sorting and trafficking of transmembrane proteins. Ubiquitination is catalyzed by three classes of enzymes: ubiquitin-activating enzymes (E1s), ubiquitin-conjugating enzymes (E2s) and ubiquitin-ligating enzymes (E3s) (Hershko \& Ciechanover, 1998; Akutsu et al., 2016). Conjugation of ubiquitin to a protein substrate starts with the formation of a thioester bond between the C-terminus of ubiquitin and an internal cysteine residue of the E1 enzyme at the expense of ATP-hydrolysis, followed by the shuttling of active ubiquitin onto a specific cysteine residue of one of E2s. E2s either transfer ubiquitin to a cysteine residue of an E3 or the E2ubiquitin conjugate forms a protein complex with an E3. E3s determine the substrate specificity of ubiquitination by directly or indirectly binding to a given set of substrate proteins. Ultimately, an isopeptide bond is formed which links the $\mathrm{C}$ terminus of ubiquitin to specific internal lysine residues of the substrate proteins (Figure 1.3). Deubiquitinases (DUB) reverse ubiquitination of substrates by cleaving the isopeptide bond in an ATPindependent manner (Rape, 2017; Rotin \& Kumar, 2009).

The mammalian genome encodes a few E1, some dozens of E2 ligase, and around 600 E3 ligase genes (Tai \& Schuman, 2008). 


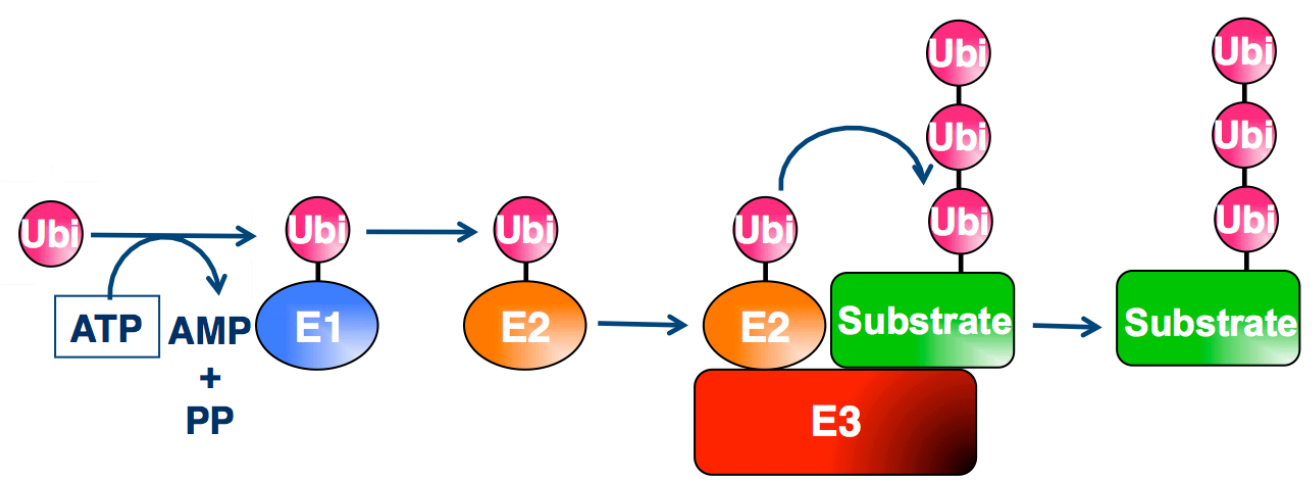

Figure 1.3. Steps of ubiquitination. Protein ubiquitination is catalyzed in three main steps. Activation performed by E1 ubiquitin activating enzymes; conjugation, performed by E2 ubiquitin conjugating enzymes, and ligation performed by E3 ubiquitin ligases (E3) respectively.

\subsubsection{Types of ubiquitination}

Ubiquitin itself contains seven lysine $(\mathrm{K})$ residues, $\mathrm{K} 6, \mathrm{~K} 11, \mathrm{~K} 27, \mathrm{~K} 29$, K33, $\mathrm{K} 48$ and K63, each of which can serve as an acceptor of the active Cterminal glycine residue to form polyubiquitin chains (polyUbs) (Figure 1.4) (Akutsu et al., 2016; Tai \& Schuman, 2008). Characteristics of complex ubiquitination are not fully understood. The most studied polyubiquitin chains are K48-linked polyUbs. This chain type leads to degradation of the substrate protein by the $26 \mathrm{~S}$ proteasome, whereas monoubiquitination as well as K63-linked polyUb chains have a role in transcriptional regulation, endocytosis, and kinase activation (Galan et al., 1997; Bach et al., 2003; Woelk et al., 2007). Ubiquitin molecules can also be further regulated by other post-translational modifications such as acetylation (Ohtake et al., 2015) and phosphorylation (Kane et al., 2014; Kazlauskaite et al., 2014; Koyano et al., 2014; Ordureau et al., 2014; Swaney et al., 2015), revealing another layer of diversity. 


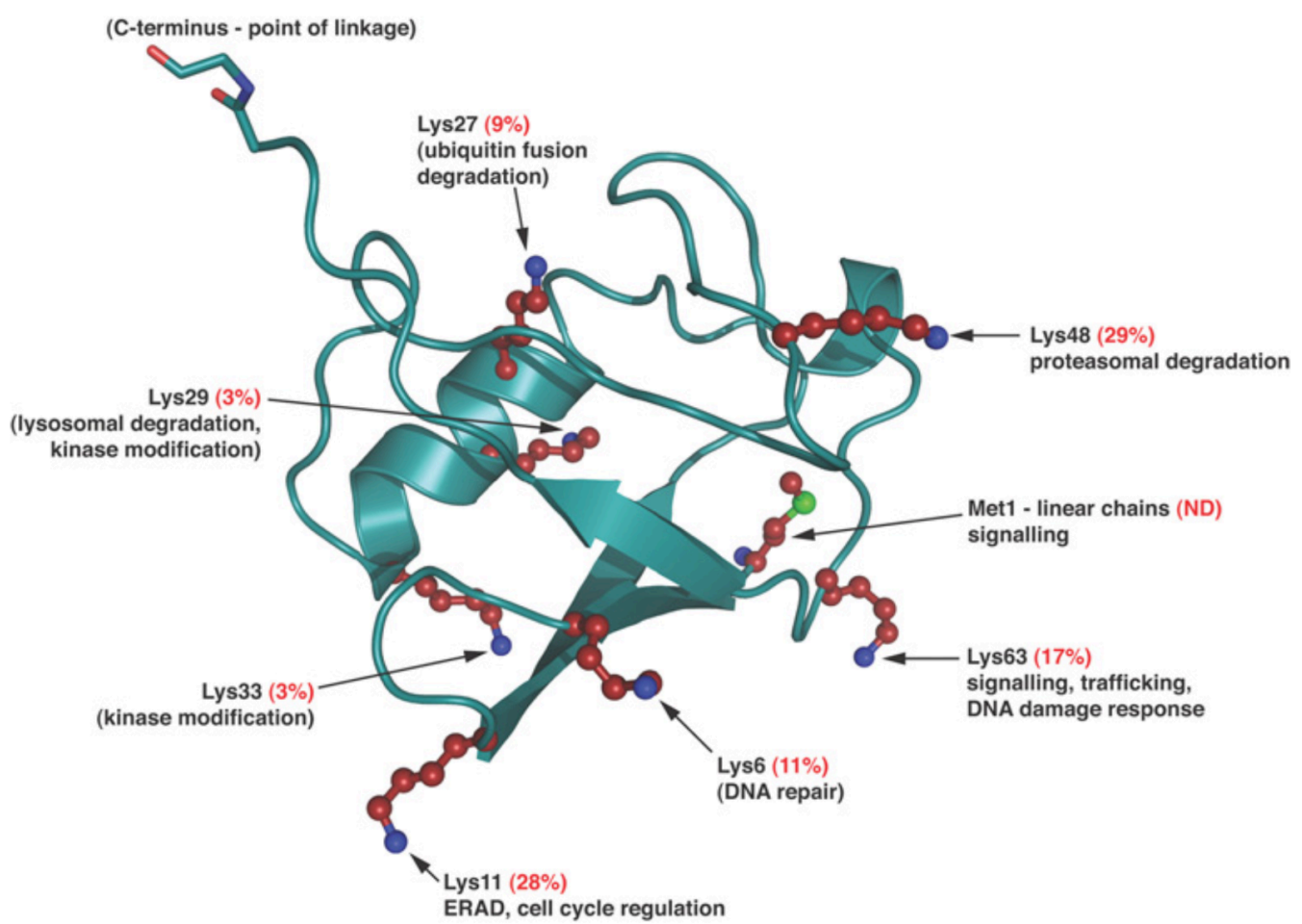

Figure 1.4. Structure of ubiquitin and its lysine residues. There are seven lysine residues (shown in red with blue nitrogen atoms) on different sides of the ubiquitin molecule. Met1 indicated with a green sulfur atom is the linkage point located close to Lys63. The C-terminal Gly75-Gly76 motif has a role in isopeptide bond formation (red oxygen atoms, blue nitrogen atoms). Red numbers in parentheses show the relative abundance (Komander, 2009, DOI: 10.1042/BST0370937).

There are two main types of E3s: Really Interesting New Gene (RING) type and the Homologous to E6-AP C-terminus (HECT) type. RING E3s, which constitute the majority of E3s, transfer ubiquitin directly to the substrate by playing a scaffold role (Rotin \& Kumar 2009). They share a CX2 CX9-39 CX1-3 HX2-3 $(\mathrm{C} / \mathrm{H}) \times 2 \mathrm{CX} 4-48 \mathrm{CX} 2 \mathrm{C}$ sequence that makes a crossbrace motif. When two zinc atoms bind via cysteine and histidine residues, the crossbrace motif is stabilized. HECT E3s, on the other hand, carry a conserved catalytic cysteine residue. Instead of direct transfer of ubiquitin, the conserved cysteine has a role as an ubiquitin acceptor from E2s. After this additional step, ubiquitin is then transferred to a lysine residue on the substrate. According to the subdomains and N-terminus homology, HECT 
type E3 ligases can be categorized into three subfamilies, the Neuronally Expressed Developmentally Downregulated 4 (Nedd4) family, the HERC family, and other HECT-type ligases (Rotin \& Kumar 2009; Komander \& Rape, 2012).

\subsubsection{Nedd4 family E3 ligases}

The Nedd4 family of HECT-type ligases consists of 8 genes in the rodent genome and 9 genes in the human genome. Based on their homologies, they fall into four subfamilies; Nedd4-, Smurf- (Smad ubiquitin regulatory factors), Wwp-, and NEDL- (Nedd4 like) subfamilies. All of the Nedd4 ligases have a common $\mathrm{C} 2$ domain in $\mathrm{N}$-terminus that is involved in autoinhibition and subcellular localization of the ligase, two to four WW domains responsible for substrate recognition by interacting with PPXY (also called PY) motif on substrates, and a catalytic HECT domain that interacts with E2 to transfers ubiquitin to the cysteine residue at its catalytic center (Figure 1.5). Nedd4 family E3 ligases play crucial roles in many physiological processes such as cell proliferation and growth, development and cancer (Rotin \& Kumar 2009). The first discovered physiological role of Nedd4-1 and Nedd4-2 dependent ubiquitination was found in the epithelial cells of the kidney tubules (Staub et al., 1996). It has been demonstrated that Nedd4-1 and Nedd4-2 regulate membrane levels of ENaC (epithelial sodium channel) via the binding of WW domains of Nedd4s to the PY motif of ENaC (Donovan \& Poronnik, 2013; Yang and Kumar, 2010). Ubiquitination via Nedd4 family E3 ligases are mostly K63 specific, and a majority of them have been linked with neuronal development in many aspects (Maspero et al., 2013). 


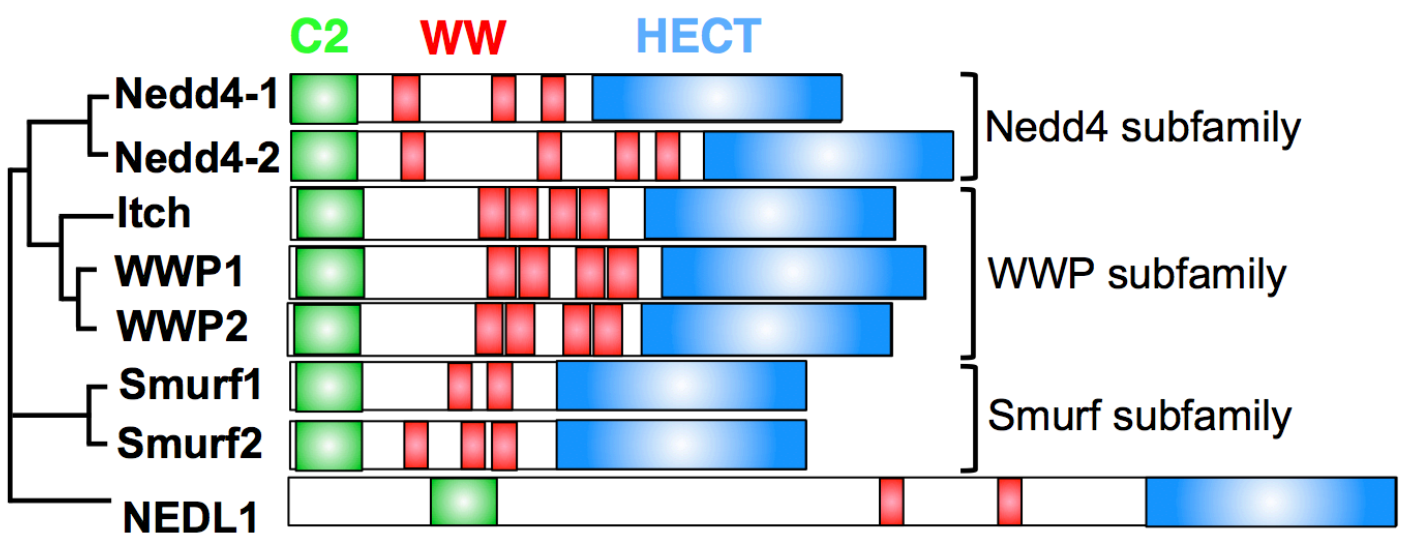

Figure 1.5. Nedd4 Family E3 ligases. Nedd4 family E3 ligases can be categorized into four subfamilies. Each of them has a conserved domain structures with a $\mathrm{C} 2$ domain in their $\mathrm{N}$ terminus mainly involved in autoinhibition and localization of the ligase, two to four internal WW domains which are responsible for substrate recruitment by interacting with PY motif on substrate proteins, and a HECT domain involved in E2 interaction and ubiquitin transfer to substrate protein.

\subsubsection{Nedd4 ligases in the brain}

Expression of Nedd4s start from early stages in mouse central nervous system, reaches to the highest level during neurogenesis, and decreases until adulthood. Nedd4-1 expression is found ubiquitously in the brain, whereas Nedd4-2 expression is more limited. Additionally, these two ligases have different substrate proteins although they share high homology (Anan et al., 1998; Kumar et al., 1997).

Nedd4-1 and Nedd4-2 are essential genes. Both Nedd4-1 and Nedd4-2 knockout (KO) mice are perinatally lethal. It has been shown that Nedd4-1 KO mice show severe developmental retardation, and they are quite smaller in size because of disrupted insulin-like growth factor-1 signaling; whereas 
Nedd4-2 KO mice do not have a change in size, and lethality occurs due to an ENaC-related lung phenotype (Boase et al., 2011; Cao et al., 2008; Shi et al., 2008).

Given that Nedd4-1 and Nedd4-2 are both highly expressed during development, it has been supported with recent studies that Nedd4-1 and Nedd4-2 have critical roles in neuronal development like neurite outgrowth, axon guidance, neuronal survival, and cell fate determination. Zebrafish have only one Nedd4 gene, which plays a crucial role in the dorsoventral patterning of the neural ectoderm (Bakkers et al., 2005). Drosophila Nedd4 regulates the cell fate by downregulating the Notch pathway (Dalton et al., 2011; Sakata et al., 2004). Conditional Nedd4-1 KO mice have a reduction in dendrite branching (Kawabe et al, 2010). Nedd4-1 has also been characterized as a positive regulator of axonal growth in hippocampal neurons as a downstream of PI3K/PTEN/mTOR pathway (Hsia et al., 2014). In humans, the Nedd4-2 gene has found to be linked with seizures and photosensitive epilepsy (Zhu et al, 2017; Vanli-Yavuz et al, 2015).

Nedd4-1 and Nedd4-2 also target several ion channels such as voltagegated sodium channels (Rougier et al., 2005), voltage-gate potassium channels (KCNQ) channels (Ekberg et al., 2007), and voltage-gated calcium channels (Rougier et al., 2011). Nedd4-2 also regulates the amount of plasma membrane glutamate transporters, such as EAAT, EAAT2 and EAAT3/4 (Sopjani et al., 2010). Protein kinase C (PKC) phosphorylates Nedd4-2, which enhances its association with and ubiquitination of EAAT2, resulting in endocytosis (Garcia-Tardon et al., 2012). PKC-dependent activation of Nedd4-2 has also been linked to regulation of dopamine transporters (Vina-Vilaseca \& Sorkin, 2010). Likewise, Nedd4s target AMPA-type glutamate receptors. It has been shown in hippocampal neurons that ubiquitination of GluA1-containing AMPA receptors via Nedd41 causes internalization of the receptor and translocation to the lysosome (Lin et al., 2011). Additionally, polymorphisms in Nedd4-1 and Nedd4-2 have been linked with a number of diseases, such as hypertension (Van Huysse et al., 2012), epilepsy (Dibbens et al., 2007), and have a role in 
stroke recovery (Sang et al., 2006. Lackovic et al., 2012). All together highlighting the crucial roles of Nedd4-mediated ubiquitin (Donovan \& Poronnik, 2013).

\subsubsection{Ubiquitination and memory formation}

Learning and memory have been extensively studied using the Morris water maze (MWM) test, a test for spatial learning (Morris, 1984; Vorhees \& Williams, 2010). There are several mutant mice with a gain- or loss-offunction of genes involved in excitatory synaptic transmission showing enhanced memory formation, such as transgenic $N R 2 B$ overexpressing mice (Tang et al., 1999; Wang et al., 2009), Cyclin-dependent kinase 5 (Cdk5) conditional KO mice (Hawasli et al., 2007), transgenic p25 overexpressing mice (Fischer et al., 2005), transgenic mice overexpressing neuron-specific motor protein kinesin family protein 17 (Kif17) (Wong et al., 2002), opioid receptor-like-1 (ORL 1$)$ KO mice (Mamiya et al., 2003), transgenic mice overexpressing hepatocyte growth factor (Hgf) (Kato et al., 2012), voltage-gate calcium channel $\beta$ subunit (Cavß3 KO) mice (Jeon et al., 2008), and D-amino-acid oxidase (Dao) KO mice (Maekawa et al., 2005)

Not many studies have been reported regarding to ubiquitination and memory formation. There are only a few E3 ligase KO mice related with learning and memory, including E6-AP ubiquitin ligase (Ube3A) KO (Jiang et al., 1998), neuron specific anaphase promoting complex 2 (Apc2) conditional KO (Kuczera et al., 2001) and inducible reporter of the LDL receptor (IDOL) KO (Gao et al., 2017), all of them revealing impaired spatial learning, and there are no studies linking enhanced memory formation with ubiquitination (Lip et al., 2017). 


\subsection{Aims of the study}

Ubiquitination is one of the most crucial regulatory mechanisms necessary for neuronal functioning as well as fundamental cellular functions. In this study, we wanted to elucidate the roles of Nedd4 Family E3 ligases in the mouse brain, with the focus of synaptic plasticity since there is still not much known about the involvement of ubiquitination process in synapse and synaptic plasticity. In the first part, after identifying the substrate, we characterized the substrate through biochemical studies, and then focused on in vivo studies such as behavioral and electrophysiological analysis as well as super resolution imaging. 


\section{MATERIALS AND METHODS}

\subsection{Animals}

Nedd4-1 ${ }^{f / f}$ and Nedd4-2/f mouse lines were generated by Dr. Hiroshi Kawabe and Prof. Dr. Nils Brose (Kawabe et al., 2010). The NEX-Cre mouse line was created and provided by Dr. Goebbels and Prof. Dr. Klaus A. Nave (Goebbels et al,, 2006). The Prrf $7^{f / f}$ mouse line was created and provided by Dr. Hrdinka and Prof. Dr. Michael Kreutz (Hrdinka et al., 2016). All animal experiments were performed in agreement with the guidelines for the welfare of experimental animals issued by the State Government of Lower Saxony (Niedersächsisches Landesamt für Verbraucherschutz und Lebensmittelsicherheit (LAVES) and the Max Planck Society (proportional to National Institute of Health Guidelines). Permissions 33.9-42502-04$13 / 1359$, 33.19-42502-04-15/1954, and 33.19-42502-04-16/2173 were licensed.

\subsection{Reagents}

\subsubsection{Chemicals}

Table 1. Chemicals used in this study

\begin{tabular}{|l|l|}
\hline Acrylamide/N, $N^{\prime}$-Methylene-bis-Acrylamide & National Diagnostic \\
\hline Adenosine Triphosphate (ATP) & Sigma-Aldrich \\
\hline Agarose (UltraPure agarose) & Invitrogen \\
\hline Ammonium Persulfate (APS) & Merck \\
\hline Ampicillin & Invitrogen \\
\hline Aprotinin & Roche \\
\hline BCA Protein Assay Reagent A \& B & Thermo \\
\hline Benzonase & Sigma \\
\hline Boric Acid & Merck \\
\hline Bovine serum albumin (BSA), Fraction V & Biomol \\
\hline
\end{tabular}




\begin{tabular}{|c|c|}
\hline Bromophenol blue & Pierce \\
\hline CHAPS & Biomol \\
\hline Comassie Brilliant Blue R250 & BioMol \\
\hline Darbecco Modified Eagle's Medium (DMEM) & Gibco, Invitrogen \\
\hline Dimethyl Sulfoxide (DMSO) & Sigma-Aldrich \\
\hline Dithiothreitol (DTT) & Sigma-Aldrich \\
\hline DNA Ladder Mix Sample, GeneRuler & Fermentas \\
\hline DPBS & Gibco, Invitrogen \\
\hline dNTPs & GE Healthcare \\
\hline Skim Milk & Nestle \\
\hline ECL Detection Reagents I-II & Amersham, GE Healthcare \\
\hline ECL Supersignal & Thermo \\
\hline EDTA & Merck \\
\hline Ethanol & Sigma-Aldrich \\
\hline Ethidium Bromide (1\% solution) & Carl Roth \\
\hline Ethylene Glycol Tetraacetic Acid (EGTA) & Sigma-Aldrich \\
\hline FastGreen & Sigma-Aldrich \\
\hline Fish Skin Gelatin (FSG) & Sigma-Aldrich \\
\hline GelRed & Biotium \\
\hline Glucose & Sigma-Aldrich \\
\hline Glutathione (GSH) & Sigma-Aldrich \\
\hline Glycerol & Sigma-Aldrich \\
\hline Glycine & Sigma-Aldrich \\
\hline Goat Serum & Gibco, Invitrogen \\
\hline HEPES & Sigma-Aldrich \\
\hline Hydrochloric Acid (HCl) & Merck \\
\hline IPTG & BioMol \\
\hline Kanamycin & Invitrogen \\
\hline Leupeptin & Roche \\
\hline Luria Broth (LB) & Sigma-Aldrich \\
\hline Magnesium Chloride $\left(\mathrm{MgCl}_{2} 6 \mathrm{H}_{2} \mathrm{O}\right)$ & Sigma-Aldrich \\
\hline Methanol & J.T. Baker \\
\hline $\mathrm{N}$-Ethylmaleimide $\left(\mathrm{C}_{6} \mathrm{H}_{7} \mathrm{NO}_{2}, \mathrm{NEM}\right)$ & Sigma-Aldrich \\
\hline Neurobasal A Medium & Gibco, Invitrogen \\
\hline N'N'N'-Tetramethylethyl Enediamine & Serva \\
\hline
\end{tabular}




\begin{tabular}{|l|l|}
\hline Opti-MEM & Invitrogen \\
\hline Paraformaldehyde (PFA) & Serva \\
\hline Poly-L-lysine (PLL) & Sigma \\
\hline Phosphate Buffered Saline (PBS) & PAA Laboratories \\
\hline Phenylmethylsulfonyl Fluoride (PMSF) & Roche \\
\hline Protein Molecular Weight Standards & Invitrogen \\
\hline Restriction Endonucleases & New England Biolabs \\
\hline RNase OUT & Invitrogen \\
\hline Sodium Bicarbonate $\left(\mathrm{NaHCO}_{3}\right)$ & Merck \\
\hline Sodium Butyrate & Merck \\
\hline Sodium Chloride & Merck \\
\hline Sodium Deoxycholate & Wako \\
\hline Sodium Dodecyl Sulfate $(\mathrm{SDS})$ & Gerbu \\
\hline Sodium Phosphate $\left(\mathrm{NaH}_{2} \mathrm{PO}_{4}\right)$ & Roche \\
\hline Sucrose & Sigma-Aldrich \\
\hline Triton X-100 & Roche \\
\hline Trizma base & Sigma-Aldrich \\
\hline Trizol & Thermo \\
\hline Tween 20 & Sigma-Aldrich \\
\hline Ubiquitin & Boston Biochem \\
\hline X-Gal & BioMol \\
\hline
\end{tabular}

\subsubsection{Enzymes}

Table 2. Commercial enzymes used during this study

\begin{tabular}{|l|l|}
\hline Gateway LR Clonase Enzyme Mix & Invitrogen \\
\hline Alkaline Phosphatase & Roche \\
\hline DNasel (RNase free) & Roche \\
\hline Pfu Polymerase & Stratagene \\
\hline SuperScript III Reverse Transcriptase & Thermo \\
\hline SYBR Green PCR master mix & Applied Biosystems \\
\hline T4 DNA Ligase & Invitrogen \\
\hline Taq Polymerase (REDTaq) & Sigma-Aldrich \\
\hline
\end{tabular}




\subsubsection{Bacterial strains}

Table 3. Bacterial strains used in this study

\begin{tabular}{|l|l|}
\hline E. coli $\mathrm{DH}$ a competent cells & Thermo \\
\hline E. coli Electro10-Blue competent cells & Stratagene \\
\hline E. coli XL-1 Blue competent cells & Stratagene \\
\hline E. coli TOP10 competent cells & Invitrogen \\
\hline
\end{tabular}

\subsubsection{Kits and apparatus}

Table 4. Kits and apparatuses used in this study

\begin{tabular}{|c|c|}
\hline PureLink Quick Plasmid Miniprep Kit & Invitrogen \\
\hline PureLink HiPure Plasmid Midiprep Kit & Invitrogen \\
\hline ZymoPURE Plasmid Miniprep Kit & Zymo \\
\hline EndoFree Plasmid Maxi Kit & Qiagen \\
\hline ZymoClean Gel DNA Recovery & Zymo \\
\hline Quick RNA Mini Prep Kit & Zymo \\
\hline Direct-zol RNA Mini Prep Plus Kit & Zymo \\
\hline TOPO TA Cloning Kit & Invitrogen \\
\hline LigaFast $^{\mathrm{TM}}$ Rapid DNA Ligation System & Promega \\
\hline BCA Protein Assay Kit & Thermo \\
\hline QuickChange II Site-Directed Mutagenesis Kit & Stratagene \\
\hline Nexttec Genomic DNA Isolation Kit & Nexttec \\
\hline
\end{tabular}

\subsubsection{Vector plasmids}

Table 5. List of vectors used in this study

\begin{tabular}{|l|l|}
\hline pCRII TOPO & Invitrogen (K4620-01) \\
\hline pCAG Prr7 EGFP & Provided by Dr. Bekir Altas \\
\hline pEYFP HA Prr7 Bfr PDZ & Provided by Dr. Bekir Altas \\
\hline
\end{tabular}




\begin{tabular}{|l|l|}
\hline pEYFP HA Prr7 Bfr PDZ & Generated in this study \\
\hline pEYFP HA Prr7 Bfr PDZ & Provided by Rashi Goel \\
\hline pEYFP HA Prr7 Bfr PDZ & Generated in this study \\
\hline pFUMVW & Provided by Dr. Hiroshi Kawabe \\
\hline pFUMVW-iCre & Provided by Dr. Hiroshi Kawabe \\
\hline pCX::myrVenus & Provided by Dr. Anna-Katerina Hadjantonakis \\
\hline pFUGW & $\begin{array}{l}\text { Provided by Dr. Inder M. Verma (Addgene } \\
\text { \#12263) }\end{array}$ \\
\hline pFUGW-iCre & Provided by Dr. Richard L. Huganir \\
\hline BL544-hN4-2 WT & Provided by Dr. Hiroshi Kawabe \\
\hline BL544-hN4-2 C/S (C885S) & Provided by Dr. Hiroshi Kawabe \\
\hline
\end{tabular}

\subsubsection{Oligonucleotides}

Oligonucleotide primers were synthesized in the Max Planck Institute for Experimental Medicine DNA Core Facility by using ABI 5000 DNA/RNA synthesizer.

Table 6. List of oligonucleotides used in this study (F: forward, R: reverse)

\begin{tabular}{|l|l|}
\hline $\begin{array}{l}\text { Primer } \\
\text { no }\end{array}$ & Sequence $\left(5^{\prime}-3^{\prime}\right)$ \\
\hline 34358 & GACGAGTTCGAAGAGGATGC (qRT-PCR for Prr7, F) \\
\hline 34359 & GAGGGGCAACTGTGGTTC (qRT-PCR for Prr7, R) \\
\hline 20495 & $\begin{array}{l}\text { GCTTGCTGGTGAAAAGGACCTCTCGAAG (qRT-PCR for } \\
\text { HPRT1, F) }\end{array}$ \\
\hline 20496 & $\begin{array}{l}\text { CCCTGAAGTACTCATTATAGTCAAGGGCAT (qRT-PCR for } \\
\text { HPRT1, R) }\end{array}$ \\
\hline 14539 & ATGGTGAAGGTCGGTGTGA (qRT-PCR for GAPDH, F) \\
\hline 14540 & AATCTCCACTTTGCCACTGC (qRT-PCR for GAPDH, R) \\
\hline
\end{tabular}




\begin{tabular}{|l|l|}
\hline 9146 & CTTCCTCCCTGGAGAAGAGC (qRT-PCR for b-actin, F) \\
\hline 9147 & ATGCCACAGGATTCCATACC (qRT-PCR for b-actin, R) \\
\hline 33278 & $\begin{array}{l}\text { GAATCGGACATGTCTAAGCCGGCGTGCTTCGAGGAGGCGGT } \\
\text { G (Mutagenesis of PY1 of Prr7, F) }\end{array}$ \\
\hline 33279 & $\begin{array}{l}\text { GCCATCAGCACCGCCTCCTCGAAGCACGCCGGCTTAGACAT } \\
\text { GTCCGATTC (Mutagenesis of PY1 of Prr7, R) }\end{array}$ \\
\hline 33280 & $\begin{array}{l}\text { CTGATGGCCGAGCCGCCGGCTCCCTTCAGCGAGGTGCTCA } \\
\text { CGGACAC (Mutagenesis of PY2 of Prr7, F) }\end{array}$ \\
\hline 33281 & $\begin{array}{l}\text { CGAGTGTCCGTGAGCACCTCGCTGAAGGGAGCCGGCGGCT } \\
\text { CGGCCATCAG (Mutagenesis of PY2 of Prr7, R) }\end{array}$ \\
\hline
\end{tabular}

\subsubsection{Antibodies}

Table 7. List of primary antibodies used in this study

\begin{tabular}{|l|l|l|l|l|l|}
\hline Antibody & \multirow{2}{*}{$\begin{array}{l}\text { Host } \\
\text { Species }\end{array}$} & Origin & \multicolumn{3}{|l|}{ Usage and Dilution } \\
\cline { 4 - 6 } & Rabbit & Sigma (Cat\#AV40173; & WB & IHC & ICC \\
\hline CamKII & Mouse & $\begin{array}{l}\text { Abcam (Cat\# ab22609, } \\
\text { RRID:AB_447192) }\end{array}$ & $1: 2500$ & - & - \\
\hline $\begin{array}{l}\text { CamKII (P- } \\
\text { Thr286) }\end{array}$ & Rabbit & $\begin{array}{l}\text { Phospo-solutions (Cat\# } \\
\text { p1005-286, } \\
\text { RRID:AB_2492051) }\end{array}$ & $1: 1000$ & - & - \\
\hline Drebrin1 & Mouse & $\begin{array}{l}\text { Provided by Dr. Irina } \\
\text { Majoul }\end{array}$ & $1: 200$ & - & - \\
\hline GFP & Rabbit & $\begin{array}{l}\text { MBL (Cat\# 598S, } \\
\text { RRID:AB_591816) }\end{array}$ & - & $1: 1000$ & $1: 1000$ \\
\hline GluA1 & Rabbit & $\begin{array}{l}\text { SYSY (Cat\# 182 003, } \\
\text { RRID:AB_2113441) }\end{array}$ & $1: 1000$ & - & - \\
\hline
\end{tabular}




\begin{tabular}{|c|c|c|c|c|c|}
\hline GluA2 & Rabbit & $\begin{array}{l}\text { SYSY (Cat\# } 182 \text { 103, } \\
\text { RRID:AB_2113732) }\end{array}$ & $1: 1000$ & - & - \\
\hline GluR2/3 & Rabbit & $\begin{array}{l}\text { Milipore (Cat\# 07-598, } \\
\text { RRID:AB 11213931) }\end{array}$ & $1: 1000$ & - & - \\
\hline GluN1 & Mouse & $\begin{array}{l}\text { SYSY (Cat\# } 114011, \\
\text { RRID:AB 887750) }\end{array}$ & $1: 1000$ & - & - \\
\hline GluN2B & Rabbit & $\begin{array}{l}\text { SYSY (Cat\# } 244 \text { 103, } \\
\text { RRID:AB_10805405) }\end{array}$ & $1: 500$ & - & - \\
\hline HA (HA.11) & Mouse & $\begin{array}{l}\text { Biolegend (Cat\# 901515, } \\
\text { RRID:AB_2565334) }\end{array}$ & $1: 1000$ & - & $1: 500$ \\
\hline Nedd4-1 & Mouse & $\begin{array}{l}\text { BD Biosciences (Cat\# } \\
611481, \\
\text { RRID:AB_398941) }\end{array}$ & $1: 250$ & - & - \\
\hline Nedd4-2 & Rabbit & $\begin{array}{l}\text { CST (Cat\#4013; } \\
\text { RRID:AB_1904063) }\end{array}$ & $1: 1000$ & - & - \\
\hline Nedd4-2 & Rabbit & SYSY (Cat\#283003) & - & $1: 2000$ & - \\
\hline Prr7 & Mouse & $\begin{array}{l}\text { Exbio (Cat\# 11-617- } \\
\text { C100, } \\
\text { RRID:AB_10734067) }\end{array}$ & $1: 500$ & - & - \\
\hline PSD-95 & Mouse & $\begin{array}{l}\text { BD (Cat\#610495; } \\
\text { RRID:AB_397861) }\end{array}$ & $1: 500$ & - & - \\
\hline Transferrin & Mouse & $\begin{array}{l}\text { Invitrogen (Cat\# 13- } \\
\text { 6800, RRID:AB_86623) }\end{array}$ & $1: 1000$ & - & - \\
\hline Ubiquitin & Rabbit & $\begin{array}{l}\text { DAKO (Cat\#Z0458; } \\
\text { RRID:AB_2315524) }\end{array}$ & $1: 1000$ & - & - \\
\hline $\begin{array}{l}\text { Ubiquitin } \\
\text { (K63) }\end{array}$ & Rabbit & $\begin{array}{l}\text { Merck Milipore (Cat\#05- } \\
\text { 1308; } \\
\text { RRID:AB_1587580) }\end{array}$ & $1: 100$ & - & - \\
\hline Ubiquitin & Rabbit & CST (Cat\#3936S) & $1: 200$ & - & - \\
\hline
\end{tabular}




\begin{tabular}{|l|l|l|l|l|l|}
\hline$\beta$-Tubulin & Mouse & $\begin{array}{l}\text { Sigma (Cat\# T4026, } \\
\text { RRID:AB_477577) }\end{array}$ & $1: 5000$ & - & - \\
\hline
\end{tabular}

Table 8. List of secondary antibodies used in this study

\begin{tabular}{|c|c|c|c|c|}
\hline $\begin{array}{l}\text { Recognized } \\
\lg G\end{array}$ & \begin{tabular}{|l} 
Host \\
Species
\end{tabular} & $\begin{array}{l}\text { Conjugated } \\
\text { substrate/Dye }\end{array}$ & Origin & $\begin{array}{l}\text { Usage, } \\
\text { Dilution }\end{array}$ \\
\hline Mouse & Goat & $\begin{array}{l}\text { HRP (Cat\#1721011; } \\
\text { 11125936) }\end{array}$ & BioRad & WB, 1:2500 \\
\hline Rabbit & Goat & $\begin{array}{l}\text { HRP (Cał\#1721019; } \\
\text { 11125143) }\end{array}$ & BioRad & WB, $1: 2500$ \\
\hline Mouse & Goat & $\begin{array}{l}\text { IgG IRDye800 } \\
\text { (Cat\#610-132-121; } \\
\text { RRID:AB_220125) }\end{array}$ & Rockland & $\begin{array}{l}\text { WB, } \\
1: 10000\end{array}$ \\
\hline Rabbit & Goat & $\begin{array}{l}\text { IgG IRDye800 } \\
\text { (Cat\#611-132-122; } \\
\text { RRID:AB_220152) }\end{array}$ & Rockland & $\begin{array}{l}\text { WB, } \\
1: 10000\end{array}$ \\
\hline Mouse & Goat & $\begin{array}{l}\text { IgG IRDye680 } \\
\text { (Cat\#610-130-121; } \\
\text { RRID:AB_220121) }\end{array}$ & Rockland & \begin{tabular}{|l|} 
WB, \\
$1: 10000$
\end{tabular} \\
\hline Rabbit & Goat & $\begin{array}{l}\text { IgG IRDye680 } \\
\text { (Cat\#611-130-122; } \\
\text { RRID:AB_220148) }\end{array}$ & Rockland & $\begin{array}{l}\text { WB, } \\
1: 10000\end{array}$ \\
\hline Mouse & Goat & $\begin{array}{l}\text { Alexa Fluor } 488 \\
\text { (Cat\#A11029) }\end{array}$ & Life & $\begin{array}{l}\text { IHC/ICC, } \\
1: 1000\end{array}$ \\
\hline Rabbit & Goat & $\begin{array}{l}\text { Alexa Fluor } 488 \\
\text { (Cat\#A-11008; } \\
\text { RRID:AB_143165) }\end{array}$ & $\begin{array}{l}\text { Invitroge } \\
\mathrm{n}\end{array}$ & $\begin{array}{l}\text { IHC/ICC, } \\
1: 1000\end{array}$ \\
\hline Rabbit & Goat & $\begin{array}{l}\text { Alexa Fluor } 555 \text { (Cat\# } \\
\text { A-21429, } \\
\text { RRID:AB_2535850) }\end{array}$ & $\begin{array}{l}\text { Invitroge } \\
\mathrm{n}\end{array}$ & $\begin{array}{l}\text { IHC/ICC, } \\
1: 1000\end{array}$ \\
\hline
\end{tabular}




\subsection{Molecular biology}

\subsubsection{Bacterial transformation of plasmid DNA}

\subsubsection{Chemical transformation}

Frozen DH5a chemical competent E. coli cells were thawed on ice and 18$20 \mu \mathrm{l}$ was transferred to a pre-chilled round bottom falcon tube. Cells were mixed with 1-2 $\mu \mathrm{l}$ of plasmid DNA and the mixture in the falcon tube was kept on ice for 30 minutes. The tube was placed in a waterbath adjusted to $42^{\circ} \mathrm{C}$ for 30 seconds. After the heat shock, the tube was kept on ice for 3 minutes. $700 \mathrm{ul}$ pre-warmed SOC media was added to the transformed E.coli, which was incubated with moderate shaking for $1-1.5$ hour at $37^{\circ} \mathrm{C}$ for recovery. After that, the cells were centrifuged at $10,000 \mathrm{rpm}$ using a microcentrifuge (Eppendorf 5417R) for 2 minutes, and the supernatant was discarded. The E.coli pellet was resuspended and cells were plated on appropriate selection agar plates and incubated overnight at $37^{\circ} \mathrm{C}$.

LB medium: $25 \mathrm{~g}$ Luria Broth (LB, Invitrogen) in $1 \mathrm{~L}$ distilled $\mathrm{H}_{2} \mathrm{O}$, and autoclaved.

SOC medium (reagents in final concentration): $20 \mathrm{mM}$ glucose, $2 \%(\mathrm{w} / \mathrm{v})$ tryptone (DIFCO), 0.5\% (w/v) yeast extract (DIFCO), $10 \mathrm{mM} \mathrm{NaCl}, 2.5 \mathrm{mM}$ $\mathrm{KCl}, 20 \mathrm{mM} \mathrm{MgCl}_{2}$, in $\mathrm{ddH}_{2} \mathrm{O}$ and autoclaved.

LB agar plates: $15 \mathrm{~g}$ Bacto-agar (Invitrogen) in $1 \mathrm{~L}$ LB medium, and autoclaved. $50 \mu \mathrm{g} / \mathrm{ml}$ of ampicillin or $25 \mu \mathrm{g} / \mathrm{ml}$ of kanamycin was added for selection.

\subsubsection{Electro-transformation}

A vial $(50 \mu \mathrm{l})$ of frozen $\mathrm{XL}-1$ Blue electro-competent $E$. coli cells was thawed on ice and mixed with 1-2 $\mu$ l of plasmid DNA. Then, the mixture was 
transferred to a pre-chilled electroporation cuvette $(0.1 \mathrm{~cm}$, BioRad), and an electric pulse of $1.80 \mathrm{kV}$ ( $E$. coli pulser, BioRad) was applied. Immediately after the electroporation, bacterial cells were taken out of the cuvette. The following procedures are same as described in chemical transformation above in 2.3.1.1.

\subsubsection{Glycerol stock preparation}

E. coli culture transformed with a construct of choice was grown overnight. $800 \mu \mathrm{l}$ of culture was taken and mixed with $200 \mu \mathrm{l}$ of $80 \%$ autoclaved glycerol, vortexed, and stored at $-80^{\circ} \mathrm{C}$ as a stock. In order to grow a culture, a piece of frozen stock was picked using a pipette tip and transferred into LB medium with an appropriate antibiotic.

\subsubsection{Plasmid DNA purification}

Plasmid DNA was purified from bacteria according to manufacturer's protocols using ZymoPURE Plasmid Miniprep Kit (Zymo), PureLink Quick Plasmid kits (Invitrogen), or Endo-free Plasmid Maxi Kit (Qiagen). Plasmid DNA was then air dried and resuspended in TE buffer or endotoxin free TE buffer.

TE buffer: $10 \mathrm{mM}$ Tris-HCl pH 7.4 (Sigma-Aldrich), 1 mM EDTA (SigmaAldrich).

\subsubsection{Determination of DNA concentration}

After diluting DNA samples 1:100 with TE buffer, absorptions were measured at 260 and $280 \mathrm{~nm}$ wavelength using an UltraSpec 3100pro (Amersham) to define the concentration of $D N A$. $O D_{260} / O D_{280}$ ratio around 1.8 was accepted as a pure DNA sample. 


\subsubsection{DNA sequencing}

Sequencing of DNA was done by the DNA Core Facility of MPlem by using Applied Biosystems 373 DNA Sequencer.

\subsubsection{DNA digestion with restriction endonucleases}

DNA was digested by specific restriction endonucleases according to the instructions provided by New England BioLabs. Briefly, the appropriate amount of DNA was digested for 2-3 hours in the appropriate buffer and temperature conditions depending on the enzyme used.

\subsubsection{Agarose gel electrophoresis}

In order to analyze the size or purify isolated DNA or RNA samples, nucleotide samples were subjected to agarose gel electrophoresis in 1-2\% agarose (UltraPure, Invitrogen) gel containing $0.1 \%$ GelRed (Biotium) or ethidium bromide. DNA or RNA fragments were then separated in TBE buffer at constant current (100-150 V), and imaged under UV-light (Intas) (254 or $314 \mathrm{~nm}$ ). The approximate DNA size was estimated with Gene Ruler DNA Ladder Mix (Fermentas) that was loaded on the same gel.

TBE buffer:

50 mM Tris-Base, 50 mM Boric acid, 2 mM EDTA, pH 8.0

\subsubsection{Gel extraction}

Agarose gel electrophoresis was followed by extraction of interested DNA band with a surgical scalpel from the agarose gel followed by purification using ZymoClean Gel DNA Recovery Kit (Zymo) according to the manufacturer's protocol. 


\subsubsection{DNA ligation}

After digestion, gel electroporation, and gel extraction of linear plasmid DNA and insert DNA, they were mixed in a molar ratio of $1: 3$ or $1: 1$, and ligation was performed according to the manufacturer's protocols of LigaFast ${ }^{\mathrm{TM}}$ Rapid DNA Ligation System by adding $1 \mu \mathrm{l}$ T4 DNA ligase and the ligasespecific buffer in reaction volume of $10 \mu \mathrm{l}$ with the presence of $0.5 \mu \mathrm{M}$ ATP. The ligation reaction was kept at room temperature for 20 minutes.

\subsubsection{Polymerase chain reaction (PCR)}

Desired DNA fragments were amplified by PCR according to the manufacture's protocol using Pfu DNA polymerase (Cloned Pfu Polymerase $A D$ or Turbo Pfu Polymerase AD, Agilent Technologies). For genotyping PCR, Red-Taq DNA polymerase (Sigma-Aldrich) was used. Reactions were carried out on a Gene Amp 9700 PCR cycler (Applied Biosystems) or Peltier Thermal Cycler PTC-225 (MJ Research, Bio-Rad) with the conditions below:

Step 1: $95^{\circ} \mathrm{C}$ for $3 \mathrm{~min}$

Step 2: $95^{\circ} \mathrm{C}$ for $30 \mathrm{sec}$

Step 3: annealing temperature for $30 \mathrm{sec}$

Step 4: $72^{\circ} \mathrm{C}$ for extension time (500 bp per $1 \mathrm{~kb}$ of DNA) (30-35 cycles from Step 2 to 4 )

Step 5: $72^{\circ} \mathrm{C}$ for $10 \mathrm{~min}$

Annealing temperatures, extension times, and cycle numbers were adjusted according to the expected length of the PCR product and melting temperature of primers. 


\subsubsection{TOPO-TA subcloning}

The PCR products were subcloned into pCRII-TOPO vectors by using TOPO TA cloning Kits (Invitrogen) according to the manufacturer's instructions.

\subsubsection{Site-directed mutagenesis}

For mutagenesis of cDNA, QuickChange II Site-Directed Mutagenesis Kit (Stratagene) was used according to the manufacturer's protocol. Briefly, partially overlapping forward and reverse primers with a point mutation were designed. The entire plasmid DNA was amplified in $25 \mu \mathrm{l}$ of reaction mixtures containing oligonucleotide primers, dNTPs, and Pfu DNA polymerase (Stratagene) in the appropriate reaction buffer. PCR was carried out with the following protocol:

Step 1: $95^{\circ} \mathrm{C}$ for $3 \mathrm{~min}$

Step 2: $95^{\circ} \mathrm{C}$ for $30 \mathrm{sec}$

Step 3: $65^{\circ} \mathrm{C}$ for $1 \mathrm{~min}$

Step 4: $72^{\circ} \mathrm{C}$ for 3 min (5 cycles from Step 2 to Step 4)

Step 5: $95^{\circ} \mathrm{C}$ for $30 \mathrm{sec}$

Step 6: $60^{\circ} \mathrm{C}$ for $1 \mathrm{~min}$

Step 7: $72^{\circ} \mathrm{C}$ for $3 \mathrm{~min}$ ( 5 cycles from Step 5 to Step 7)

Step 8: $95^{\circ} \mathrm{C}$ for $30 \mathrm{sec}$

Step 9: $55^{\circ} \mathrm{C}$ for $1 \mathrm{~min}$

Step 10: $72^{\circ} \mathrm{C}$ for 3 min (30 cycles from Step 8 to Step 10)

Step 11: $72^{\circ} \mathrm{C}$ for $10 \mathrm{~min}$

Next, the PCR product was incubated with $1-2 \mu$ of $D p n l$ at $37^{\circ} \mathrm{C}$ for 2 hours to digest the template plasmid. Chemical competent $E$. coli was transformed with the PCR product. Plasmid DNAs amplified and purified from single colonies were subjected to DNA sequencing for the verification of the mutation. 


\subsubsection{Isolation of genomic DNA from mouse tail biopsies}

For isolation of genomic DNA from mouse tail samples, Nexttec genomic DNA isolation kit was used according to the manufacturer's protocol (Nexttec).

\subsubsection{Mutant mouse genotyping}

Genotyping of mutant mice was assessed in the DNA Core Facility of MPIEM by using PCR using oligonucleotide primers listed below (Wt, wild type allele; Cre, knock-in allele with Cre).

Table 9. Genotyping information of mouse lines used in this study

\begin{tabular}{|c|c|c|}
\hline Mouse line & Primers & PCR product size \\
\hline NEX1-Cre & $2409 / 3131 / 3132$ & Wt: $750 \mathrm{bp}$, Cre: $550 \mathrm{bp}$ \\
\hline Nedd4-1 $^{\mathrm{f} / \mathrm{f}}$ & $10906 / 10907$ & Wt: $200 \mathrm{bp}$, Cre: $300 \mathrm{bp}$ \\
\hline Nedd4-2 $^{\mathrm{f} / \mathrm{f}}$ & $12804 / 12806$ & Wt: $200 \mathrm{bp}$, Cre: $300 \mathrm{bp}$ \\
\hline Prr7 $^{\mathrm{flf}}$ & $37556 / 37557$ & Wt: $274 \mathrm{bp}$, Cre: $420 \mathrm{bp}$ \\
\hline
\end{tabular}

All genotyping PCRs were performed with the following protocol:

Step 1: $96^{\circ} \mathrm{C}$ for $3 \mathrm{~min}$

Step 2: $94^{\circ} \mathrm{C}$ for $30 \mathrm{sec}$

Step 3: $64^{\circ} \mathrm{C}$ for $1 \mathrm{~min}$

Step 4: $72^{\circ} \mathrm{C}$ for $1 \mathrm{~min}$ (32 cycles from Step 2 to 4 )

Step 5: $72^{\circ} \mathrm{C}$ for $7 \mathrm{~min}$ 


\subsubsection{RNA isolation}

Instruments used for RNA isolation were cleaned with $70 \%$ ethanol (Sigma) and RNA-Zap (Thermo Fisher) before starting the experiment. Brain tissue was collected from mice and flash-frozen in liquid nitrogen. It was followed by homogenization in 600-1000 $\mu \mathrm{l}$ of Trizol (Thermo Fisher) in $2 \mathrm{ml}$ plastic tubes by using a Ultra Turrax homogenizer (IKA Labtechnik) for 40 seconds and incubated at room temperature for 3 minutes. Samples were centrifuged at $10,000 \mathrm{rpm}$ using a microcentrifuge for 2 minutes. Supernatants were transferred to clean tubes and mixed with equal volumes of $\mathrm{EtOH}$. Solutions were applied onto Zymo Spin Columns to concentrate RNA on the beads matrix (Direct-zol, RNA MiniPrep Plus, Zymo) and RNA was eluted by adding appropriate amount of buffer according to the manufacturer's protocol.

\subsubsection{Measuring RNA concentration}

RNA concentrations were estimated with a NanoDrop 2000c spectrophotometer (Thermo) by dropping $1 \mu \mathrm{l}$ of the sample onto the measurement pedestal. $O D_{260} / O D_{280}$ ratio around 2 was accepted as a pure sample.

\subsubsection{7. cDNA synthesis}

cDNA was synthesized from purified RNA with the SuperScript III FirstStrand Synthesis System (Invitrogen) according to manufacturer's manual using anchored oligo $(\mathrm{dT})_{20}$ and random hexamers. For each reaction, $1 \mu \mathrm{g}$ of total RNA was used. After terminating the reaction by incubation at $85^{\circ} \mathrm{C}$ for 5 minutes, samples were used as cDNA templates for qRT-PCR. 


\subsubsection{Real time quantitative reverse transcription $P C R$ (qRT-PCR)}

qRT-PCR for cDNA synthesis and quantification was performed in 384 well plates (Roche). For each gene, a master mix was prepared with the presence of $5 \mu \mathrm{l}$ of SYBR Green (Invitrogen), $0.1 \mu \mathrm{l}$ of each primer, and $1 \mu \mathrm{l}$ molecular biology grade $\mathrm{H}_{2} \mathrm{O} .4 \mu \mathrm{l}$ of cDNA sample was mixed with $6 \mu \mathrm{l}$ of master mix into each well. All procedures were performed on ice, and exposure to room light was minimized. The plate was centrifuged at $1000 \mathrm{~g}$ for 5 minutes and put in the Light Cycler 480 (Roche Applied Science) with the following protocol. Primer information was given in Table 6 .

Pre-incubation

Step $1: 95^{\circ} \mathrm{C}$ for $10 \mathrm{~min}$

Amplification

Step 2: $95^{\circ} \mathrm{C}$ for $10 \mathrm{sec}$

Step 3: $60^{\circ} \mathrm{C}$ for $30 \mathrm{sec}$

Step 4: $72^{\circ} \mathrm{C}$ for $1 \mathrm{~min}$ ( 45 cycles from Step 2 to 3 )

Cooling

Step 5: $40^{\circ} \mathrm{C}$ for $10 \mathrm{sec}$

Samples were run as triplicates for each gene of interest, and if the cycle number to reach the threshold cycle is $5 \%$ more or less than other two duplicates, the value was excluded as an outlier. Relative levels of amplified products were normalized to levels of housekeeping genes, GAPDH, $H P R T 1$ and beta-actin. The translational efficiency was calculated according to $2^{-\Delta \Delta C(T)}$ method (Livak \& Schmittgen, 2001). 


\subsection{Cell biology}

\subsubsection{Media and solutions}

10\% FCS/DMEM

$500 \mathrm{ml}$ DMEM, $50 \mathrm{ml} \mathrm{FCS}$, L-Glutamine (Invitrogen, Cat\#25030081), $5 \mathrm{ml}$ Penicillin/Streptomycin (100x, Invitrogen, Cat\#10378016).

Complete Neurobasal Medium

$500 \mathrm{ml}$ Neurobasal A, $5 \mathrm{ml}$ GlutaMAX I (Invitrogen, Cat\#35050061), $10 \mathrm{ml}$ B-27 supplement (Invitrogen, Cat\#17504044), $1 \mathrm{ml}$ Penicillin/Streptomycin (100x, Invitrogen).

\section{Papain Solution}

20-25 units of Papain (Worthington) were added to $1 \mathrm{ml}$ of Dulbecco's Modified Eagle's Medium (DMEM, Gibco, Life Technologies, Cat\#41965039) supplemented with $0.1 \mathrm{mg} / \mathrm{ml}$ cysteine, $1 \mathrm{mM} \mathrm{CaCl}$, and $0.5 \mathrm{mM}$ EDTA. After resolving papain by bubbling with carbogen $(95 \%$ oxygen, $5 \%$ carbon dioxide) for $10-20$ min, the solution was sterilized using a $0.22 \mu \mathrm{m}$ filter (Millipore, Cat\#GSWP04700).

\section{Stop Solution}

$2.5 \mathrm{mg} / \mathrm{ml}$ BSA, $2.5 \mathrm{mg} / \mathrm{ml}$ trypsin inhibitor, 10\% FCS in DMEM. The solution was pre-warmed at $37^{\circ} \mathrm{C}$ before use.

HEK cell medium

$500 \mathrm{ml}$ DMEM, $50 \mathrm{ml}$ FBS, $5 \mathrm{ml}$ GlutaMAX, $5 \mathrm{ml}$ Penicillin/Streptomycin.

\subsubsection{Treatment of coverslips for culturing primary neurons}

Coverslips (Menzel-Gläser) were incubated with $1 \mathrm{M} \mathrm{HCl}$ for 16-20 hours, rinsed with $\mathrm{dH}_{2} \mathrm{O}$, treated with $70 \%$ ethanol, and rinsed again with $\mathrm{dH}_{2} \mathrm{O}$. They were put in cell culture dishes under the fume hood and exposed to UV for at least half an hour. Prior to seeding neurons, the coverslips were 
incubated with poly-L-lysine (Sigma-Aldrich, Cat\#A-005-C) diluted 1:10 in DPBS (Gibco, Life Technologies, Cat\#14190-044) at least for 2 hours at $37^{\circ} \mathrm{C}$ in order to provide adhesion to the neurons. Later, coverslips were washed with PBS three times, and incubated with Complete Neurobasal medium at $37^{\circ} \mathrm{C}$ until seeding of neurons.

\subsubsection{Primary mouse neuron culture preparation}

For primary cortical neuron culture, cortices of E16 mice; for primary hippocampal neuron culture, hippocampi of $\mathrm{PO}$ mice were dissected in icecold HBSS under a stereomicroscope and incubated with $1 \mathrm{ml}$ of papain solution in $1.5 \mathrm{ml}$ plastic tube at $37^{\circ} \mathrm{C}$ with gentle agitation. After 1 hour of incubation, the papain solution was removed and tissues were incubated with the pre-warmed stop solution at $37^{\circ} \mathrm{C}$ for 20 minutes with mild shaking. The stop solution was removed and brain tissues were triturated in $200 \mu \mathrm{l}$ pre-warmed complete Neurobasal medium by pipetting up and down for 20 times. The tube was kept a while to settle the debris down, and isolated neurons in the supernatant were transferred into $1 \mathrm{ml}$ of complete Neurobasal medium. The number of cells was estimated using a Naubauer counting chamber. 30,000-60,000 cells per $\mathrm{cm}^{2}$ were plated for immunocytochemistry and 120,000-300,000 cells per $\mathrm{cm}^{2}$ were seeded for biochemical experiments. The day that culture is prepared was counted as day in vitro 0 (DIV0). Neurons were kept in 500-1000 $\mu \mathrm{l}$ of complete Neurobasal medium per each well of 24 -well plate at $37^{\circ} \mathrm{C}$ with $5 \% \mathrm{CO}_{2}$ (HERA-cell240 incubator, Heraeus). After keeping neurons for 2-3 hours in the seeding medium, it was changed to fresh complete Neurobasal medium and kept until the DIV of interest. 


\subsubsection{HEK293FT cell line}

HEK293FT cells (Invitrogen, Cat\#R70007; RRID:CVCL_6911) were cultured on $15 \mathrm{~cm}$ Petri dishes (Corning) in $20 \mathrm{ml}$ of $10 \%$ FBS/DMEM at $37^{\circ} \mathrm{C}$ with $5 \% \mathrm{CO}_{2}$ (HERA-cell240 incubator, Heraeus). For passaging, confluent cells were washed with PBS, incubated with $1 \mathrm{ml}$ of $0.05 \%$ Trypsin solution (Gibco, Life Technologies, Cat\#25300054) for 3-5 minutes at $37^{\circ} \mathrm{C} .9 \mathrm{ml}$ of the fresh medium was added to stop trypsinization and then the cells were plated on new Petri dishes for the purpose of biochemical experiments or lentivirus production.

\subsubsection{Lentivirus preparation}

1.6 X $10^{7}$ HEK293FT cells were plated on two poly-L-Lysine coated $15-\mathrm{cm}$ plastic dishes and cultured for 24 hours in 10\% FBS/DMEM until confluency, and cells on two plates were passaged onto five poly-L-lysine coated $15 \mathrm{~cm}$ plates in order to have the confluency of $80-90 \%$. On the next day, the media was changed to $20 \mathrm{ml}$ of pre-warmed $10 \%$ FBS/OPTI-MEM. The cells were co-transfected with $40 \mu \mathrm{g}$ of lentivirus backbone vector [i.e. FUGW, FUGW-iCre, BL544-hN4-2 WT, or BL544-hN4-2 C/S] with $16 \mu \mathrm{g}$ of plasmids encoding Gag polyprotein (pCMVdeltaR8.2; Addgene plasmid \# 12263 ; http://n2t.net/addgene:12263 ; RRID:Addgene_12263) and envelope protein (pMD2.G; Addgene plasmid \# 12259 ; http://n2t.net/addgene:12259 ; RRID:Addgene_12259), using Lipofectamine2000 according to the manufacturer's protocol. Cells were kept in $37^{\circ} \mathrm{C}$ incubator with $5 \% \mathrm{CO}_{2}$. After 8-16 hours, the media was changed to $20 \mathrm{ml}$ of pre-warmed $2 \%$ FBS/Sodium Butyrate (10 mM)/DMEM. 48 hours after transfection, culture medium was harvested in $50 \mathrm{ml}$ Falcon tubes and centrifuged at $1000 \mathrm{~g}$ at $4^{\circ} \mathrm{C}$ for $5 \mathrm{~min}$ to remove the debris. Supernatant was filtered using $45 \mu \mathrm{m}$ filters (Millipore, Cat\#HAWp04700) and loaded to AMICON Centrifugal Filter (100 kDa, Millipore, Cat\#ACS510024) and centrifuged at $3500 \mathrm{~g}$ at $4^{\circ} \mathrm{C}$ to 
concentrate the virus. The final volume of the lentivirus solution was adjusted to $1 \mathrm{ml}$ per $15 \mathrm{~cm}$ petri dish, and the aliquots were frozen in liquid nitrogen to store at $-80^{\circ} \mathrm{C}$ for further use.

\subsubsection{Lentiviral infection of neurons}

After preparation, the virus solution was applied to cultured neurons at the stage of DIV0 or DIV1. At DIV7, after washing four times with PBS, neurons were fixed, and used for further staining experiments. The titer of virus solution was determined by counting the relative number of GFP- or dsRedexpressing cells in all DAPI- and MAP2-positive cells.

\subsubsection{Immunocytochemistry}

Cells cultured on coverslips were fixed with $4 \%$ paraformaldehyde (PFA)/PBS for 15 minutes at $4^{\circ} \mathrm{C}$, followed by washing with PBS three times. Residual active PFA was quenched by incubation with $1 \mathrm{mg} / \mathrm{ml} \mathrm{NaBH}_{4}$ for 5 minutes. Coverslips were washed with PBS three times and incubated with blocking buffer at room temperature for 1 hour. Next, samples were incubated with primary antibodies diluted in blocking buffer for 16-20 hours at $4^{\circ} \mathrm{C}$ with gentle shaking. Coverslips were washed 3 times with PBS, and incubated with secondary antibodies for 1 hour at room temperature. After washing 3 times with PBS, coverslips were rinsed with $\mathrm{dH}_{2} \mathrm{O}$ and mounted onto microscope glass slides (MENZEL-GLASER, Cat\#6310108) with Immu-mount mounting medium (Thermo Scientific, Cat\#10662815). Immunostained cells were imaged with Zeiss Axio Imager Z1 epiflorescence or Leica SP2 confocal microscopy.

Blocking buffer: $10 \%$ goat serum (Gibco, Life Technologies, Cat\#50062Z), 0.3\% Triton X-100 (Roche, Cat\# 11332481001), 5\% sucrose, 1\% BSA (Biomol, Fraction V, Cat\#10735108001) in PBS 


\subsection{Biochemistry}

\subsubsection{Homogenization of mouse brain}

Mice were anesthetized with isoflurane (CP pharma) and decapitated. Cortices or hippocampi were dissected; tissues were homogenized with 10 strokes at $1200 \mathrm{rpm}$ (Braun POTTER'S Homogenizer) in $1 \mathrm{ml}$ Solution A using a Teflon-glass homogenizer (Sartorius) at $4^{\circ} \mathrm{C}$. The sample was left on ice for $3 \mathrm{~min}$ and procedure was repeated once more.

Solution A: $0.32 \mathrm{M}$ Sucrose, $1 \mathrm{mM} \mathrm{NaHCO} 3,10 \mu \mathrm{g} / \mathrm{ml}$ Aprotinin, $1 \mu \mathrm{g} / \mathrm{ml}$ Leupeptin, $100 \mu \mathrm{M}$ PMSF

\subsubsection{Harvesting neuron culture}

For biochemistry, neurons in one well of the 24-well plate were washed three times with PBS, and then were harvested by adding $60 \mu \mathrm{l}$ of Laemmli Buffer supplemented with 250 units of Benzonase and $5 \mathrm{mM} \mathrm{MgCl}$ (Laemmli, 1970).

Laemmli Buffer: 10\% Glycerol, 50 mM Tris-Cl pH 6.8, 2 mM EDTA, 2\% SDS, 100 mM DTT, 0.05\% Bromophenol blue

\subsubsection{Estimation of protein concentration}

In order to quantify protein concentration, the bicinchoninic acid (BCA) method was used. After the reaction with the BCA regents (BCA assay kit, Thermo Piece, Cat\#23225) according to the supplied protocol, absorbance value for each sample was measured at $652 \mathrm{~nm}$. The protein concentration of the sample was estimated in the linear range of the reaction. 


\subsubsection{Sodium dodecyl sulfate polyacrylamide gel electrophoresis (SDS-PAGE)}

Proteins were separated based on their molecular size by SDS-PAGE under denaturing conditions (Summers et al., 1965). An SDS-PAGE gel was prepared using the Bio-Rad Mini-PROTEAN 251 or in-house made casting system. $10-50 \mu \mathrm{g}$ of the protein sample was loaded by using a syringe (Hamilton Bonaduz) along side with PageRuler or PageRuler Plus Prestained Protein Ladders (Thermo Scientific, Cat\#26616, Cat\#26619).

Upper stacking gel:

$5 \%$ acrylamide/N,N'-Methylene-bis-Acrylamide (29:1) Solution (AMBA), 125 $\mathrm{mM}$ Tris- $\mathrm{HCl}(\mathrm{pH} 6.8), 0.1 \%$ SDS, $0.05 \%$ ammonium persulfate (APS), 0.005\% TEMED

Lower separating gel:

8-15\% AMBA, $325 \mathrm{mM}$ Tris- $\mathrm{HCl}$ (pH 8.8), 0.1\% SDS, 0.05\% APS, $0.005 \%$ TEMED

Running buffer:

$25 \mathrm{mM}$ Tris- $\mathrm{HCl}, 250 \mathrm{mM}$ Glycine, $0.1 \%$ SDS (pH 8.8)

\subsubsection{Western blotting}

After SDS-PAGE, proteins in the gel were electrophoretically transferred onto a nitrocellulose membrane (Amersham Protran, $0.2 \mu \mathrm{m} \mathrm{NC,} \mathrm{GE}$ Healthcare) in between 2 Whatmann papers (GE Healthcare Life Sciences) in transfer buffer with a constant current of $100 \mathrm{~mA}$ for 12 hours in a tankblotting unit (Towbin et al., 1979). Then, to stain transferred proteins, the membrane was stained in Ponceau or Memcode solution (Pierce, Thermo, Cat\#24580). The membrane was washed and incubated with the blocking buffer for 45-60 min to prevent non-specific binding of antibodies to the membrane. The membrane was incubated with one or two of the primary 
antibodies listed in Table 7 for three hours at room temperature with moderate agitation in blocking buffer with the presence of Tween. The membrane was washed three times with TBS-T, and further incubated with secondary antibodies conjugated with horseradish peroxidase (HRP) or fluorophores (Table 8) for 45-60 min. After removing nonspecifically bound secondary antibodies by washing with TBS-T three times, the signal on the membrane was developed with enhanced chemiluminescence (ECL) system (Solution I and II, GE Healthcare) on X-ray films (Amersham Hyperfilm ECL, GE Healthcare) or detected with Odyssey CLx Infrared Imaging System (LI-COR Biosciences). Quantification of protein band intensities was assessed via the Image-Studio Software (Odyssey System) or ImageJ.

Transfer buffer: 25 mM Tris-base, 190 mM Glycine, 20\% (w/v) methanol

TBS: $10 \mathrm{mM}$ Tris-HCl, $150 \mathrm{mM} \mathrm{NaCl}, \mathrm{pH} 7.5$

TBS-T: TBS, $0.1 \%$ Tween-20

Ponceau Solution: 0.1\% (w/v) Ponceau S, 5\% (v/v) Acetic acid

Blocking buffer: $5 \%(\mathrm{w} / \mathrm{v})$ skimmed milk (Frema), TBS.

Blocking buffer for phosphorylated antibodies: $5 \%(w / v)$, TBS.

\subsubsection{Purification of recombinant GST-fused proteins}

GST gene fusion system (GE Healthcare Life Sciences) was employed to purify GST-fused recombinant proteins. The cDNA fragment encoding the full-length N4-2 was subcloned into a pDEST15 vector, and backtransformed into BL21 Rossetta E.coli strain. A single colony was picked and the E.coli were inoculated in $50 \mathrm{ml}$ LB medium supplemented with ampicillin at $37^{\circ} \mathrm{C}$ overnight. In the next day, the culture of E.coli was 
transferred into 1 liter of LB media including ampicillin and incubated again until the optical density at $600 \mathrm{~nm}\left(\mathrm{OD}_{600}\right)$ reached 1 . Then, expression of the GST fusion proteins was induced with $0.5 \mathrm{mM}$ isopropyl- $\beta-D-1-$ thiogalactopyranoside (IPTG) for 6 hours at $20^{\circ} \mathrm{C}$. Cells were harvested by centrifugation at $3500 \mathrm{~g}$ at $4^{\circ} \mathrm{C}$ for 30 minutes. The pellet was washed with PBS and resuspended in $50 \mathrm{ml}$ of resuspension buffer. $5 \mathrm{ml}$ aliquots of cell suspension were flash frozen in liquid nitrogen and kept at $-80^{\circ} \mathrm{C}$ for further usage.

For further purification, aliquots were thawed by soaking in warm water and ice sequentially and supplemented with protease inhibitors $(10 \mu \mathrm{g} / \mathrm{ml}$ Aprotinin, $1 \mu \mathrm{g} / \mathrm{ml}$ Leupeptin, $100 \mu \mathrm{M}$ PMSF), $1 \mathrm{mg} / \mathrm{ml}$ lysozyme, and 0.05 $\mathrm{mg} / \mathrm{ml}$ DNase. Then, the cell suspension was sonicated for 20 seconds on ice, and an equal volume of resuspension buffer containing $2 \%$ CHAPS was added to solubilize the proteins. After $30 \mathrm{~min}$ incubation at $4^{\circ} \mathrm{C}$, the insoluble fraction was removed by centrifugation at $10,000 \mathrm{~g}$ for $10 \mathrm{~min}$ at $4^{\circ} \mathrm{C}$ and the supernatant was harvested as the starting material of GST-fused protein. $850 \mu \mathrm{l}$ the supernatant was incubated with $50 \mu \mathrm{g}$ of Glutathione (GSH) Sepharose beads (GE Healthcare, Cat\#17-0756-01) according to the manufacturer's instructions. After washing 3 times with wash buffer, the bound fractions of GST-fusion proteins were eluted with $40 \mathrm{mM}$ reduced GSH.

Resuspension buffer: $50 \mathrm{mM}$ Tris- $\mathrm{HCl}\left(\mathrm{pH}\right.$ 8), $500 \mathrm{mM} \mathrm{NaCl}, 5 \mathrm{mM} \mathrm{NaCl}_{2}$, $5 \mathrm{mM}$ DTT, $10 \mu \mathrm{g} / \mathrm{ml}$ Aprotinin, $1 \mu \mathrm{g} / \mathrm{ml}$ Leupeptin, $100 \mu \mathrm{M}$ PMSF Wash buffer: $50 \mathrm{mM}$ Tris- $\mathrm{HCl}(\mathrm{pH}$ 8), $500 \mathrm{mM} \mathrm{NaCl}, 1 \%$ CHAPS, 5mM DTT

\subsubsection{Protein extraction from HEK293FT cells}

For the production of recombinant substrate proteins, HEK293FT cells were split and plated in $6 \mathrm{~cm}$ dishes as described in section 2.4.4, and transfected with HA tagged Prr7-expression vectors. 48 hours after transfection, cells on the dish were washed with PBS with protease inhibitors $(10 \mu \mathrm{g} / \mathrm{ml}$ Aprotinin, 
$1 \mu \mathrm{g} / \mathrm{ml}$ Leupeptin, $100 \mu \mathrm{M}$ PMSF) and frozen at $-80^{\circ} \mathrm{C}$. After thawing cells at room temperature, cells were lysed by incubating with $500 \mu$ l of lysis buffer containing $0.5 \% \operatorname{SDS}$ at $65^{\circ} \mathrm{C}$ for $15 \mathrm{~min}$. Samples were centrifuged at $16,000 \mathrm{~g}$ for $30 \mathrm{~min}$ and $500 \mu \mathrm{l}$ of the supernatant was diluted with $4.5 \mathrm{ml}$ of $0.5 \%$ Triton $\mathrm{X}-100$ containing Lysis buffer so that SDS concentration was reduced to the level below the critical micelle concentration.

Lysis buffer: $20 \mathrm{mM}$ Tris-HCl (pH 7.5), $1 \mathrm{mM}$ EDTA, $150 \mathrm{mM} \mathrm{NaCl,} 5 \mathrm{mM}$ $\mathrm{MgCl}_{2}, 2 \mathrm{mM}$ DTT, $10 \mu \mathrm{g} / \mathrm{ml}$ Aprotinin, $1 \mu \mathrm{g} / \mathrm{ml}$ Leupeptin, $100 \mu \mathrm{M}$ PMSF, 250 units of Benzonase

\subsubsection{In vitro binding assay}

$50 \mu \mathrm{g}$ of the purified GST-N4-2 was immobilized on $50 \mu$ glutathione Sepharose beads, which were subsequently equilibrated with five bed volumes of binding buffer. Recombinant substrate proteins extracted from HEK293FT cells in 2.5.7 were loaded on glutathione Sepharose beads and the beads were washed with five bed volumes of binding buffer to remove non-specifically bound proteins. Proteins bound on the beads were eluted with $200 \mu \mathrm{l}$ of Laemmli buffer, and HA-tagged substrates in the eluate were detected by Western blotting using anti-HA antibody.

Binding buffer: 20 mM Tris-HCl (pH 7.5), 1 mM EDTA, 150 mM NaCl, 2 mM DTT, $1 \%$ Triton $\mathrm{X}-100$

\subsubsection{In vivo ubiquitination assay}

Cell based ubiquitination assay was performed by expressing substrate, E3 ligase, and ubiquitin in HEK293FT cells using Lipofectamine2000 (Invitrogen, Cat\#11668019). After 48 hours of incubation, cells were washed with PBS including NEM and plates were stored at $-80^{\circ} \mathrm{C}$. Then, they were 
thawed on ice, and by using a scraper, lysates were harvested with $200 \mu \mathrm{l}$ ubiquitination lysis buffer in $2 \mathrm{ml}$ plastic tubes and boiled at $65^{\circ} \mathrm{C}$ for $20 \mathrm{~min}$. $1.8 \mathrm{ml}$ Dilution buffer was added and SDS was neutralized and followed by centrifugation at $10,000 \mathrm{rpm}$ for $10 \mathrm{~min}$ at $4^{\circ} \mathrm{C}$. Substrate was then immunoprecipitated using the anti-HA beads (Roche). After washing three times with washing buffer, beads were harvested with Laemmli Buffer containing DDT for SDS-PAGE and Western blotting.

NEM: $125.6 \mathrm{mg} \mathrm{NEM}$ in $1 \mathrm{ml}$ 100\% Ethanol

$20 \mathrm{mM}$ NEM/PBS: $1 \mathrm{ml}$ of NEM in $50 \mathrm{ml}$ ice-cold PBS

Ubiquitination Lysis Buffer: 50 mM Tris-HCl (pH 7.5), $300 \mathrm{mM} \mathrm{NaCl}, 1 \%$ SDS, supplemented with 250 units of Benzonase and $5 \mathrm{mM} \mathrm{MgCl} 2$

Dilution Buffer: Ubiquitination Lysis Buffer with 1.11\% Triton X-100

Washing Buffer: Ubiquitination Lysis Buffer with 1\% Triton X-100

\subsubsection{Biotinylation assay in primary cultured neurons}

High-density neurons (500,000-1,000,000 cells) were plated and infected with viruses EGFP and EGFP-Cre at DIV1. At DIV15, cells were washed with ice cold PBS, and incubated with Biotin (Thermo, Cat\#21331, 1mg/ml Biotin in Tyrode's working solution) for 20 minutes at $4^{\circ} \mathrm{C}$ with a gentle shake in every 5 minutes. Cells were quenched with $30 \mathrm{mM}$ ammonium chloride, followed by a single TBS wash, then harvested with RIPA buffer supplemented with inhibitors by using a cell scraper. The cell lysate was rotated at $4^{\circ} \mathrm{C}$ for $10 \mathrm{~min}$ and centrifuged at $12,000 \mathrm{rpm}$ for $15 \mathrm{~min}$ at $4^{\circ} \mathrm{C}$. The supernatant was collected and protein concentrations were measured by the BCA method (Thermo). Equal amounts of control and N4-2 KO samples were incubated with streptavidin beads overnight at $4^{\circ} \mathrm{C}$ to capture biotinylated proteins. After spinning down and extensive washing of the beads, biotinylated proteins were harvested with Laemmli Buffer containing $50 \mathrm{mM}$ DDT for further SDS-PAGE and Western blotting. 
TBS: $20 \mathrm{mM}$ Tris-HCl, $150 \mathrm{mM} \mathrm{NaCl}, \mathrm{pH} 7.5$

RIPA buffer: 20 mM Tris-HCl, 150 mM NaCl, pH 7.5, 1\% Triton X-100, 0.5\% Sodium deoxycholate, 0.1\% SDS, $10 \mu \mathrm{g} / \mathrm{ml}$ Aprotinin, $1 \mu \mathrm{g} / \mathrm{ml}$ Leupeptin, 100 HM PMSF, phosphatase inhibitor (PhosStop, Roche, Cat\#4906845001)

Tyrode's solution: $140 \mathrm{mM} \mathrm{NaCl}, 2.4 \mathrm{mM} \mathrm{KCl}, 10 \mathrm{mM}$ HEPES, $10 \mathrm{mM}$ D+glucose monohydrate, $2 \mathrm{mM} \mathrm{CaCl}_{2}, 1.25 \mathrm{mM} \mathrm{MgCl}_{2}$, $\mathrm{pH} 7.6$

\subsubsection{Subcellular fractionation of mouse brain}

Cortices of 6 week-old mice were dissected with ice cold Solution A (0.32 M Sucrose, $1 \mathrm{mM} \mathrm{NaHCO}$, Aprotinin, $1 \mu \mathrm{g} / \mathrm{ml}$ Leupeptin, $100 \mu \mathrm{M}$ PMSF, phosphatase inhibitor (PhosStop, Roche) on ice and stored at $-80^{\circ} \mathrm{C}$ until further use. Cortices from one mouse were homogenized in $3 \mathrm{ml}$ Solution A with 10 strokes at $12,000 \mathrm{rpm}$ with a Teflon-glass homogenizer, and homogenates were loaded on the top of a discontinuous sucrose density gradient with $0.85 \mathrm{M}, 1.0 \mathrm{M}$ and $1.2 \mathrm{M}$ sucrose layers. Samples were centrifuged at $82,500 \mathrm{~g}$ for 2 hours at $4^{\circ} \mathrm{C}$ (SW41 rotor, Beckman Coulter) for fractionation. The fraction above the $0.85 \mathrm{M}$ sucrose was harvested as the supernatant fraction $(\mathrm{S})$, and the interphase between 1.0 $\mathrm{M}$ and $1.2 \mathrm{M}$ sucrose layers harvested as the synaptosome fraction (P2C). The P2C fraction was diluted with Solution A and centrifuged at 32,800 $\mathrm{g}$ for $20 \mathrm{~min}$ (TLA100.3 rotor, Beckman Coulter). The pellet was resuspended in $2.4 \mathrm{ml}$ of $6 \mathrm{mM}$ Tris- $\mathrm{Cl}$, pH 8.0 using 21G and 27G needles (Becton Dickinson), and incubated for 45 minutes on ice for osmotic shock. Next, samples were centrifuged again at $32,800 \mathrm{~g}$ for $20 \mathrm{~min}$ (TLA100.3 rotor). The supernatant was harvested as synaptic cytoplasm and crude synaptic vesicle fractions, and the pellet was resuspended in $250 \mu \mathrm{l} 6 \mathrm{mM}$ Tris- $\mathrm{Cl}, \mathrm{pH} 8.0$ as the crude synaptic membrane (CSM) fraction using $21 \mathrm{G}$ and $27 \mathrm{G}$ needles. Subfractions were subjected to Western blotting for PSD-95 and Rab-GDI as markers for postsynaptic density and cytoplasm. 


\subsection{Histology}

\subsubsection{In utero electroporation (IUE)}

\subsubsection{Preparation of glass capillaries}

Micropipettes were prepared from 1.5-1.8 X $100 \mathrm{~mm}$ borosilicate glass capillaries (Kimble and Chase) by HEKA PIP5 temperature controlled pipette puller. The filament of was heated approximately to $1200^{\circ} \mathrm{C}$, and the speed to pull the glass capillary was controlled manually to get slow expansion of heated glass.

\subsubsection{Preparation of plasmid DNA for IUE}

Plasmid DNA was purified with EndoFree Plasmid Maxi Kit (Qiagen) and final DNA concentration was adjusted to $1.5 \mu \mathrm{g} / \mu \mathrm{l}$ with endotoxin-free TE buffer. Plasmid DNA was mixed with 0.1\% Fast Green FCF (Sigma-Aldrich) to monitor the amount of plasmid solution injected to the lateral ventricle. DNA mixture was loaded into the microcapillary by using microloader pipette tips, and the tip of the microcapillary was cut with fine forceps to have the liquid flowing.

\subsubsection{Procedure}

E14.5 mouse embryos were subjected to IUE based on previously published work (Saito \& Nakatsuji, 2001, Matsui et al., 2011, dal Maschio et al., 2012). Briefly, the pregnant mouse was deeply anesthetized by inhalation of isoflurane/oxygen, and placed on a warm heating pad $\left(32^{\circ} \mathrm{C}\right)$ during the surgery. Before the surgery, the loss of toe pinch-reflex was checked to be able to continue with the surgical procedure. Vidisic gel (Bausch and Lomb) was applied onto each cornea to avoid any damage. A $2 \mathrm{~cm}$ incision of the abdominal cavity was made and embryos within the uterus were exposed, and subsequently moistened with warm PBS including $2000 \mathrm{U} / \mathrm{ml}$ penicillin, 
and $2 \mathrm{mg} / \mathrm{ml}$ streptomycin (Gibco). In brief, a glass micropipette was filled with 0 DNA Fast Green mixture and injected into the lateral ventricle of the brain of the pups by applying pressure using a pneumatic pump (PV820), followed by an electric current applied with ElectroSquare Porator (ECM830BTX Harvard Apparatus) for $50 \mathrm{~ms}$ with $950 \mathrm{~ms}$ interval via a homemade forceps-type electrode. The uterus with embryos was put back to the abdomen, and closed with absorbable surgical sutures (Safil, Aesculap; 4/0, 28"; HR17), and the skin with $9 \mathrm{~mm}$ Autoclips (Clay Adam). For the pain management after operation, $3 \mathrm{mg}$ buprenorphine (Temgesic) was given to the mouse subcutaneously. After the operation, the mouse was kept on the warm pad until it regained consciousness, and then monitored regularly.

\subsubsection{Perfusion}

Perfusion with 4\% PFA in PB buffer was done transcardially with the help of a pump apparatus PA-SF (IKA Labortechnik) according to previously published protocols (Gage et al., 2012). Briefly, the mouse was deeply anesthetized by injecting of avertin-99\% 2,2,2-tribromoethanol (Alta Aesar) dissolved in 2-methylbuthanol (Sigma) (0.2 ml per mouse of approximately $20 \mathrm{~g}$ ) intraperitoneally. Upon verifying the surgical plane of anesthesia by the lack of toe pinch-response, a lateral incision through the abdominal wall was made and the diaphragm was separated from the liver until the full exposure of the pleural cavity has been achieved by cutting through the rib cage. Then, a 25-gauge winged cannula was inserted to the posterior edge of the left ventricle of the heart, and a small incision was made to right atrium to discharge blood. Mice were perfused with PBS with the pump speed of 12 , which is equal to $8 \mathrm{ml} / \mathrm{min}$ for 1 minute, and then with $4 \%$ PFA/PB for 3 minutes. The brain was then removed from the skull, and incubated with $4 \%$ PFA/PB buffer at $4^{\circ} \mathrm{C}$ for $16-20$ hours with mild agitation. The brain was transferred to PBS with $0.01 \%$ sodium azide (Sigma-Aldrich) and kept at $4^{\circ} \mathrm{C}$ with moderate shaking overnight. Chemically fixed brains were cryoprotected with $30 \%$ Sucrose/PB and kept at $-80^{\circ} \mathrm{C}$ until used. 


\subsubsection{Immunohistochemistry}

50 to $100 \mu \mathrm{m}$-thick brain sections were prepared by Vibratome (Leica VT1000S) or Cryostat (Leica CM3050S), washed with PBS three times at room temperature, and incubated for 5 minutes with moderate shaking with $1 \mathrm{mg} / \mathrm{ml}$ sodium borohydride (Sigma-Aldrich) solution in PBS. Subsequently, the sections were washed with PBS and incubated with the blocking solution for 1 hour at room temperature, followed by an incubation with the primary antibody for $16-20$ hours at $4^{\circ} \mathrm{C}$. The sections were then washed in PBS 3 times for 30 minutes, and incubated with secondary antibodies coupled to a fluorophore of choice with DAPI. Sections were washed with PBS 3 times for 30 minutes, and mounted with cover glass (Menzel-Gläser) and mounting medium (Immu-Mount).

Blocking solution: $7.5 \%$ goat serum, $0.5 \%(\mathrm{v} / \mathrm{v})$ Triton X-100, PBS

\subsection{Behavioral analysis}

Behavioral analysis of N4-2 conditional knockout mice (cKO) was performed by Prof. Dr. Hannelore Ehrenreich, Sahab Arinrad and Anja Ronnenberg (Clinical Neuroscience, MPlem, Göttingen) based on previously published papers (Dere et al., 2014, Tantra et al., 2014, Winkler et al., 2018, Dere et al., 2018).

\subsubsection{Animals and housing conditions}

For behavioral testing, mice were kept in groups of 3-5 in standard cages, with food, and water available ad libitum with the temperature of $20-22^{\circ} \mathrm{C}$. Mice were housed under a 12 hour light-dark cycle with lights on at $7 \mathrm{AM}$, and all behavioral experiments were performed by a blind observer during the light phase of the day (between 8 AM and 5 PM). Male Nedd4- $2^{\mathrm{fff}} ; N E X$ - 
$\mathrm{Cre}^{+/-}(\mathrm{N}=13)$, and their control Nedd4- $2^{\mathrm{f} / \mathrm{f}}$ littermates $(\mathrm{N}=16)$ were tested in an extensive behavioral test battery after the mice turned 2 months old. The tests were assessed in the following order: elevated plus-maze, open field, hole board, rotarod, bar test, pre-pulse inhibition (PPI), hearing, grip strength, vision, Morris water-maze (MWM), and MWM reversal test. The order of the tests was arranged according to the invasiveness of the test with a minimum of 1 day interval. After all of the tests were completed, the mice were sacrificed at the age of 5 months and the cortex and the hippocampus were dissected out and stored at $-80^{\circ} \mathrm{C}$ for biochemical analyses.

\subsubsection{Elevated plus-maze}

Each mouse was put on a central platform facing an open arm of the plusmaze (gray Perspex with a $5 \mathrm{~cm} \times 5 \mathrm{~cm}$ central platform, two open and two walled arms with the size of $30 \mathrm{~cm} \times 5 \mathrm{~cm} \times 15 \mathrm{~cm}$ and illumination density of $1351 \mathrm{x})$. Behavior of each mouse was recorded for 5 minutes by an overhead video camera assisted with a computer having automated tracking-software system (Viewer2, Biobserve, Germany) in order to calculate the time, number of visits, path length as well as velocity.

\subsubsection{Open field}

Exploratory capacity of the mice in a new environment was investigated using a gray Perspex arena having $120 \mathrm{~cm}$ in diameter, surrounded by a wall of $25 \mathrm{~cm}$ height. Each mouse was put into the center of the open field and let the mouse explore the field for 7 minutes. The exploratory ability of the mouse was recorded via the tracking-software; time, path length, and velocity in the central, intermediate, and peripheral zones of the open field were measured. 


\subsubsection{Hole board}

A water deprived mouse was placed into the center of the hole board (transparent Perspex chamber with the dimensions of $50 \mathrm{~cm} \times 50 \mathrm{~cm} \times 36$ $\mathrm{cm}$ ), having an additional non-transparent floor $3 \mathrm{~cm}$ above the bottom of the chamber with 16 holes of $2.2 \mathrm{~cm}$ diameter containing water, and was allowed to explore the chamber for 5 minutes. The number of explored holes by counting head dips was counted by two layers of infrared photo beams attached to a computer assisted with the AKS software (TSE Systems, Bad Homburg, Germany).

\subsubsection{Rotarod}

The rotarod (Ugo Basile Srl, Comerio, Italy), which has a horizontal rotating drum was set from 4 to $40 \mathrm{rpm}$ with a total of 5 minutes. Mice were put on the drum, and soon after they were balanced, the drum was accelerated. The time that mice fell from the drum was measured for two consecutive days.

\subsubsection{Bar test}

Each mouse was carefully carried by the tail to steel horizontal bar with a 12 $\mathrm{cm}$ length, $2.5 \mathrm{~mm}$ diameter and allowed to grasp the bar with both forepaws. Then, the mouse was moved down to make contact with the floor via hind paws before its tail was released. Catatonic signs were counted manually by measuring time of the mouse stood without moving with the minimum of 1 forepaw on the bar and both hind paws on the ground (Janova et al., 2018). 


\subsubsection{Pre-pulse inhibition (PPI)}

Mice were put in small metal cages ( $82 \mathrm{~mm} \times 40 \mathrm{~mm} \times 40 \mathrm{~mm}$ ) in order to minimize major movements and exploratory activity, and they were equipped with a sensor measuring vertical movements of the floor. The cages were put in four sound attenuating cabinets (TSE Systems, Bad Homburg, Germany). Startle reflexes were evoked by applying acoustic stimuli via a loudspeaker. For PPI, in brief, the startle pulse was assessed with or without a pre-pulse stimulus of 70,75 , or $80 \mathrm{~dB}$ intensities. For each mouse, the amplitudes were averaged from two trials and PPI was calculated as the percentage of the startle response using the following formula: \% PPI = 100-[(startle amplitude after pre-pulse) / (startle amplitude after pulse only) $X 100]$.

\subsubsection{Hearing}

In this test, the startle reaction to an acoustic stimulus (pulse) on a forcesensitive platform was measured over a period of $100 \mathrm{~ms}$, beginning with the onset of the pulse. A habilitation session with a $65 \mathrm{~dB}$ background white noise was followed by stimuli of different intensity varying between 65 and $120 \mathrm{~dB}$. The amplitude of the startle response was set as the difference between the maximum force detected and the force measured before stimulus onset. For each individual mouse, the amplitudes of the startle responses were averaged according to each stimulus intensity.

\subsubsection{Grip strength}

A grip strength meter (TSE Systems, Bad Homburg, Germany) was used for measuring the forelimb grip strength. Individual mouse was lifted by the tail and allowed its forepaws to grasp a wire grid followed by a gentle backward pull parallel to the surface until mice let the grid go. The peak force coming 
from the forelimbs was measured. Average of three trials per each mouse was taken for statistical analysis (Netrakani et al., 2015).

\subsubsection{Vision}

Visual integrity of the mice was analyzed in an apparatus consisting of a Perspex box with the dimensions of $70 \mathrm{~cm} \times 35 \mathrm{~cm} \times 30 \mathrm{~cm}$ with a transparent floor. The box was put on the edge of a bench with the position of half on the bench (ground side), half above the floor (air side). Each mouse was placed in the center of the base and its behavior was recorded for 5 minutes by measuring the percentage of time spent on the ground versus air side of the box as well as path length and velocity.

\subsubsection{Morris Water Maze and reversal}

A circular tank with a diameter $1.2 \mathrm{~m}$ and depth $0.4 \mathrm{~m}$, containing opaque water $\left(25 \pm 1^{\circ} \mathrm{C}\right.$, depth $\left.0.3 \mathrm{~m}\right)$ was assisted with an escape platform $(10 \mathrm{~cm}$ $X 10 \mathrm{~cm}$ ) standing $1 \mathrm{~cm}$ below the water level. First, the mice were tested to swim towards the visible platform marked using a flag, and latency was measured with a video-tracking system for 2 days (non-spatial training). The extra-maze cues were hidden during this trial. Then, it was followed by the hidden platform test for 8 days in which the position of the platform was changed and fixed throughout the test. Each mouse was trained to find a hidden platform that was merged $0.5 \mathrm{~cm}$ below water level. Every time, the mouse was put in the center of one of the four quadrants of the pool facing the pool wall, and needed to relocate the hidden platform with the help of extra-maze cues on the walls of the room (spatial training). Each mouse had four trials with an interval of 5 minutes, and allowed to look for the platform for 90 seconds. If the mouse failed to find the platform, it was taken to the platform and kept there for 20 seconds. The latency to find the platform was measured. 
The spatial probe trial started one day after the hidden platform training, in which the platform was removed from the pool and mice were let swim for 90 seconds in order to check if the mice had developed a spatial bias for the previous platform quadrant or not. Time spent in platform zone, as well as latency, number of visits, and path length of each mouse was measured.

Lastly, reversal learning was tested to see cognitive flexibility. The experimental procedure was the same as hidden platform training, but the escape platform was relocated from the original position to a new quadrant. Reversal learning lasted for 3 days followed by a probe trial. Time spent in platform zone, as well as latency, number of visits, and path length of each mouse was measured.

\subsection{Electrophysiology}

3-4 week old mice were anesthetized with Isofluorane and decapitated by cervical dislocation. The whole brain was removed from the skull and the hippocampus was isolated and immediately sliced with the thickness of 300 $\mu \mathrm{m}$ using a tissue chopper (MclLWAIN). Slices were transferred to a chamber filled with carbogen (95\% oxygen and 5\% carbon dioxide)-supplied artificial cerebrospinal fluid (ACSF) at $32^{\circ} \mathrm{C}$ for recovery. After recovery, slices were kept at room temperature with continuous carbogen. For the measurement of input-output curve (I/O), paired-pulse ratio (PPR) and early phase-long term potentiation (E-LTP) and late phase-long term potentiation (L-LTP), each slice was put on a recording chamber kept at $32^{\circ} \mathrm{C}$ supplied with carbogenated ACSF. The recording electrode (2-3 $M \Omega$ ) was then filled with ACSF. In order to evoke fEPSPs, electric stimulations were applied to the Stratum radiatum at CA3/CA1 junction activating Schaffer collaterals by using concentric metal bipolar electrode with duration of $100 \mu \mathrm{s}(1 \times 100 \mathrm{~Hz}$ for E-LTP, 3 X $100 \mathrm{~Hz}$ for L-LTP), and recorded from the Stratum radiatum of the CA1 area by recording pipette. The recordings were done with the help of Multiclamp 700B amplifier and a Digidata 1440A. Data analysys was done using AxographX. 
ACSF: $120 \mathrm{mM} \mathrm{NaCl}, 26 \mathrm{mM} \mathrm{NaHCO} 3,1 \mathrm{mM} \mathrm{KH} \mathrm{PO}_{4}, 2 \mathrm{mM} \mathrm{KCl}, 1 \mathrm{mM}$ $\mathrm{MgCl}_{2} \times 6 \mathrm{H}_{2} \mathrm{O}, 10 \mathrm{mM}$ Glucose, $2 \mathrm{mM} \mathrm{CaCl} 2$

\subsection{Live imaging of primary cultured neurons}

Primary cultured cortical neurons from $N 4-2^{f / f}$ mice were prepared and infected with lentivirus to express EGFP alone or EGFP together with Cre recombinase. At the stage of DIV16, Celltox green dye (Promega, Cat\#G8741, 1000X) was applied in order to identify nuclei of dead cells. Subsequently, NMDA was applied to the culture medium at the concentration of $100 \mu \mathrm{M}$ for $25 \mathrm{~min}$. NMDA was washed out and live imaging experiments were started using Incucyte Live imaging system (Sartorius) with 10X objective lens for 25 hours. A snap shot of neurons was taken every hour.

\subsection{Statistical analysis}

All statistics were performed using Prism Graph Pad software. For the comparison of two groups, Student t-test was applied after confirming the normal distribution. For the comparison of multiple groups, analysis of variance (ANOVA) test with Tukey posthoc test. All results are presented as average \pm standart error of the mean (SEM). 


\section{RESULTS}

\subsection{Role of Nedd4s in the postsynaptic density}

\subsubsection{Localization of Nedd4-2 in the neuron}

In order to study the subcellular localization of Nedd4-2 in the neuron, we prepared primary cultured hippocampal neurons from Nedd4-1 (N4-1) and Nedd4-2 (N4-2) brain specific conditional KO mouse (Nedd4-1 ${ }^{\mathrm{f} / \mathrm{f}}$;Nedd4$2^{\mathrm{f} / \mathrm{f}} ; E m \times 1-C r e, \quad N 4-1 / 2$ bDKO) and control (Nedd4-1 ${ }^{\mathrm{f} / \mathrm{f}} ; N e d d 4-2^{\mathrm{f} / \mathrm{f}}, \quad N 4-1 / 2$ CTL), mice. Neurons were fixed at 19 days in vitro (DIV19) with 4\% PFA and $4 \%$ sucrose for immunocytochemistry. Fixed neurons were stained with the anti-N4-2 antibodies together with the anti-PSD-95 antibody as a postsynaptic marker, and imaged with confocal microscopy (Figure 3.1). In N4-1/2 CTL neurons, punctate signals were detected from the anti-N4-2 antibody partially colocalizing with signals from the anti-PSD-95 antibody. In N4-1/2 bDKO neurons, the number of punctate signals from the anti-N4-2 antibody was reduced. This result indicates that endogenous N4-2 partially enriches at the synapse.
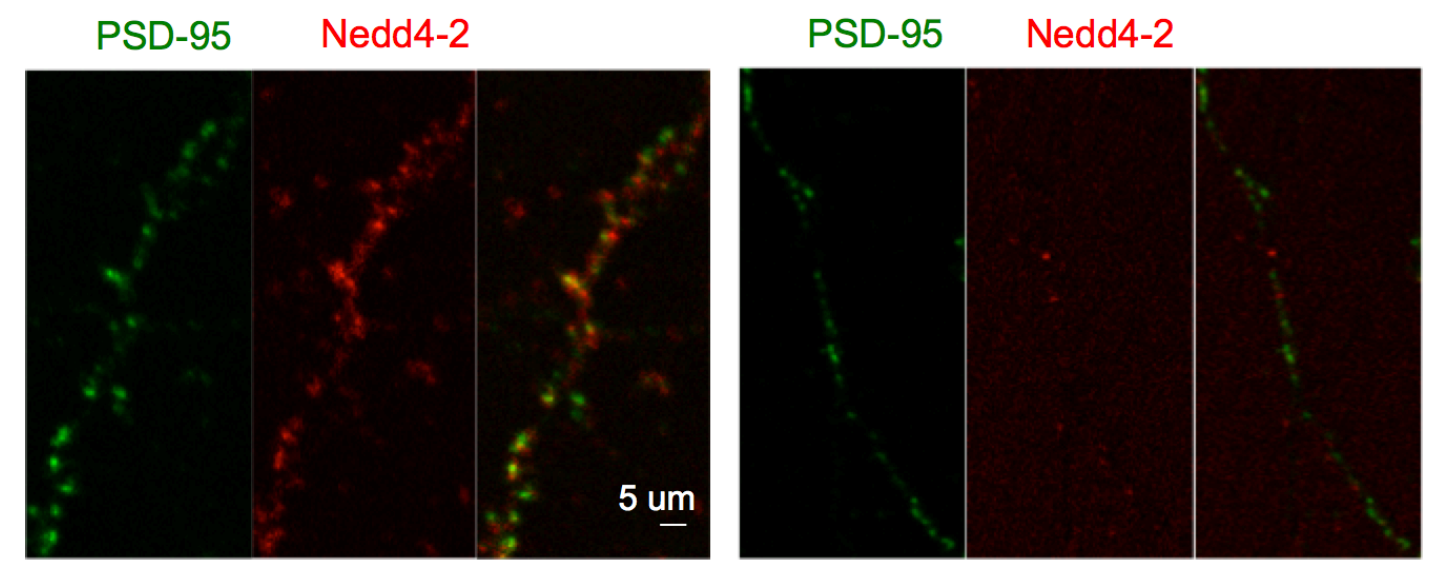

Figure 3.1. Localization of $\mathbf{N 4 - 2}$ in primary cultured neurons. Immunofluorescence signals from anti-N4-2 and anti-PSD-95 antibodies in DIV19 hippocampal neurons prepared from N4-1/2 CTL (Nedd4-1/f/finedd4$2^{\mathrm{f} / \mathrm{f}}, \mathrm{N} 4-1 / 2 \mathrm{CTL}$ ) (left three panels) and N4-1/2 bDKO (Nedd4-1/f/f ; $2^{\mathrm{f} / \mathrm{f}} ; E m \times 1-\mathrm{Cre}$ ) (right three panels) mice. Note that N4-2 shows colocalization with PSD-95 in N4-1/2 CTL neurons. Scale bar; $5 \mu \mathrm{m}$. 


\subsubsection{Identification of proline-rich protein 7 (Prr7) in proteome screen of Nedd4-1;Nedd4-2 substrates}

Given that K63-linked polyubiquitin chain (K63-polyUbi) plays crucial roles in endocytosis and lysosomal degradation (Erpapazoglou et al., 2014, Piper et al., 2014), and that Nedd4 family E3 ligases conjugate K63-linked polyubiquitin chains to substrates (Maspero et al., 2013), we hypothesized that physiological substrates of N4-1 and N4-2 are upregulated on the synaptic plasma membrane from N4-1/2 bDKO compared to the CTL. Biochemically purified synaptic plasma membrane (SM) fractions from N41/2 bDKO and N4-1/2 CTL mice cortices (Mizoguchi et al., 1989) were subjected for comparative mass spectrometry by isobaric tags for relative and absolute quantitation (iTRAQ) in order to identify proteins upregulated in N4-1/2 bDKO samples as potential substrates (Ross et al., 2004; Schmidt et al., 2013). Among five proteins upregulated in N4-1/2 bDKO samples, Prr7 was the only neuron specific protein while others are only expressed in astrocytes (i.e. gap junction protein alpha 1 (Gja1) and ATP-sensitive inward rectifier potassium channel 10 (Kcnj10) or ubiquitously (i.e. NADH dehydrogenase iron-sulfur protein 6 (Ndufs6 and CDGSH iron-sulfur domain-containing protein 1 (Cisd1) (Table 3.1) [Dr. Bekir Altas, Dr. Olaf Jahn, Dr. Samir Karaca, Dr. Henning Urlaub (Altas, 2016, PhD thesis)].

Table 3.1. Proteins upregulated in N4-1/2 bDKO in mass spectrometry

\begin{tabular}{|c|c|c|c|c|c|}
\hline & $\begin{array}{c}\text { Protein } \\
\text { Name }\end{array}$ & $\begin{array}{l}\text { Gene } \\
\text { Name }\end{array}$ & $\begin{array}{c}\text { Uniprot } \\
\text { Accession } \\
\text { Number }\end{array}$ & $\begin{array}{l}\text { Forward } \\
\text { Normalized } \\
\text { DKO/WT }\end{array}$ & $\begin{array}{c}\text { Reverse } \\
\text { Normalized } \\
\text { DKO/WT }\end{array}$ \\
\hline 1 & Proline-rich protein 7 & Prr7 & Q3V012 & 1.65 & 1.77 \\
\hline 2 & Gap junction protein alpha 1 & Gja1 & P23242 & 1.65 & 1.96 \\
\hline 3 & $\begin{array}{l}\text { ATP-sensitive inward rectifier } \\
\text { potassium channel } 10\end{array}$ & Kcnj10 & Q9JM63 & 1.98 & 3.06 \\
\hline 4 & $\begin{array}{l}\text { NADH dehydrogenase } \\
\text { iron-sulfur protein } 6\end{array}$ & Ndufs6 & P52503 & 1.57 & 1.41 \\
\hline 5 & $\begin{array}{l}\text { CDGSH iron-sulfur } \\
\text { domain-containing protein } 1\end{array}$ & Cisd1 & Q91WS0 & 1.46 & 1.48 \\
\hline
\end{tabular}




\subsubsection{Neuronal $\mathbf{N} 4-2$ as a relevant E3 ligase gene for the regulation of Prr7 protein level}

Prr7 is a single pass transmembrane protein with a short $\mathrm{N}$-terminal extracellular region and a relatively long C-terminal cytoplasmic region. Prr7 has three potential WW domain-binding PY motifs in the middle of its cytoplasmic region and a PDZ-domain binding motif at its C-terminus, through which Prr7 forms a protein complex with PSD-95 and NMDA receptors (Murata et al., 2005). The result of the proteome screen was verified by quantitative Western blotting with the anti-Prr7 antibody in N4-1/2 CTL and N4-1/2 bDKO cortical lysates (Appendix, Figure 5.1 A (Altas, 2016, $\mathrm{PhD}$ thesis). Prr7 level was increased 2-fold in N4-1/2 bDKO compared to N4-1/2 CTL. In order to determine if this increase in Prr7 protein expression is because of altered mRNA expression, we performed qRT-PCR (Anindya et al., 2007; Nakamura et al., 2011; Rossi et al., 2005). We did not detect any significant increase in Prr7 mRNA level in N4-1/2 bDKO, indicating that Prr7 protein level is regulated by of N4-1 and N4-2 E3 ligases posttranscriptionally (Figure 3.2 A).

We also demonstrated that neuron-specific N4-1 and N4-2 double

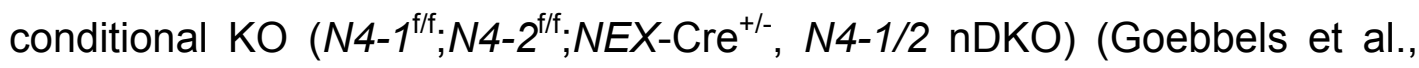
2006) showed an increase in Prr7 protein at the level similar to N4-1/2 bDKO (Figure 5.1 B), we concluded that neuronal N4-1 and/or N4-2 are responsible for the downregulation of Prr7.

Next, we studied the protein levels of Prr7 in N4-1 single brain-specific conditional KO $\left(\mathrm{N} 4-1^{\mathrm{ftf}} ; \mathrm{N} 4-2^{+/+} ; E m \times 1-\mathrm{Cre}^{+/-}, \mathrm{N} 4-1 \mathrm{bKO}\right)$ and in N4-2 single brain-specific conditional KO $\left(\mathrm{N4} 4-^{+/+} ; \mathrm{N4} 42^{\mathrm{ff/}} ; \mathrm{Em} \times 1-\mathrm{Cre}^{+/}, \mathrm{N} 4-2\right.$ bKO$)$. As shown in Figure 5.1 C and D, Prr7 was increased in N4-2 bKO significantly, while the loss of N4-1 itself has no impact on Prr7 level. We also measured Prr7 protein level in hippocampal lysates from 4 week-old mice (Figure 3.2 $B$ ), and detected a significant increase in N4-2 nKO (named N4-2 KO hereafter). Taken all together, we conclude that N4-2 is a critical gene to suppress the expression of Prr7. 


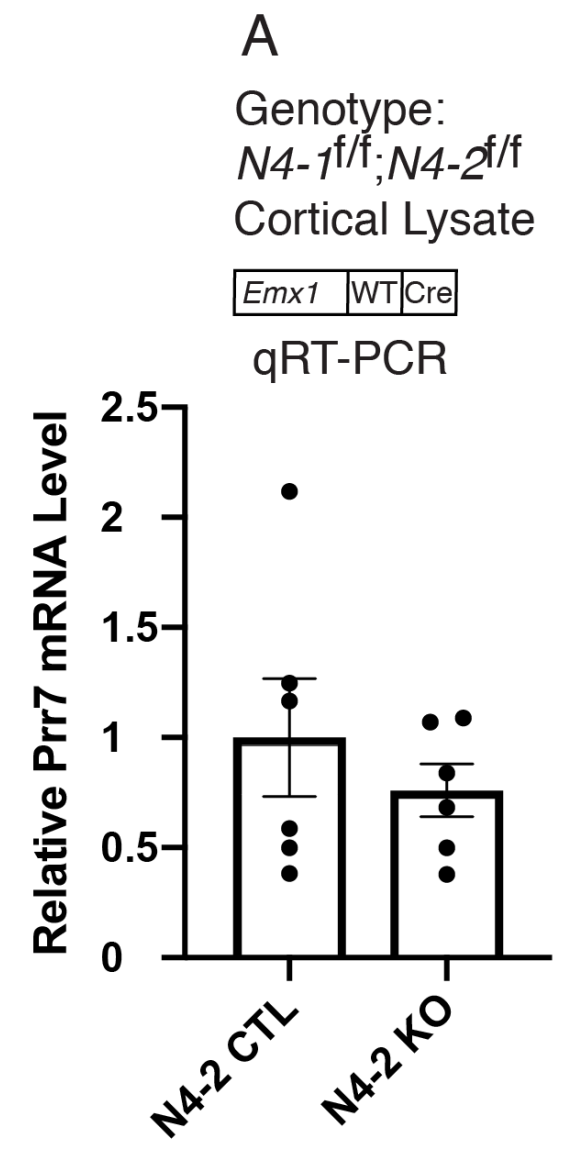

B

Genotype:

N4-2f/f

Hippocampal Lysate

\begin{tabular}{|l|l|l|}
\hline Nex & WT & Cre \\
\hline
\end{tabular}
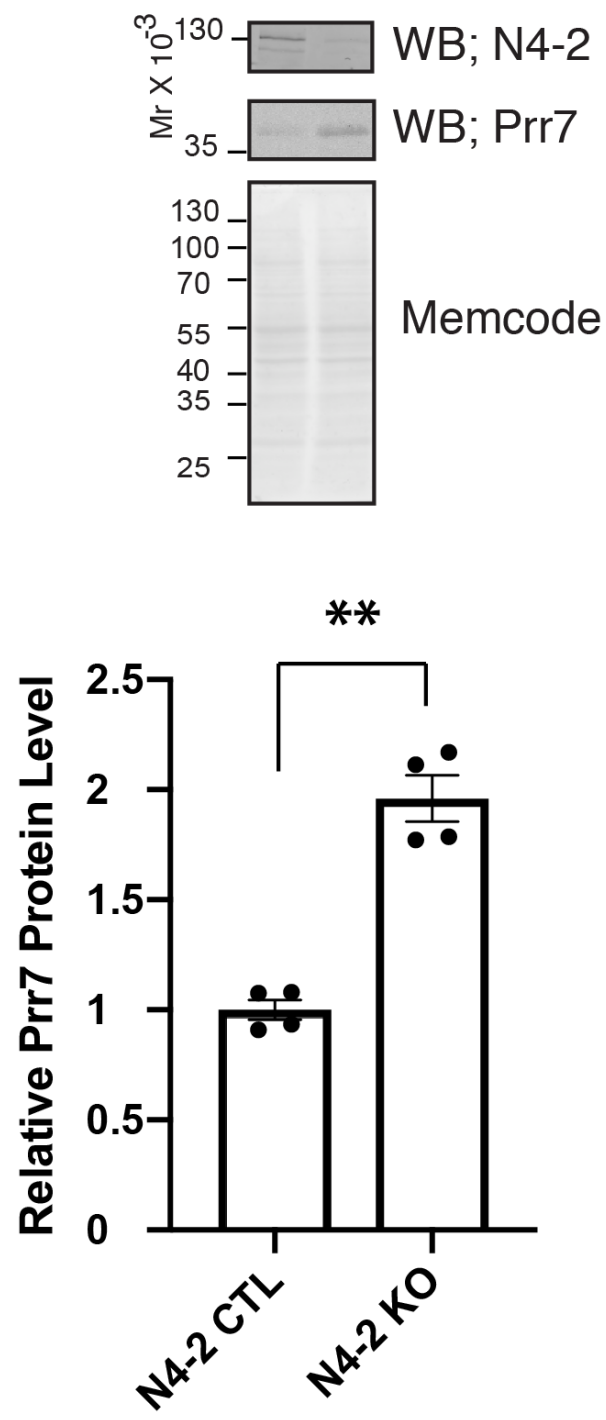

Figure 3.2. mRNA and protein levels of Prr7. (A) Unchanged mRNA level in N4-1/2 bDKO. (N4-2 CTL, $1.000 \pm 0.65 \mathrm{~N}=6$; N4-2 KO, $0.759 \pm 0.29, \mathrm{~N}=6$; $p=0.43$ ). (B) Significant increase of Prr7 expression in 4 week-old hippocampal lysate (N4-2 CTL, $1.000 \pm 0.048 \mathrm{~N}=3$; N4-2 nKO (named N4-2 KO hereafter), $1.96 \pm 0.103, N=4 ; p=0.0016)$. Represented as mean \pm SEM. 


\subsubsection{Increased surface expression of Prr7 in N4-2 KO hippocampal neurons}

Nedd4 family E3 ligases are crucial for ubiquitination of cell surface receptors, leading them to the endo-lysosomal degradation pathway (Galan et al., 1996; Staub et al., 1997; Persaud et al., 2011). To study if surface protein level of Prr7 is altered in N4-2 KO neurons, we prepared cultured N4-2 $2^{\mathrm{f} / \mathrm{f}}$ neurons, and infected lentiviruses to express EGFP or EGFP-Cre at DIV1. At DIV15, cell surface proteins were labeled by Sulfo-NHS-SS-biotin, extracted in a denaturing condition, and purified with streptavidin beads. Purified biotinylated proteins were subjected for Western blotting using the anti-Prr7 antibody. As an internal control, we studied the level of cell surface Transferrin, which is endocytosed in an ubiquitination-independent manner (Turvy \& Blum, 2001). Consistent with the result using the brain tissue (Figure 3.2), the homogenate of N4-2 KO primary neurons showed $\sim 2.5$-fold increase in the total level Prr7 protein (Figure 3.3 A). Cell surface level of Prr7 showed more robust upregulation in the absence of N4-2 (Figure 3.3 B), indicating that the dysregulation of Prr7 at the plasma membrane is probably the primary cause of the increase in N4-2 KO homogenate.

A

Genotype:

$N 4-1^{+l+} ; N 4-2^{f / f}$

Neuron Lysate
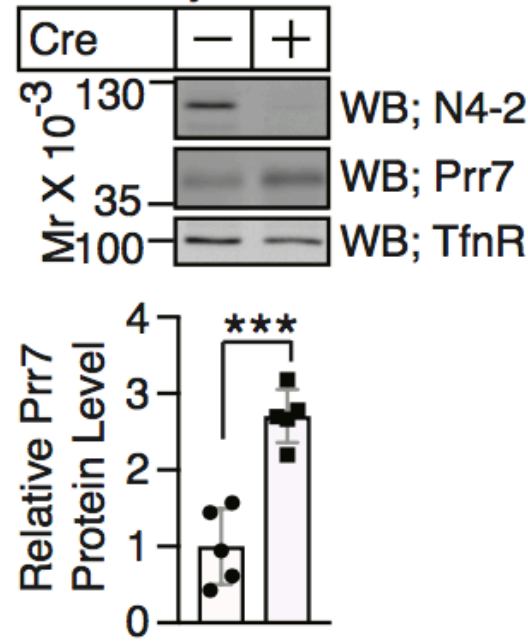

B
Genotype:

N4-1 ${ }^{+7+} ; N 4-2^{f / f}$

Biotinylated
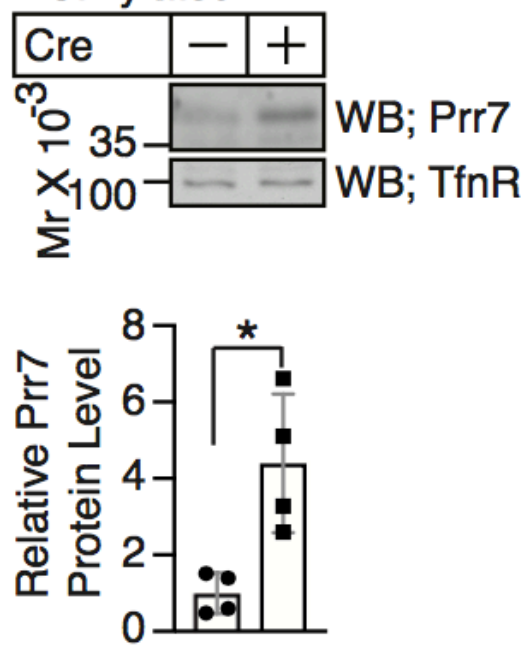
Figure 3.3. Upregulation of total and cell surface Prr7 levels in N4-2 KO neurons. (A) Prr7 levels were significantly increased in N4-2 KO neuron lysates (N4-2 CTL, $1.000 \pm 0.223, N=5 ; N 4-2 \mathrm{KO}, 2.707 \pm 0.157, N=5 ; p=$ $0.0002),(B)$ and biotinylated proteins (N4-2 CTL, $1.000 \pm 0.265, N=4 ; N 4-2$ $\mathrm{KO}, 4.400 \pm 0.911, \mathrm{~N}=4 ; \mathrm{p}=0.0114$ ).

\subsubsection{E3 ligase activity-dependent regulation of Prr7 by N4-2}

Next, we tested if expression of recombinant N4-2 (rec.N4-2) protein occludes the N4-2 KO phenotype (Figure 3.4). Primary cortical neuron cultures were prepared from $N 4-1^{f / f} ; N 4-2^{\mathrm{f} / \mathrm{f}}$ mice and infected with lentiviruses to express recombinant proteins. Upon expression of Cre recombinase (Cre+, the fourth lane in Figure 3.4), Prr7 increased 3 folds compared to the control (Cre-, the first lane in Figure 3.4). This change was reverted by overexpressing rec.N4-2 (rec.N4-2 WT, the fifth lane in Figure 3.4) but not inactive mutant of rec.N4-2 (rec.N4-2 C/S, the sixth lane in Figure 3.4). Interestingly, overexpression of rec.N4-2 C/S significantly increased Prr7 in the absence of Cre (the third lane in Figure 3.4). It is probably due to the dominant negative effect of this protein since rec.N4-2 overexpression did not increase Prr7 (the second lane in Figure 3.4). We conclude that enzymatic activity of N4-2 is required for the regulation of Prr7 protein level. 


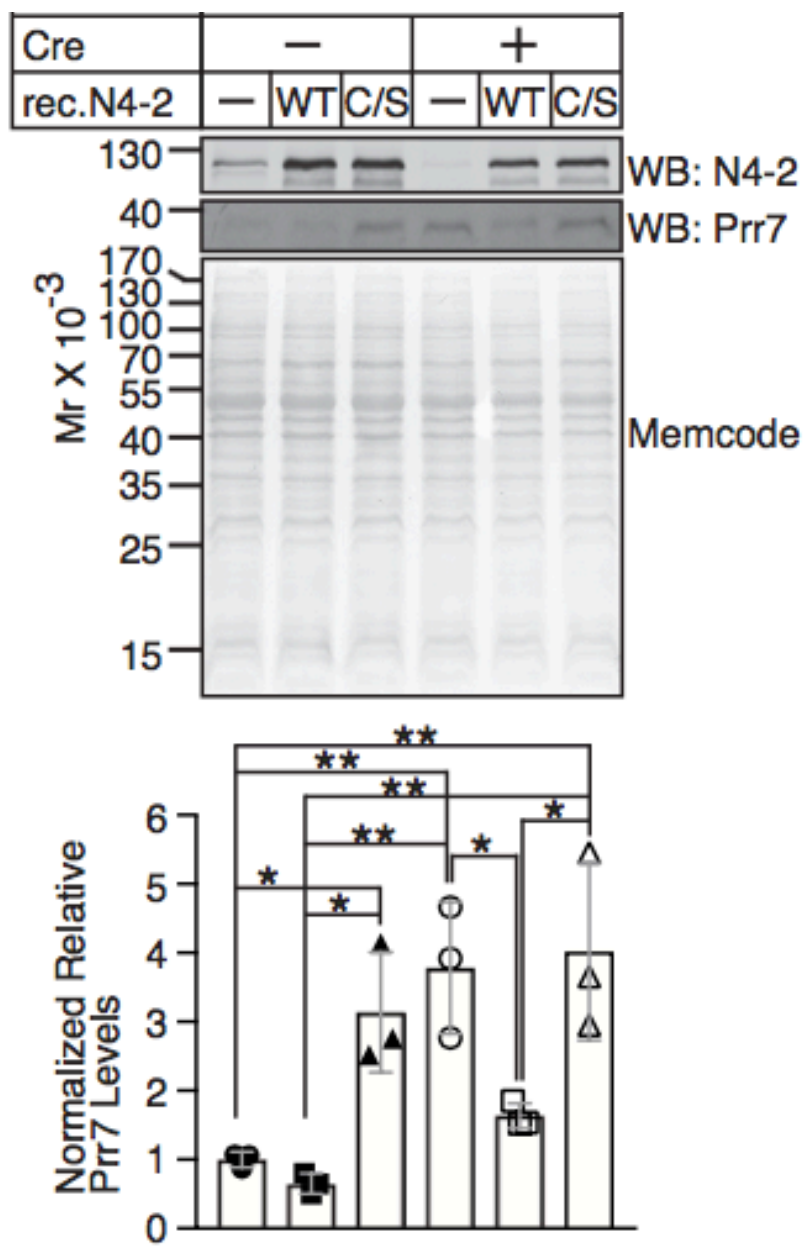

Figure 3.4. Rescue of Prr7 levels by re-expressing recombinant N4-2 in N4-1/2 KO neurons. $N 4-1^{f / f} ; N 4-2^{f / f}$ primary cortical neurons were infected with lentivirus expressing EGFP (Cre -) or EGFP and Cre (Cre +), with or without recombinant wild type N4-2 (rec.N4-2 WT) or catalytically inactive point mutant of N4-2 (rec.N4-2 C/S). Neurons were harvested at DIV17 and the level of Prr7 was analyzed by Western blotting. Signals from the antiPrr7 antibody were normalized to the signal from Memcode for the quantification. Bottom bar diagrams; quantification of relative Prr7 levels (N4-2 CTL $1.000 \pm 0.127, N=3 ; N 4-2$ bKO, $1.94 \pm 0.072, N=3 ; p=0.0030$. Represented as mean \pm SEM. ${ }^{* * *}, p<0.001 ; \quad * *, \quad 0.001<p<0.01 ; \quad$ *, $0.01<p<0.05 ; n s, 0.05<p$. One way ANOVA, Tukey test.) 


\subsubsection{Ubiquitination of Prr7 by N4-2}

We studied if N4-1 and/or N4-2 ubiquitinate Prr7 in an in vitro system using purified recombinant proteins. For this purpose, Myc-tagged cytoplasmic region of Prr7 (Myc-Prr7 Cyt) was overexpressed in HEK293FT cells and purified using anti-Myc antibody coupled beads. Myc-Prr7 Cyt was incubated with ATP, recombinant ubiquitin, and E1 enzyme in the presence or absence of E2, N4-1, and N4-2. Subsequently, samples were subjected to Western blotting using an anti-Myc antibody. As shown in Figure 5.2 A, a smear pattern was detected in the presence of the E2 enzyme and N4-2, demonstrating that Prr7 is polyubiquitinated by N4-2.

Next, we investigated if N4-1 and N4-2 ubiquitinate full-length Prr7 in the cellular environment by a cell-based ubiquitination assay. FLAG-tagged fulllength Prr7 (Prr7-FLAG) was overexpressed in HEK293FT cells with or without the EGFP-tagged N4-1 (EGFP-N4-1) and N4-2 (EGFP-N4-2). Proteins were extracted from cells in denaturing conditions with sodium dodecyl sulfate (SDS) to avoid detection of ubiquitination of Prr7-FLAGbinding proteins. After denaturation, SDS was diluted to be below critical micelle concentration with TritonX-100 containing buffer. Prr7-FLAG was immunoprecipitated and subjected to Western blotting using anti-FLAG and anti-Ub antibodies (Figure 5.2 B). EGFP-N4-1- and EGFP-N4-2-dependent ubiquitination of Prr7-FLAG was already detectable with the anti-Ub antibody (Figure $5.2 \mathrm{~B}$, the bottom panel). The ubiquitin signal from Prr7FLAG was more pronounced in EGFP-N4-2-overexpressing cells than in EGFP-N4-1-overexpressing cells despite that the expression of EGFP-N4-1 was higher than that of EGFP-N4-2 (Figure $5.2 \mathrm{~B}$ top panel). This result indicates that N4-2 has more prominent activity in ubiquitination of Prr7 than N4-1. The same samples were blotted with antibodies to K48-linked polyUb and K63-linked polyUb (Figure 5.2 fourth and fifth panels). Together with Prr7-FLAG samples, K48-linked and K63-linked tetra-Ub were loaded in order to compare the titer of two anti-polyUb antibodies. Band intensities from tetra-Ub are comparable in two blots (arrow and arrowhead in Figure $5.2 \mathrm{~B}$ ), indicating the titers of these antibodies are comparable. Interestingly, 
in the absence of overexpressed EGFP-tagged Nedd4 proteins, strong signals were detected by the anti-K48-linked polyUb antibody (the third lane in the top panel of Figure $5.2 \mathrm{~B}$ fourth panel). It is probably for the clearance of an excess of Prr7-FLAG by endoplasmic reticulum-associated protein degradation, where K48-linked polyUb plays crucial roles (Lemus and Goder, 2014; Zemoura et al., 2013) Western blotting using the anti-K63 polyUb antibody shows similar results to the anti-Ub antibody (compare third and fifth panel in Figure 5.2 B). Interestingly, overexpression of recombinant EGFP-N4-1 or -N4-2 diminished the signal from the anti-K48-linked polyUb (the first and second lanes in Figure 5.2 B fourth panel). We interpret this as a result of compensatory degradation mediated by K63-linked polyUb chains.

\subsubsection{First and second WW domain-binding PY motifs of Prr7 as responsible regions for N4-2-binding and for N4-2-dependent ubiquitination}

Each of the Nedd4 family E3 ligases recognizes its own substrates via direct bindings between WW domains of E3s and PY motifs of substrates (Staub et al., 1996; Kanelis et al., 2001; Chong et al., 2010). In order to study which PY motifs in Prr7 mediate interaction with N4-2, we generated expression vectors for missense mutants of Prr7 at the first and/or second PY motifs (PY1, PY2, and PY1/2 mutants; Figure 3.5 A). Pull-down experiments using GST-N4-2 and HA-tagged Prr7 (HA-Prr7) show that PY1 and PY2 mutants as well as wild type (WT) Prr7 bind to GST-N4-2 while the PY1/2 mutant abolishes N4-2's binding activity (Figure 3.5 B). This result indicates that one of PY1 or PY2 is sufficient for binding to N4-2 and that the loss of one is compensated by the other. Next, we studied if N4-2-Prr7 binding is required for N4-2-dependent ubiquitination of Prr7 in a cell-based ubiquitination assay. As shown in Figure $3.5 \mathrm{C}$, Immunoprecipitated HA-Prr7 from HEK293FT cells expressing recombinant N4-2 showed a robust signal from the anti-K63 polyUb antibody. HA-tagged PY1/2 mutant of Prr7, on the other hand, does not show an increase in the signal as compared to the negative 
controls, showing that the binding between WW domains of N4-2 and PY motifs of Prr7 is required for conjugation of K63 polyUb chains to Prr7.

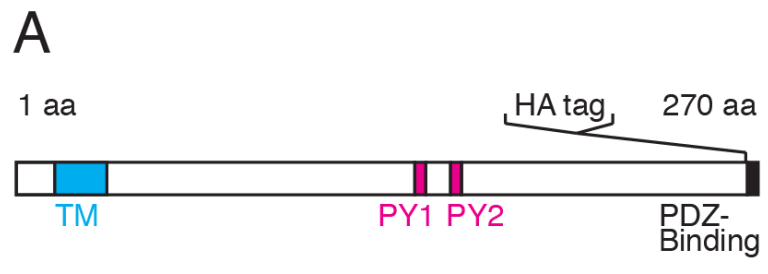

B
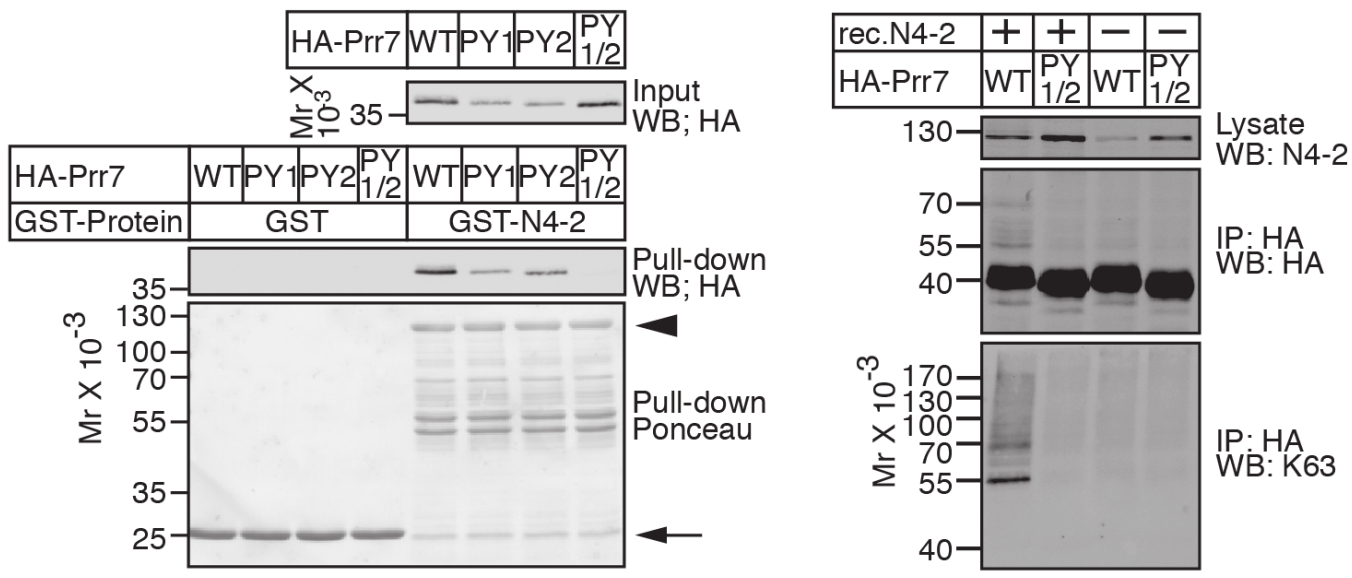

Figure 3.5. PY motif dependent binding and ubiquitination of Prr7. (A) The domain structure of Prr7. Two WW domain-binding PY motifs (PY1 and -2) are in the middle of its cytoplasmic region. The HA tag was inserted in front of the PDZ-binding motif for the biochemical experiments in (B) and (C). (B) Wild type (WT), PY1 single, PY2 single, or PY1 and PY2 double mutants (PY1/2) of HA-tagged Prr7 were expressed in HEK293FT cells (top panel). Cell extracts were subjected to affinity pull-down assay using GSTtagged full length N4-2. Note the lack of binding of PY1/2 mutant (last lane in the second panel). The amount of GST-N4-2 (arrowhead) used for the assay is comparable to that of the negative control GST (arrow) at the bottom panel. (C) Cell-based ubiquitination assay using untagged N4-2, and wild type (WT) or PY1/2 mutant of HA-tagged Prr7. Despite of the high level of N4-2 in the cell lysate in the PY1/2 expressing cells (the second lane in the top panel), the signal from the anti-K63-polyUb antibody was clearly weaker (the second lane in the bottom panel) than the one from the WT HAPrr7 expressing cells (the first lane in the bottom panel). 


\subsubsection{Subcellular localization of Prr7}

In primary cultured hippocampal neurons, Prr7 is localized at the synapse (Kravchick, et al., 2016). However, its synaptic distribution has never been addressed in the brain tissue or at the super resolution level. Given that antiPrr7 antibodies for immunohistochemistry are not available, EGFP-tagged Prr7 (Prr7-EGFP) was expressed in the hippocampal CA1 neurons to study its localization. We transfected neurons at E14.5 with expression vectors for myrVenus and Prr7-EGFP by in utero electroporation (IUE) method. Brains were fixed with 4\% PFA at P22, $70 \mathrm{~mm}$ slices were prepared, and Venus and EGFP signals were imaged at the CA1 region of hippocampus by stimulated emission depletion (STED) microscopy. As shown in Figure 3.6, Prr7-EGFP was enriched at the tip of dendritic spines.

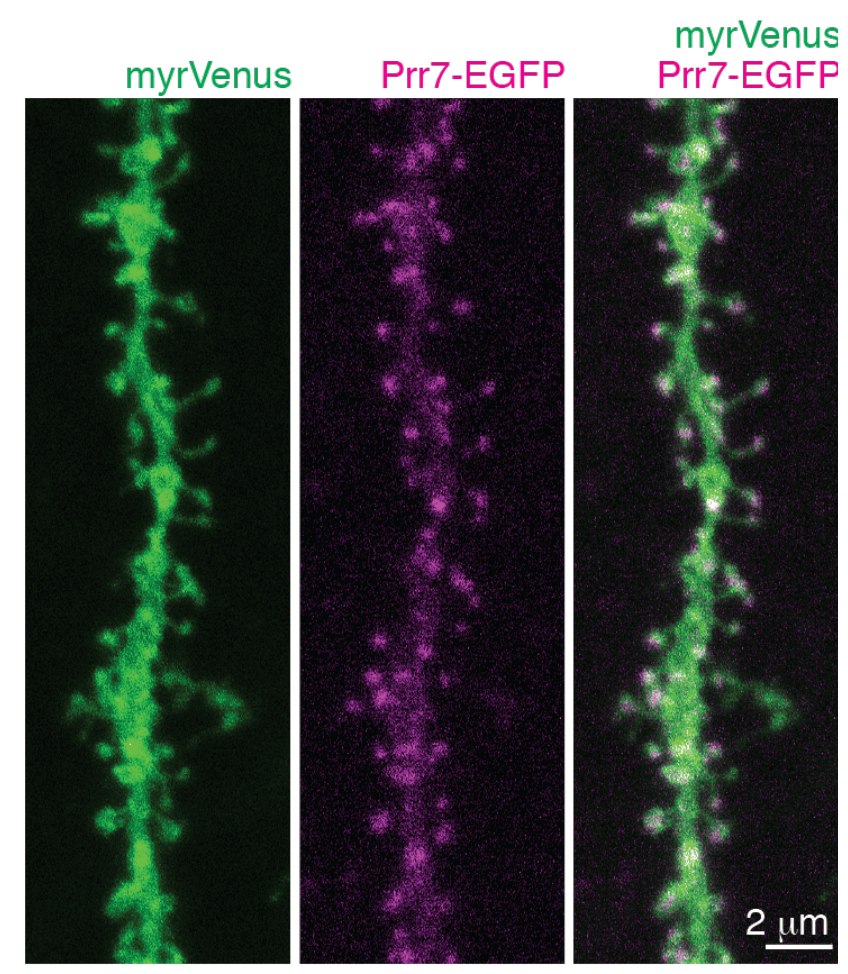

Figure 3.6. Localization of Prr7-EGFP in CA1 hippocampal neurons. Neurons were transfected with expression vectors for myrVenus and Prr7EGFP by IUE. The brain was fixed at P22 and signals from myrVenus and Prr7-GFP were acquired by STED microscopy. 


\subsubsection{N4-2 regulates spine size and leads to emergence of bifurcated spines}

Previously, we have demonstrated the relative abundance of N4-2 mRNA in central murine nervous system by in situ hybridization and observed relative enrichment of N4-2 in hippocampus (Ambrozkiewicz, 2015, PhD thesis, Figure $5.3 \mathrm{~A}$ ). Then, we studied the role of N4-2 in spinogenesis and dendritic spine morphology in the hippocampus by using in utero electroporation and targeted hippocampal progenitors at E14.5 in control $\left(N e d d 4-2^{\mathrm{f} / f}\right)$ and neuron-specific N4-2 conditional knockout mice (Nedd4$2^{\mathrm{f} / \mathrm{f}} ; \mathrm{NEX}-\mathrm{Cre}^{+/-}$, Nedd4-2 KO) by using GFP- and myr-Venus expression plasmids, and studied the total number and morphology of dendritic spines specifically on primary branches of apical dendrites of hippocampal CA1 pyramidal neurons using STED microscopy (Figure $5.3 \mathrm{~B}$ ). Despite the fact that there was no change in dendritic spine density (Fig $5.3 \mathrm{C}$ ), the morphological study of spines in N4-2 KO neurons showed an interesting phenotype. We saw an elevation in the length of filopodia, thin, and mushroom spines (Figure $5.3 \mathrm{D}$ ), and also an increase in the thin spine head size (Figure 5.3 E). In addition to that, we observed a decrease in the number of mushroom spines and increase in bifurcated spines (Figure 5.3 F) upon loss of N4-2. We concluded that the deletion of N4-2 in neurons causes some abnormalities in spine morphology, and N4-2 regulates dendritic spine development (Ambrozkiewicz, 2015, PhD thesis).

Since Prr7 is the only neuronal substrate of N4-2 found in our proteomic screen and we believe that the spine phenotype is due to the increased expression of Prr7, we decided to cross our N4-2 KO mouse line with Prr7 KO mouse line (Prr7 $7^{\mathrm{f} / \mathrm{f}}$;CamKIla-Cre) for further experiments. Importantly, regarding the possible dendritic spine experiment, Drebrin1 has a role in spine formation and stabilization (Hayashi et al., 1996; Hering \& Sheng, 2001), and the Dbn1 gene is located approximately 300 bp downstream of the last exon of Prr7 on chromosome 5. Therefore, we wanted to study the expression level of Prr7 in cortical lysates of 3 week old Prr7 KO mice by 
Western blotting to eliminate the possibility of a dendritic spine affect due to altered Drebrin1 levels. As seen in Figure 3.7, there was no significant change in Drebin1 protein expression in the cortical lysates of 3 week old mice, whereas Drebrin1 level was significantly decreased in 3 month old Prr7 KO mice, stating that spine structure could be altered in older mice.

A

Genotype:

Prrt/f

Cortical Lysate

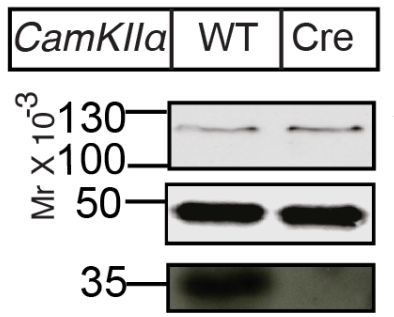

WB; Drebrin1

WB; Tubulin

WB; Prr7
B

Genotype:

Prrtf/f

Cortical Lysate

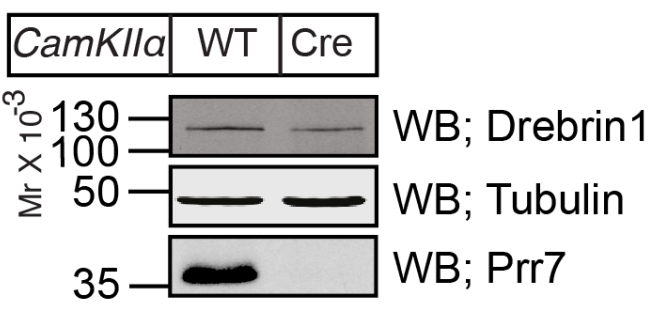

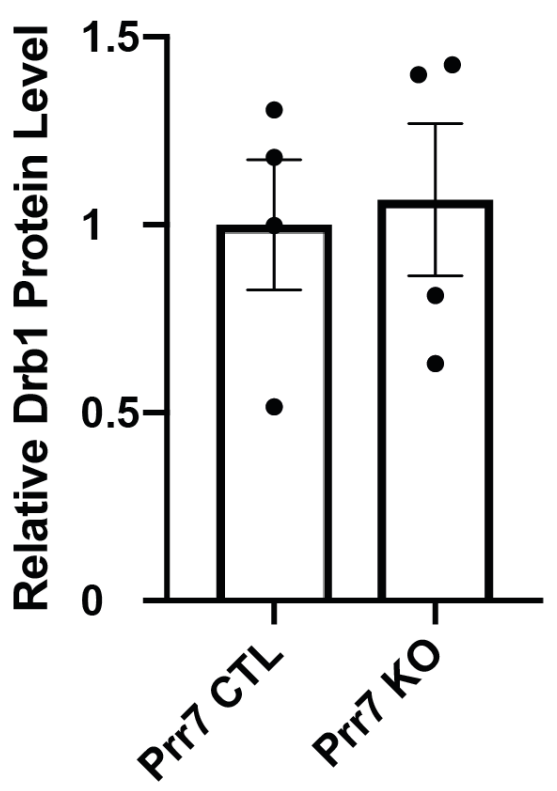

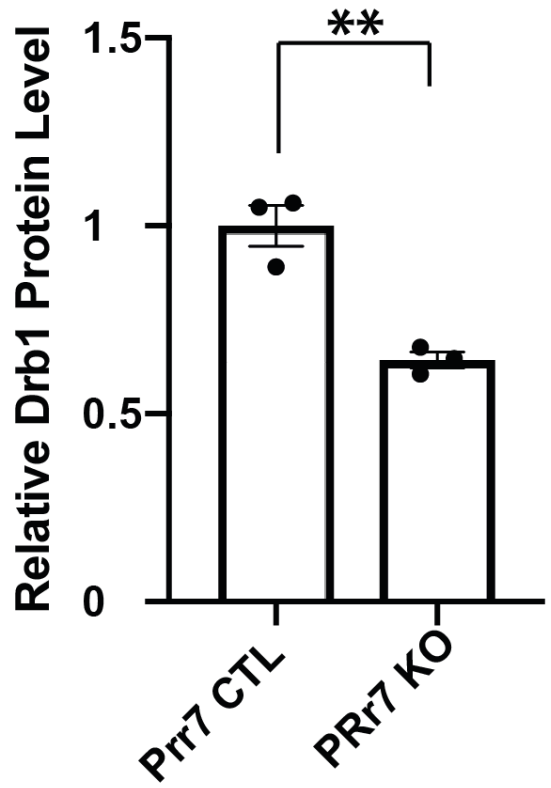

Figure 3.7. Drebrin1 protein level in $\mathbf{3}$ week-old and $\mathbf{3}$ month-old mice.

(A) Unaltered Drebrin1 levels in 3 week-old Prr7 KO mice (Prr7 CTL, 1.000 $\pm 0.082 \mathrm{~N}=5$; Prr7 KO, $1.107 \pm 0.221, \mathrm{~N}=5 ; \mathrm{p}=0.663$ ). (B) Drebrin1 level was significantly decreased in 3 month old Prr7 KO mice (Prr7 CTL, $1.000 \pm$ $0.055 \mathrm{~N}=3$; Prr7 KO, $0.643 \pm 0.021, \mathrm{~N}=3 ; \mathrm{p}=0.0036$ ). Represented as mean \pm SEM. 


\subsubsection{Improved memory formation and re-learning ability in N4-2 KO mice}

Given that N4-2 and Prr7 localize at the postsynapse and that dynamic structural change of the postsynapse in the hippocampal CA1 region is essential for special memory formation, we studied behavioral changes upon neuronal loss of N4-2 in collaboration with Prof. Dr. Hannelore Ehrenreich, Sahab Arinrad and Anja Ronnenberg (MPI-EM, Göttingen). N42 CTL and N4-2 KO were subjected to a full battery of behavioral tests, including elevated plus maze (EPM), open field (OF), holeboard exploration, prepulse inhibition, rotarod, grip strength, bar test, Morris water maze (MWM) and MWM reversal tests (Table 3.2) (Figures 3.8-3.13).

N4-2 KO mice showed no change in the elevated plus-maze in terms of time, visits, path length and velocity (Figure 3.8), as well as time spent in the open field (Figures 3.9) compared to CTL animals. However, N4-2 KO mice showed increased velocity and path length in the open field test, indicating mild hyperactivity (Figures 3.9 A and B). However, we did not see the same outcome in holeboard exploration test (Figure 3.9 F). N4-2 KO mice had impaired motor learning in motor performance tests, Rotarod, and grip strength test (Figures $3.10 \mathrm{~A}$ and 3.11 A), while sensory performance such as hearing (Figure 3.10 F) and vision (Figure 3.11 B-F) were intact. There was no difference in terms of catatonic signs in the bar test (Figure 3.10 C). Although there was an impairment in muscle strength and motor coordination in N4-2 KO, we observed increased spatial memory (Figure $3.12 \mathrm{~B}$ ) and re-learning ability in N4-2 KO mice (Figure $3.13 \mathrm{~A}$ ). In the MWM, N4-2 KO mice were found to have normal motor activity and motivation to reach to the visible platform by showing no significant change in time spent in platform zone, (Figure 3.12 C) path length (Figure 3.12 D), and in number of visits (Figure 3.12 E) and latency to first visit (Figure 3.12 $\mathrm{F}$ ), yet Figure $3.12 \mathrm{~B}$ demonstrated that N4-2 KO mice performed better shown by significantly less latency. In reversal, those mice showed no significant change in time spent in platform zone (Figure $3.13 \mathrm{~B}$ ), but performed better in terms of path length (Figure $3.13 \mathrm{C}$ ), and in number of 
visits (Figure 3.13 D) and latency to first visit (Figure 3.13 E), concluding that N4-2 KO showed an improved memory formation.

Table 3.2. Behavioral tests performed using N4-2 mice

\begin{tabular}{|c|c|c|}
\hline Behavioral domain & Test paradigm & Age $\hat{~}$ \\
\hline Anxiety & $\begin{array}{l}\text { Elevated plus maze } \\
\text { Open field }\end{array}$ & 2 months \\
\hline $\begin{array}{l}\text { Locomotion } \\
\text { exploration }\end{array}$ & $\begin{array}{l}\text { Open field } \\
\text { Holeboard exploration }\end{array}$ & 2 months \\
\hline Sensory performance & & \\
\hline Hearing & Prepulse inhibition & 3 months \\
\hline $\begin{array}{l}\text { Vision } \\
\text { Motor performance }\end{array}$ & MWM visible platform & 3 months \\
\hline Motor learning & Rotarod & 2-3 months \\
\hline Muscle strength & Grip strength & 2-3 months \\
\hline $\begin{array}{l}\text { Health status } \\
\text { Cortical } \\
\text { function }\end{array}$ & Body weight & 3 months \\
\hline Sensorimotor gating & Prepulse inhibition & \\
\hline $\begin{array}{l}\text { Catatonic signs } \\
\text { Cognition }\end{array}$ & Bar test & 2-3 months \\
\hline Spatial memory & MWM & 5 months \\
\hline Reversal memory & MWM Reversal & 6 months \\
\hline
\end{tabular}

Figure 3.8. (Figure is on the following page) General behavioral examination in N4-2 mice in elevated plus maze test. No anxiety phenotype was observed in N4-2 KO mice in Elevated Plus Maze (EPM) time in open arms (A), EPM time in walled arms (B), EPM time in center (C), EPM number of visits open arms (D), EPM visits walled arms (E), EPM visits center $(F)$, EPM path length (G), EPM velocity $(H)$, EPM \% time open arms (I), EPM \% of visits open arms (J). (N4-2 CTL $\mathrm{N}=16, N 4-2$ KO mice $\mathrm{N}=13$ ) Represented as mean \pm SEM. 
A

EPM Time Open Arms - age 9 weeks

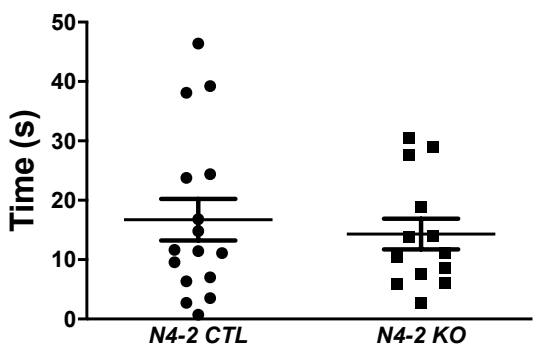

C

EPM Time Center - age 9 weeks

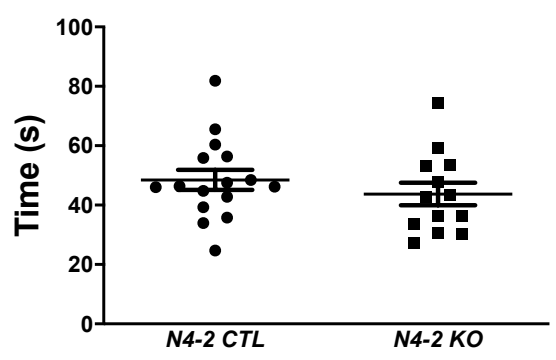

E

EPM Visits Walled Arms - age 9 weeks

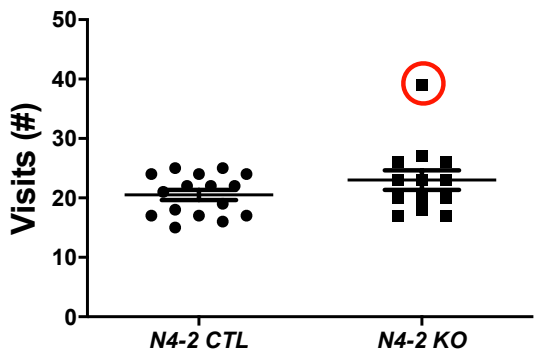

$G$

EPM Path Length - age 9 weeks

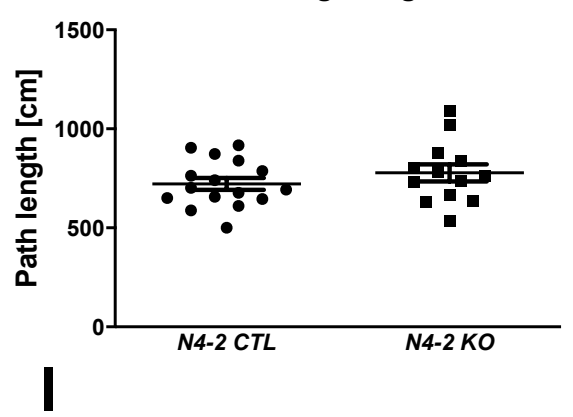

EPM \%Time Open Arms - age 9 weeks

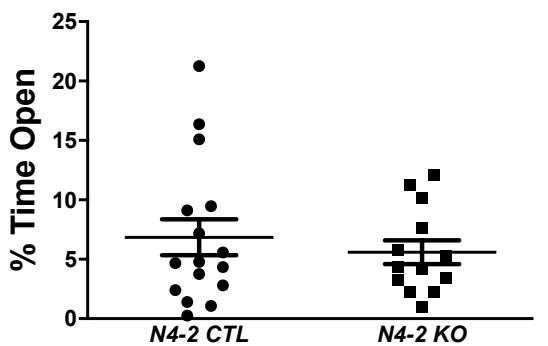

B

EPM Time Walled Arms - age 9 weeks

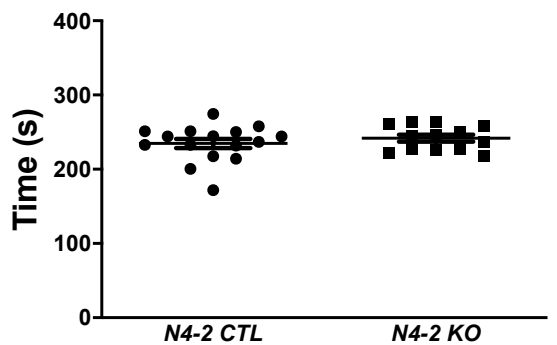

D EPM Visits Open Arms - age 9 weeks

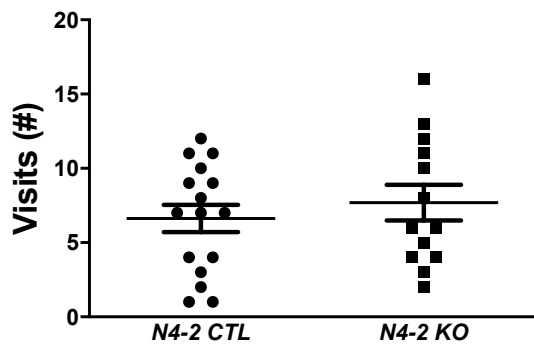

F

EPM Visits Center - age 9 weeks

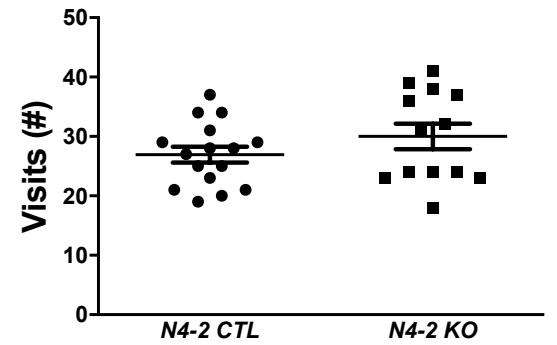

H

EPM Velocity - age 9 weeks

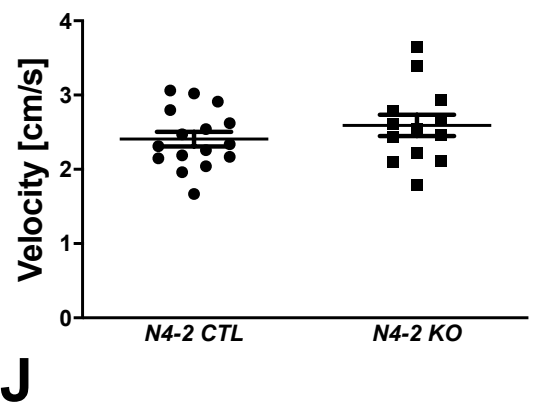

EPM \%Visits Open Arms - age 9 weeks

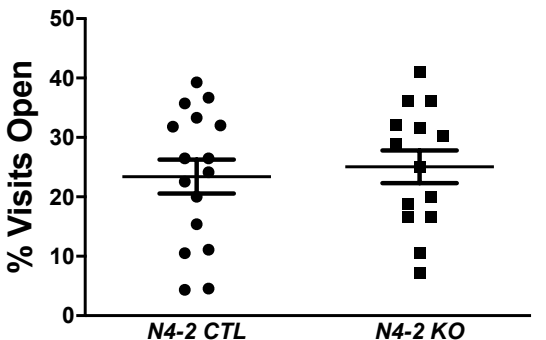


A

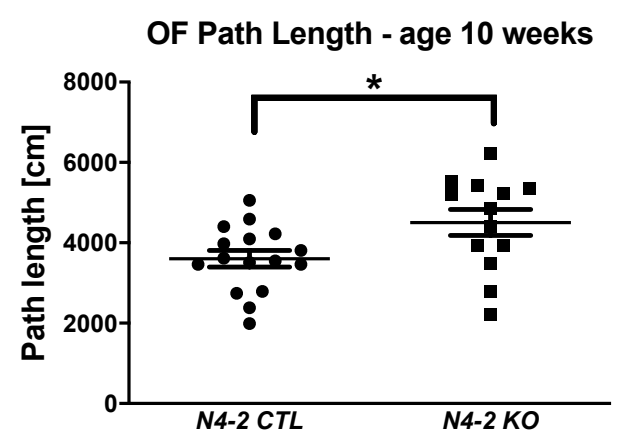

C

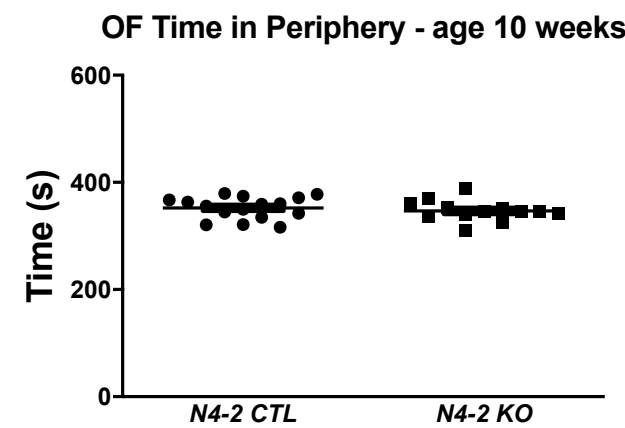

E

OF Time in Center - age 10 weeks

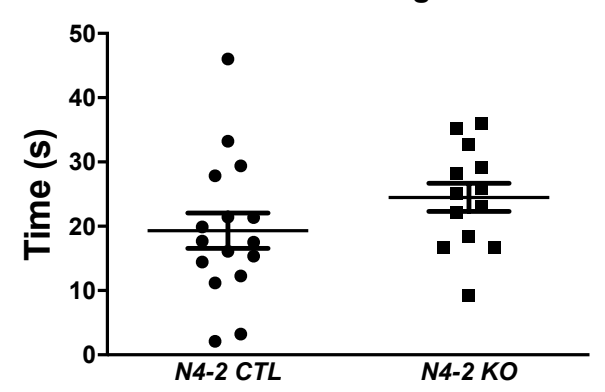

B

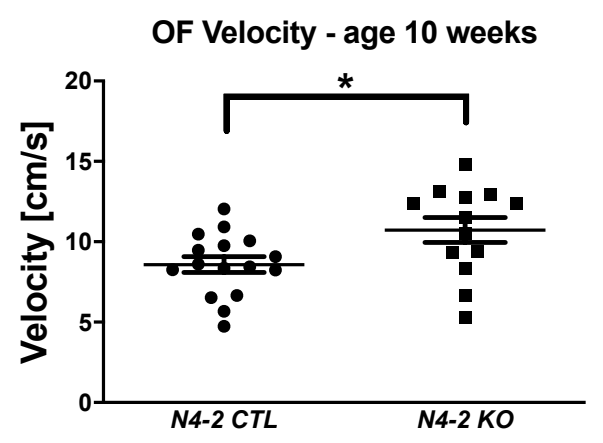

D

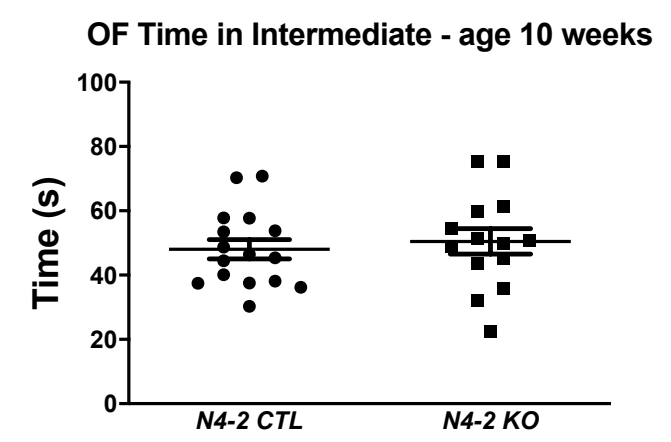

$\mathbf{F}$

Holeboard Exploration - age 10 weeks

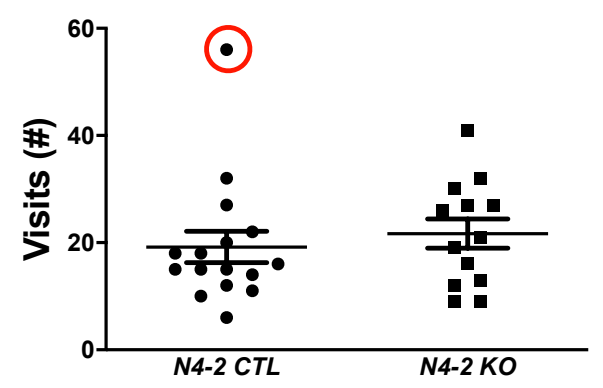

Figure 3.9. General behavioral examination in N4-2 mice in open field test. Significant increase was observed in Open Field (OF) path length (A) $(p=0.0216)$, and OF velocity ( $B)(p=0.0217)$, in $\mathrm{N} 4-2 \mathrm{KO}$ mice. No changes observed in OF time in periphery zone (C), OF time in intermediate zone (D), OF time in center zone (E), number of visits in Holeboard Exploration $(\mathrm{F})$, in control and N4-2 KO mice (N4-2 CTL N=16, N4-2 KO mice $\mathrm{N}=13$ ) Represented as mean \pm SEM. 

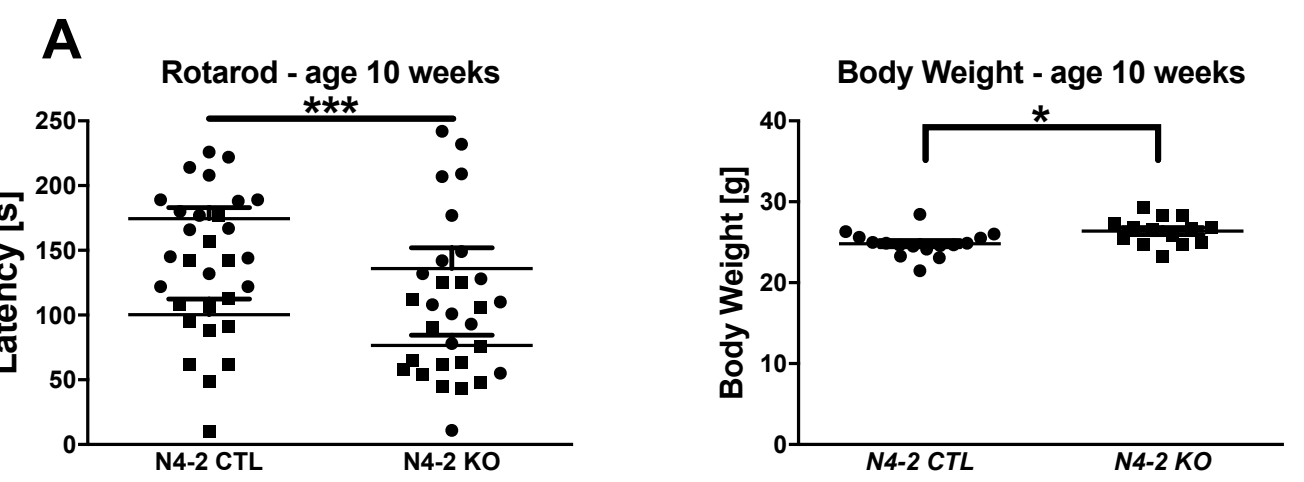

\section{C}

Catatonic signs - age 11 weeks

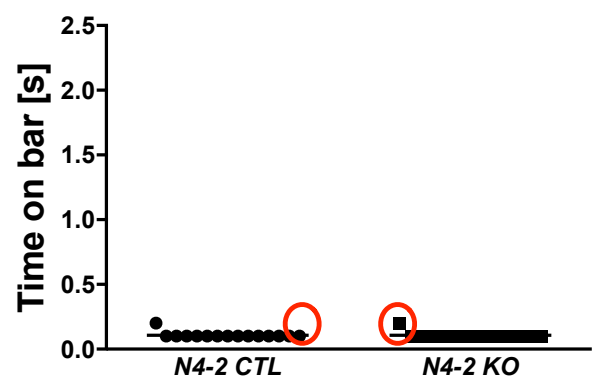

Prepulse Inhibition - age 12 weeks

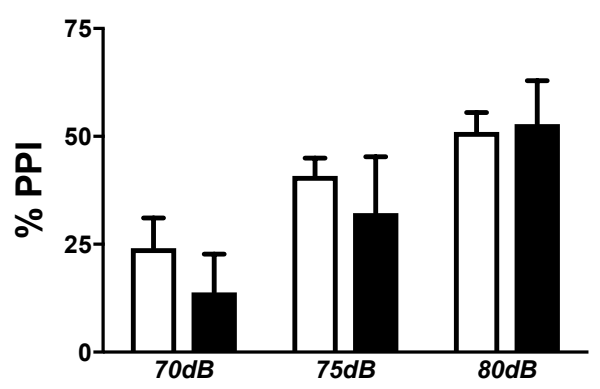

E

Body Weight - age 12 weeks
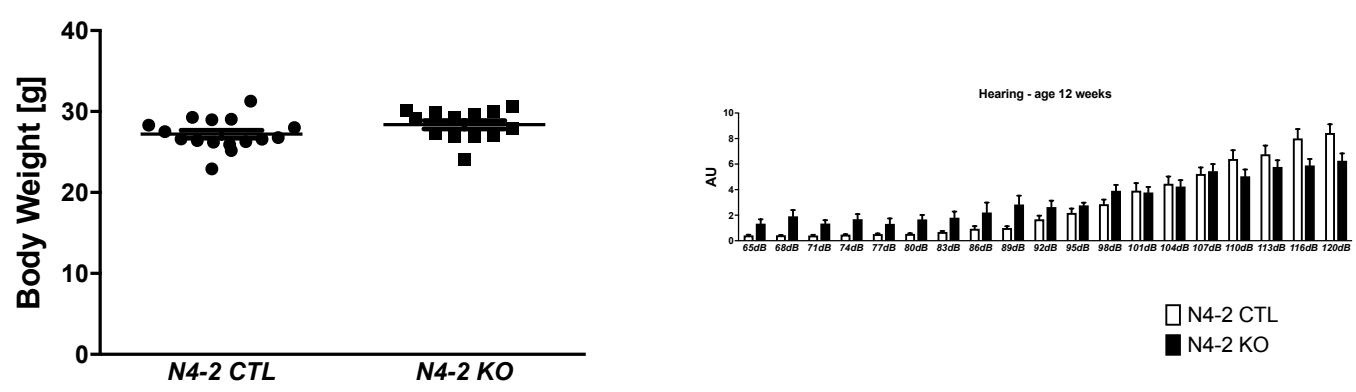

Figure 3.10. General behavioral examination in N4-2 mice in rotarod and prepulse inhibition tests. Increased latency in Rotarod (A), slightly increased body weight during the Rotarod test $(B)(p=0.0487)$, no change in Catatonic signs (C), no change in Prepulse inhibition (D), no change in body weight during Prepulse inhibition (E), no significant change in Hearing $(F)$ in N4-2 KO mice (N4-2 CTL N=16, N4-2 KO mice $\mathrm{N}=13$ ) Represented as mean \pm SEM. 
A

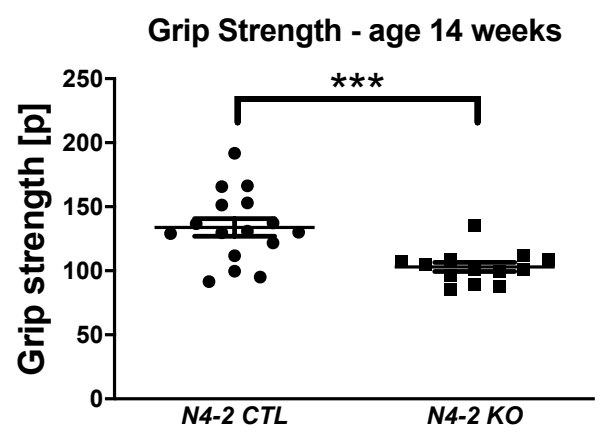

C

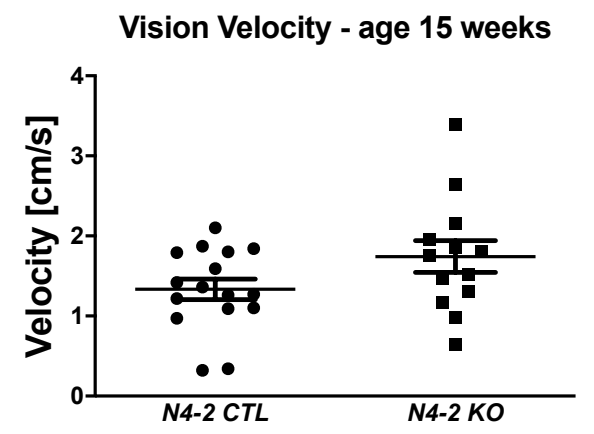

$\mathbf{E}$

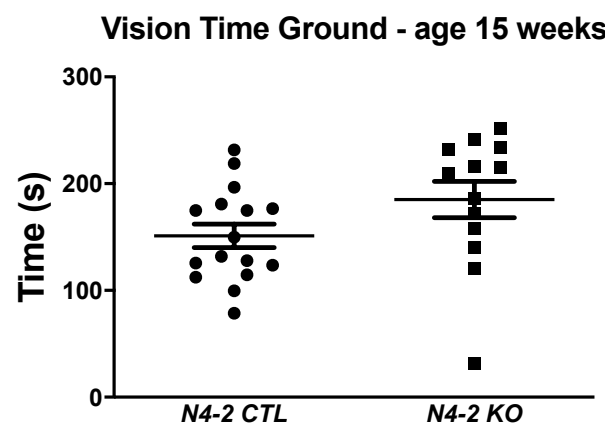

B

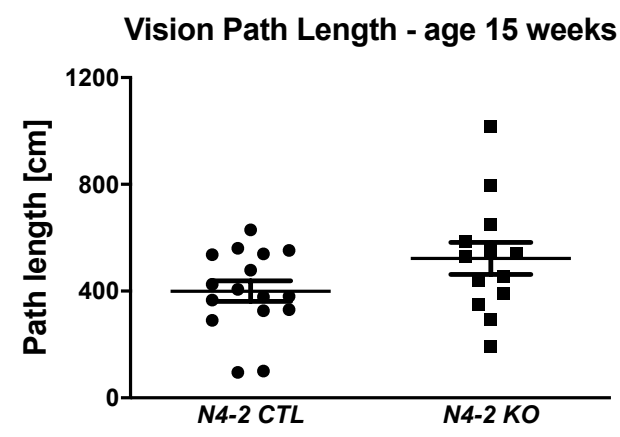

D

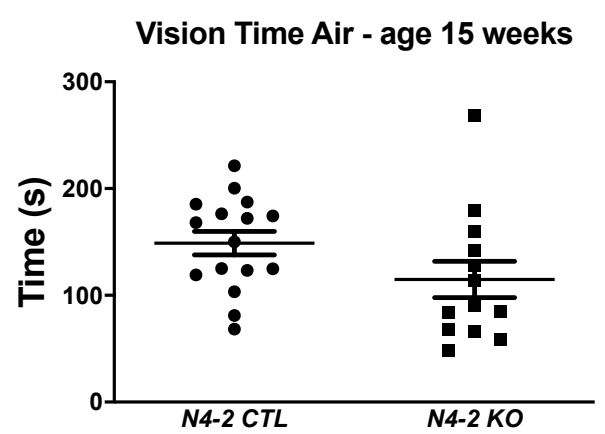

$\mathbf{F}$

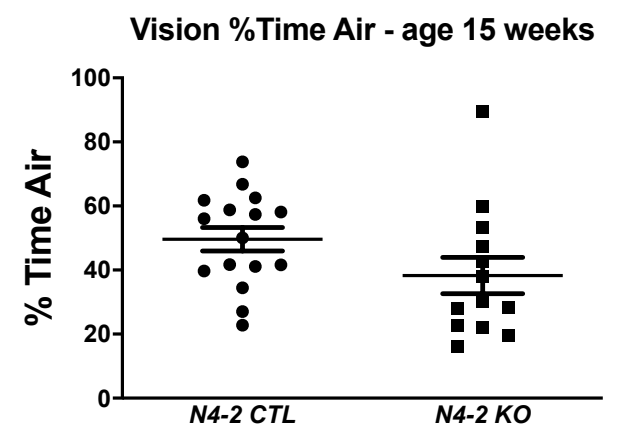

Figure 3.11. General behavioral examination in N4-2 mice in motor and visual funcitons. Decreased grip strength $(A)(p=0.0006)$, no change in vision path length $(B)$ as well as vision velocity $(C)$, vision time air $(D)$, vision time ground $(\mathrm{E})$, vision \% time air $(\mathrm{F})$ in N4-2 KO mice (N4-2 CTL N=16, N4$2 \mathrm{KO}$ mice $\mathrm{N}=13$ ) Represented as mean $\pm \mathrm{SEM}$. 
A

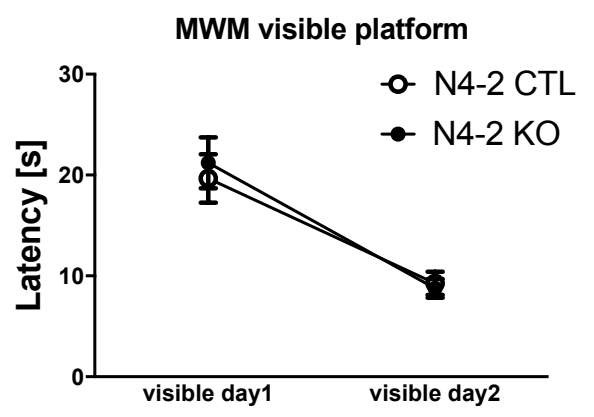

C

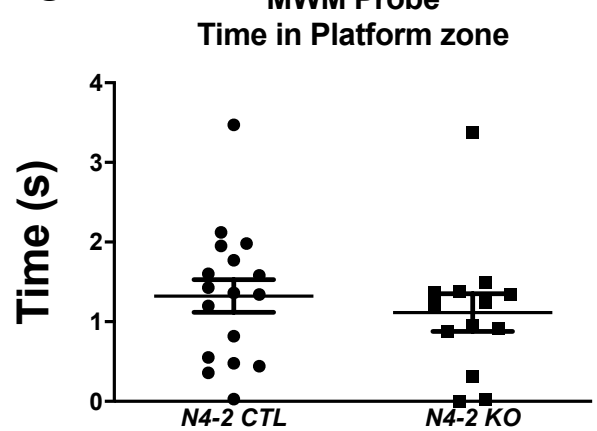

$\mathbf{E}$

MWM Probe Visits to Platform zone

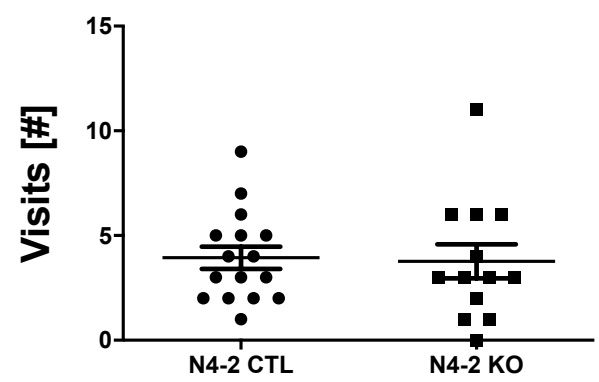

B

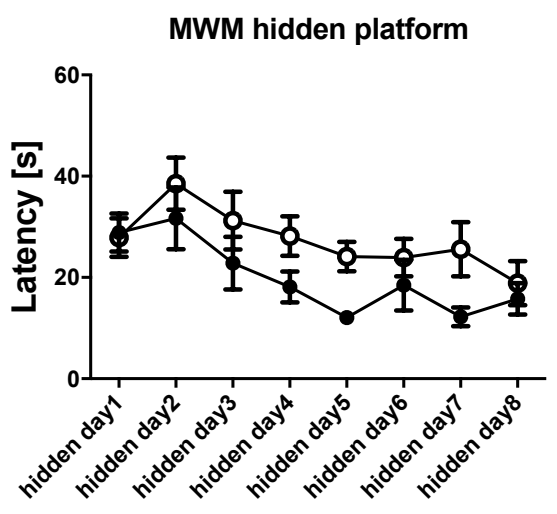

D MwM Probe Path length in Platform zone

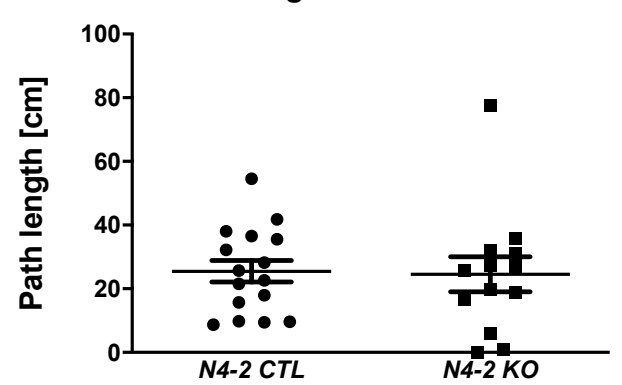

$\mathbf{F}$ MWM Probe Latency to visit Platform zone

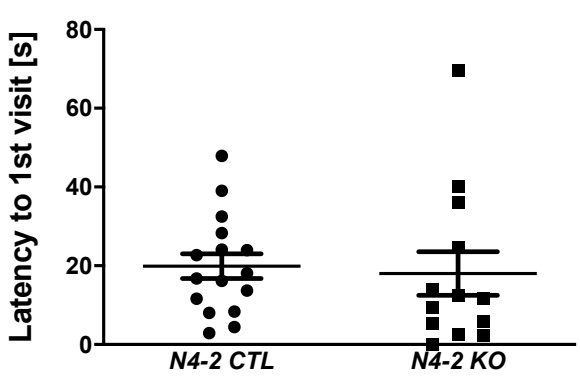

Figure 3.12. Improved memory formation in N4-2 mice. (A) No change was observed in the MWM with a visible platform. (B) Time to reach to the platform was less in N4-2 KO mice compared to CTL in the MWM with a hidden platform. No change was observed in time in the platform zone in MWM probe trial $(C)$, path length in platform zone in the MWM probe trial (D), number of visits to platform zone in MWM probe trial (E), latency to visit the platform zone in the MWM probe trial $(F)$ in N4-2 KO mice (N4-2 CTL $\mathrm{N}=16, N 4-2 \mathrm{KO}$ mice $\mathrm{N}=13$ ) Represented as mean $\pm \mathrm{SEM}$. 

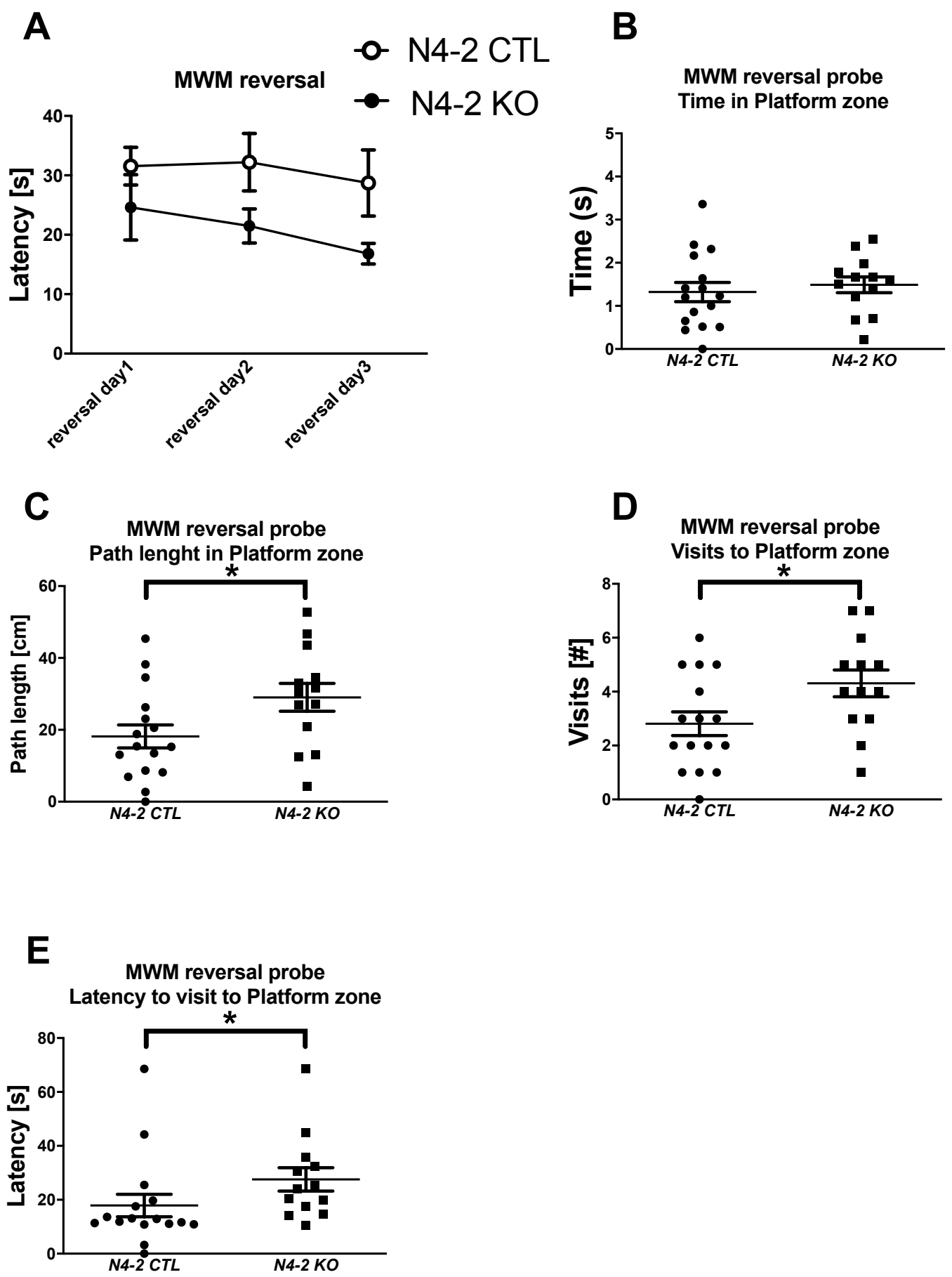

Figure 3.13. Improved re-learning ability in N4-2 mice. N4-2-KO mice exhibited enhanced re-learning ability in the MWM reversal test compared to CTL (A). Despite no change in the amount of time spent in the platform zone in the MWM reversal test (B), significant changes were observed in path length in the platform zone $(C)(p=0.038)$, and number of visits to the platform zone (D) $(p=0.0325)$, and latency to the platform zone in the in MWM reversal probe trial $(E)(p=0.0132)$ in the $N 4-2 \mathrm{KO}$ mice compared to 
the CTL (N4-2 CTL N=16, N4-2 KO mice $\mathrm{N}=13$ ) Represented as mean \pm SEM.

3.1.11. No change in postsynaptic density proteins in hippocampal tissue of N4-2 KO mice subjected to behavior analysis

After the behavioral analyses, we collected the mice and isolated the hippocampi of some pairs of the N4-2 KO and CTL mice to study levels of postsynaptic density (PSD) proteins, including Prr7 (Figure 3.14 A), GluN2B, PSD-95, CamKIla (Figure 3.14 B), GluN1, and GluA2/3 (Figure 3.14 C). We observed that there was no change in any of these proteins except for Prr7.

A

Genotype:N4-2 $f / f$

Hippocampal Lysate

\begin{tabular}{|l|l|l|}
\hline Nex & WT & re \\
\hline
\end{tabular}

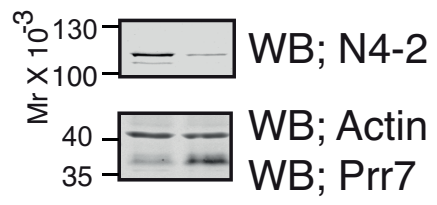

C

Genotype:N4-2f/f

Hippocampal Lysate

\begin{tabular}{|l|l|l|}
\hline Nex & WT & Cre \\
\hline
\end{tabular}

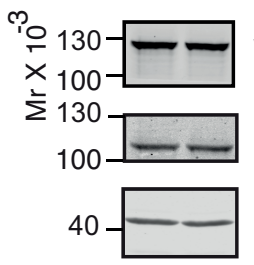

WB; GluN1

WB; GluA2/3

WB; Actin
B

Genotype:N4-2f/f

Hippocampal Lysate

\begin{tabular}{|l|l|l|}
\hline Nex & WT & Cre \\
\hline
\end{tabular}

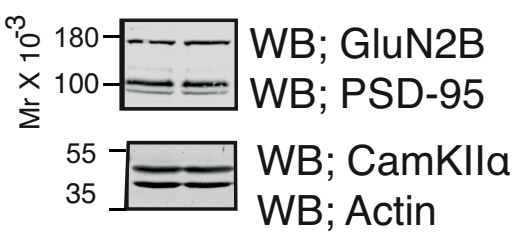

(Figure continued next page) 

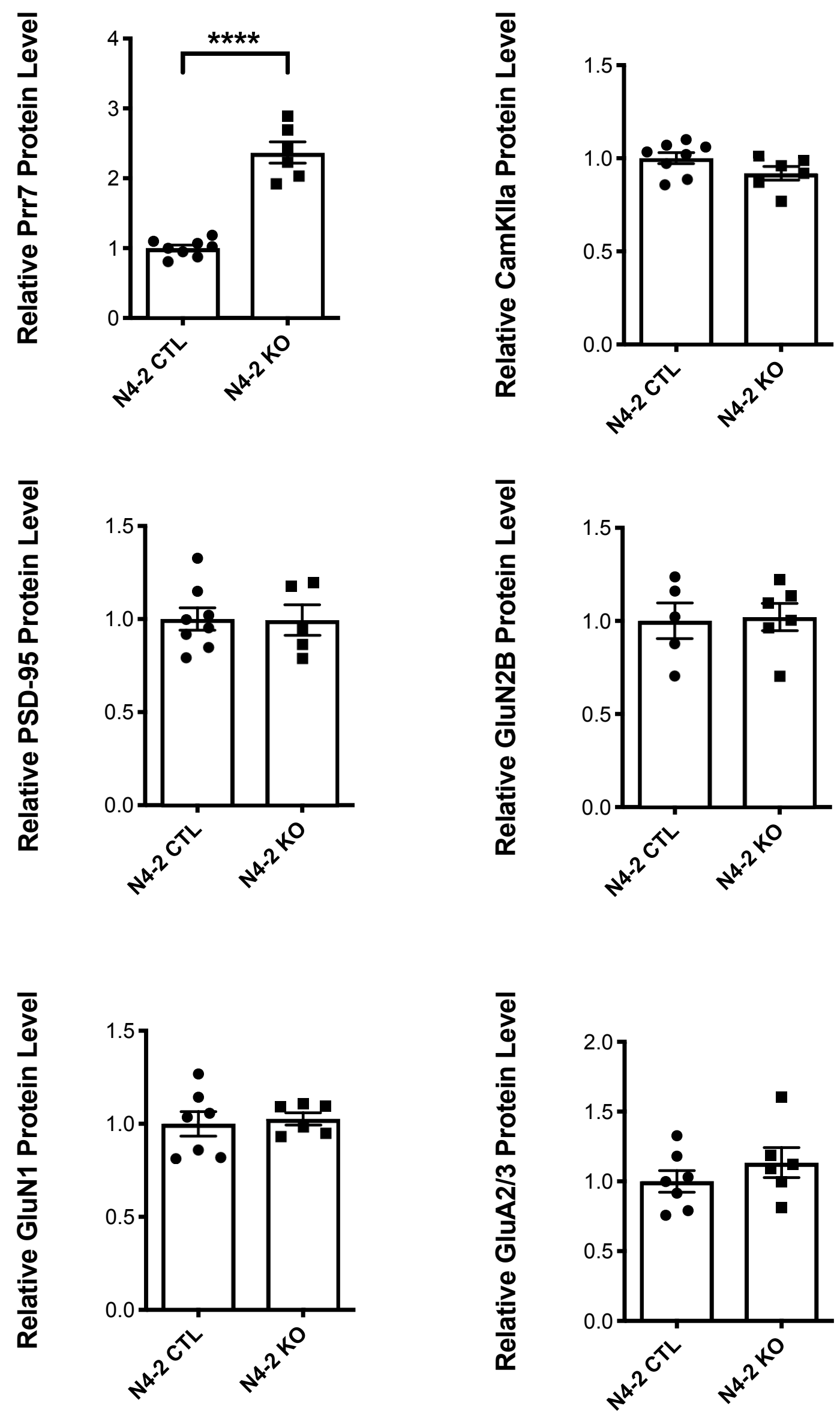
Figure 3.14. Intact expression levels of postsynaptic density proteins PSD-95, CamKIla, GluN1, GluN2B, GluA2/3. (A) Prr7 levels were significantly increased in N4-2 KO hippocampal lysates. N4-2 CTL, $1.000 \pm$ $0.05 \mathrm{~N}=8 ; N 4-2 \mathrm{KO}, 2.365 \pm 0.155, \mathrm{~N}=6 ; \mathrm{p}=0.00000052$. (B) No significant change in GluN2B levels (N4-2 CTL, $1.000 \pm 0.096 \mathrm{~N}=5 ; N 4-2 \mathrm{KO}, 1.02 \pm$ $0.081, N=6 ; p=0.87$ ), as well as PSD-95 levels (N4-2 CTL, $1.000 \pm 0.076$ $\mathrm{N}=8$; N4-2 KO, $0.994 \pm 0.082, \mathrm{~N}=5 ; \mathrm{p}=0.96$ ), and CamKIla (lower panel) (N4-2 CTL, $1.000 \pm 0.036 \mathrm{~N}=8 ; N 4-2 \mathrm{KO}, 0.919 \pm 0.036, \mathrm{~N}=5 ; \mathrm{p}=0.114)$. (C) No significant change in GluA1 levels (N4-2 CTL, $1.000 \pm 0.009 \mathrm{~N}=6$; N4-2 $\mathrm{KO}, 1.02 \pm 0.065, \mathrm{~N}=6 ; \mathrm{p}=0.98$ ), as well as GluA2/3 levels (N4-2 CTL, $1.000 \pm 0.276 \mathrm{~N}=7 ; \mathrm{N} 4-2 \mathrm{KO}, 1.3 \pm 0.373, \mathrm{~N}=6 ; \mathrm{p}=0.51$ ). Represented as mean \pm SEM.

We also performed biotinylation assays to analyze surface protein levels of AMPA and NMDA receptor subunits in N4-2 KO primary cultured hippocampal neurons. For this purpose, we did immunoblotting against GluN1, GluN2B, GluA1, and GluA2 and normalized surface protein levels to Transferrin using biotinylated samples. We did not see any significant change in any of those receptor subunits (Figures $3.15 \mathrm{~A}$ and $\mathrm{B}$ ).

A

Genotype:N4-2f/f

Biotinylated
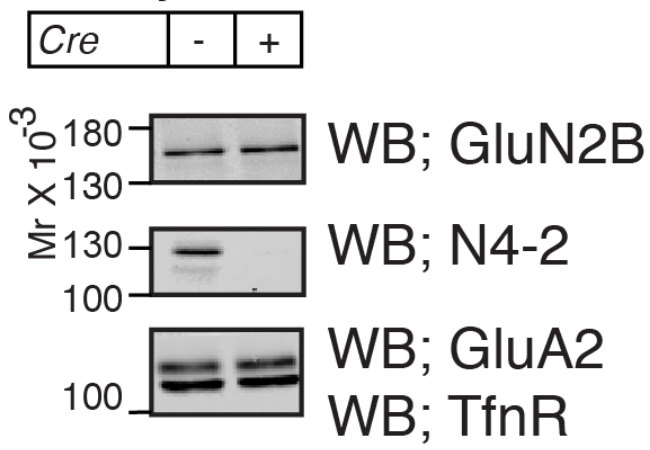

B

Genotype:N4-2f/f Biotinylated
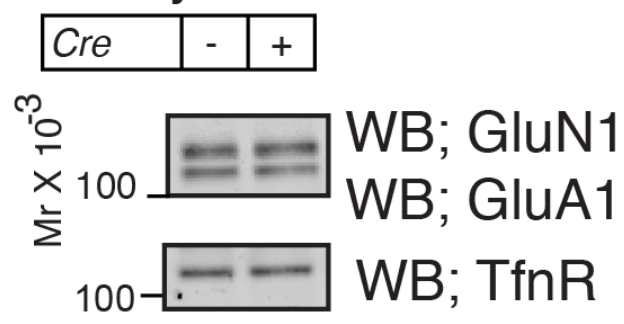

(Figure continued next page) 


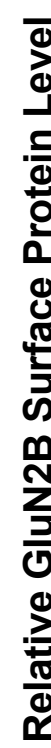
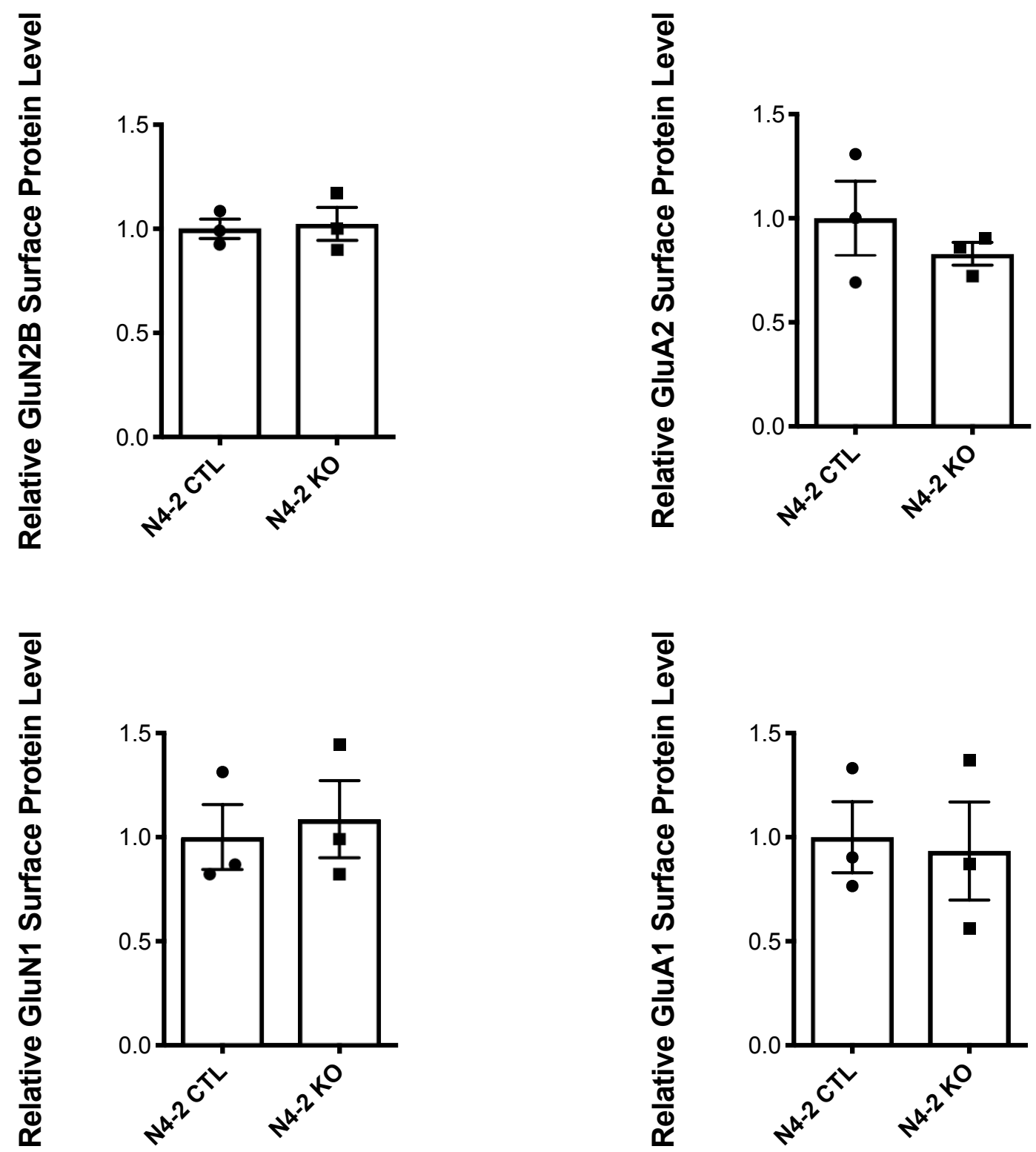

Figure 3.15. No change in surface levels of glutamate receptors in N4-2 KO hippocampal neurons. (A) No significant changes in GluN2B (N4-2 CTL, $1.000 \pm 0.046 \mathrm{~N}=3 ; N 4-2 \mathrm{KO}, 1.024 \pm 0.079, \mathrm{~N}=3 ; \mathrm{p}=0.81$ ) and GluA2 (N4-2 CTL, $1.000 \pm 0.178 \mathrm{~N}=3$; N4-2 KO, $0.828 \pm 0.055, \mathrm{~N}=3 ; \mathrm{p}=0.41$ ) (B) GluN1 (N4-2 CTL, $1.000 \pm 0.157 \mathrm{~N}=3 ; N 4-2 \mathrm{KO}, 1.086 \pm 0.186, N=3 ; p=$ 0.74 ) and GluA1 (N4-2 CTL, $1.000 \pm 0.171 \mathrm{~N}=3 ; N 4-2 \mathrm{KO}, 0.934 \pm 0.235$, $\mathrm{N}=3 ; \mathrm{p}=0.83$ ), observed in biotinylated $\mathrm{N4}-2 \mathrm{KO}$ samples. Represented as mean \pm SEM. 


\subsubsection{Electrophysiology}

Trommald and colleagues proposed a link between LTP and bifurcated spines by demonstrating that stimulated dendrites show more bifurcated spines compared to nonstimulated dendrites (Trommald et al., 1996). However, involvement of bifurcated spines in memory formation is still unclear. After discovering improved memory and re-learning ability in N4-2 $\mathrm{KO}$ mice, we did a set of electrophysiology experiments in collaboration with Prof. Dr. Jeong Seop Rhee and Dr. Erinn Gideons (MPI-EM, Göttingen) (Figures 3.16-3.17). We measured paired pulse ratios (PPR) and inputoutput $(\mathrm{I} / \mathrm{O})$ curves to analyze presynapse responses and demonstrated that the presynaptic structure was intact (Figures 3.16 A and B). There was no change between the N4-2 KO and CTL mice in either early phase LTP (ELTP) or long term depression (LTD) (Figures 3.17 A and B), whereas there was significant increase in late phase LTP (L-LTP) in N4-2 KO mice (Figure $3.17 \mathrm{C})$. Moreover, we managed to rescue this phenotype by deleting one allele of Prr7 in N4-2 KO mice $\left(N 4-2^{\mathrm{f} / \mathrm{f}} ; \mathrm{Prr}^{\mathrm{f} /+} ; \mathrm{NEX}-\mathrm{Cre}^{+/-}\right)$, indicating that Prr7 is responsible for this increase. Note that Prr7 protein levels were decreased in N4-2 KO;Prr7 heterozygous mice (Figure 3.17 D).
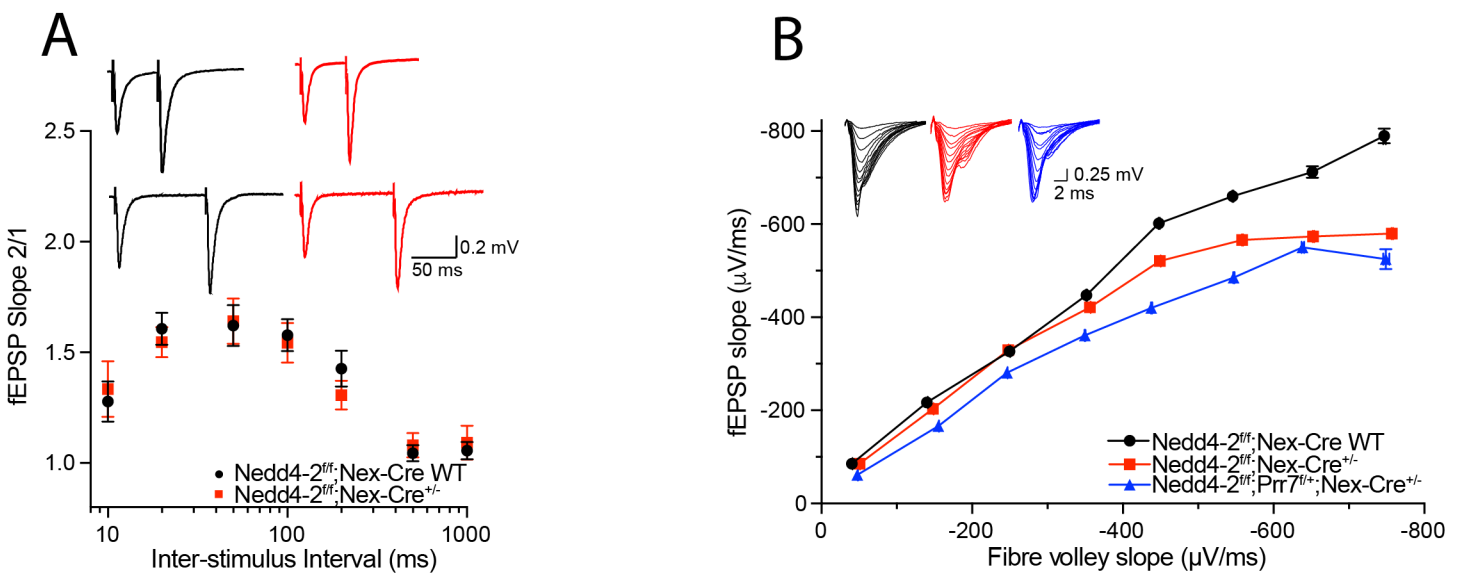

Figure 3.16. Intact presynaptic structure observed in N4-2 mice. (A) Paired pulse ratio (PPR), (B) input-output (I/O) curve showed that there is no impairment in N4-2 KO mice compared to N4-2 CTL. 
A
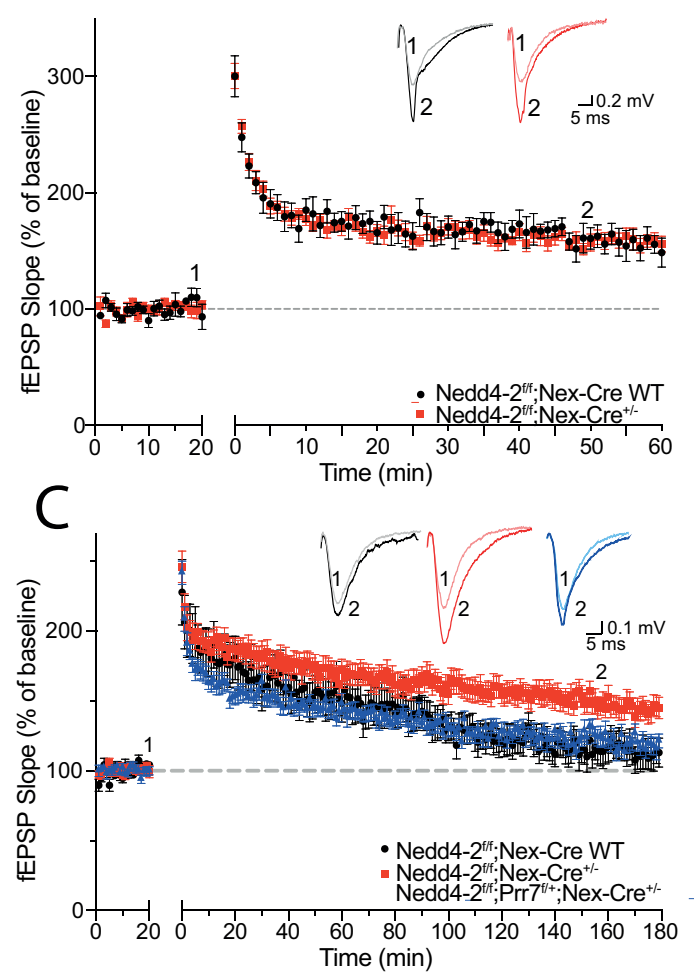

B

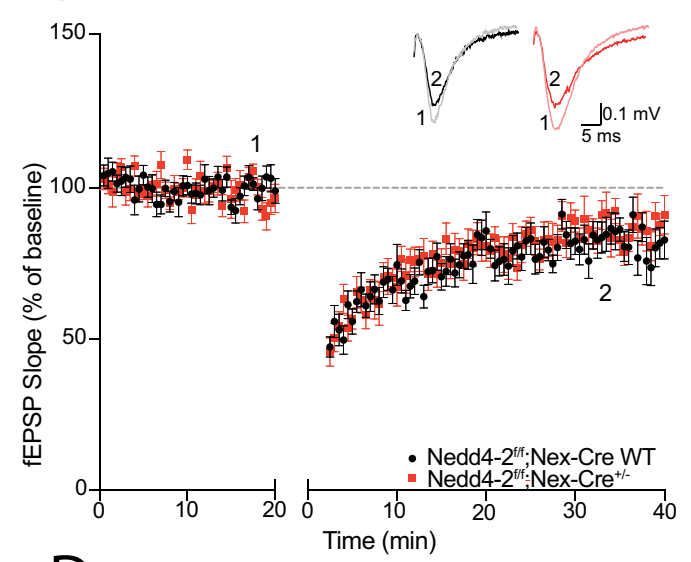

Genotype:N4-2//f

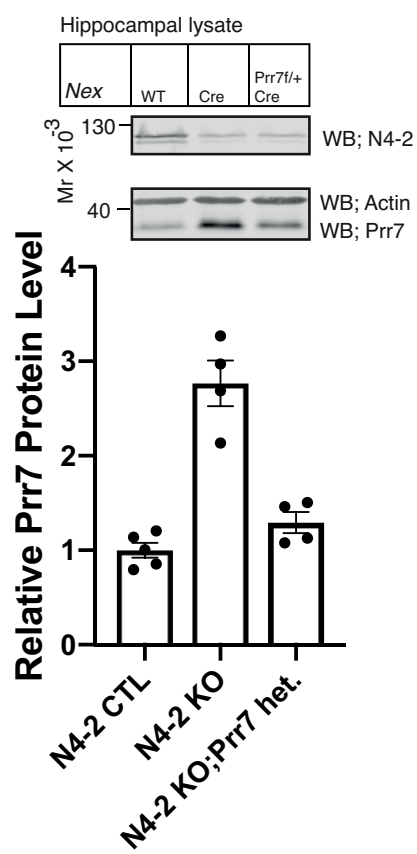

Figure 3.17. LTD and LTP measurements in N4-2 mice. No significant change in (A) E-LTP, and (B) LTD between N4-2 KO and CTL mice. (C) Significant increase in L-LTP in N4-2 KO mice, rescued by N4-2 KO, Prr7 heterozygous mice $\left(\mathrm{N} 4-2^{\mathrm{fff}} ; \mathrm{Prr}^{\mathrm{ff/}} ; \mathrm{NEX}-\mathrm{Cre}^{+/-}\right)$. (D) Decreased Prr7 protein levels in N4-2 KO;Prr7 heterozygous mice (One way ANOVA, $p<0.0001$ ). 


\subsubsection{Intact levels of p-CaMKIla and CaMKIla in stimulated hippocampal tissue of $\mathrm{N4-2} \mathrm{KO}$ mice}

Next, we studied the levels of phospho-CamKIla and in the CA1 region of the hippocampus upon stimulation of Shaffer collaterals of N4-2 KO. For this purpose, we sliced the hippocampi of 3-4 week old mice with the thickness of $300 \mu \mathrm{m}$, and incubated the slices with carbogen (95\% oxygen and $5 \%$ carbon dioxide)-supplied artificial cerebrospinal fluid (ACSF) at $32^{\circ} \mathrm{C}$ followed by 10 minutes baseline recording and 10 minutes recording after stimulation with $100 \mathrm{~Hz}$ for 3 times to induce L-LTP. Stimulated CA1 regions were isolated and lysed for immunoblotting against p-CamKIla and CamKIla. We did a pilot experiment to see if these L-LTP conditions were able to induce changes in phoshphorylation of CamKIla. In order to do this, we did immunoblotting against CamKlla, which has been linked to hippocampal LTP and learning (Hell, 2014). As shown in Figure 3.18 A, pCamKIla levels were increased upon L-LTP induction, indicating that stimulation was working. However, we were only able to detect a statistical trend in increased p-CaMKIla/CaMKIlla level (Figure 3.18 B) $(p=0.062)$. 
A B

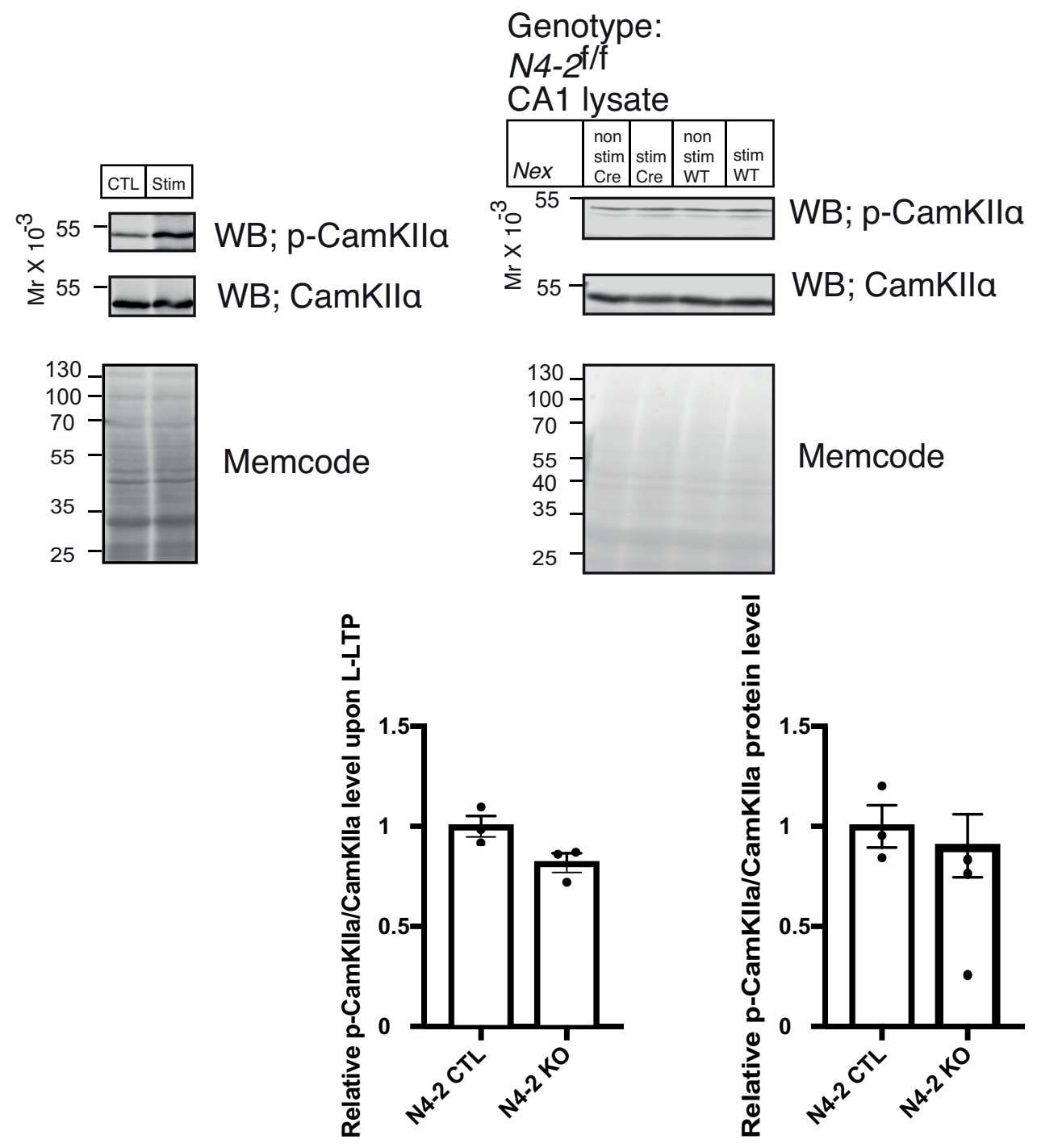

Figure 3.18. Intact levels of p-CamKIla in L-LTP-induced N4-2 KO hippocampal neurons. (A) Increased p-CamKIla levels upon L-LTP induction. (B) No change in p-CamKIla/CamKIla levels in stimulated (N4-2 CTL, $1.000 \pm 0.074 \mathrm{~N}=3 ; N 4-2 \mathrm{KO}, 0.817 \pm 0049, \mathrm{~N}=3 ; \mathrm{p}=0.062$ ) and nonstimulated pairs (N4-2 CTL, $1.000 \pm 0.168 \mathrm{~N}=3$; N4-2 KO, $0.903 \pm 0.134$, $\mathrm{N}=3 ; \mathrm{p}=0.637$ ). Represented as mean \pm SEM. 
3.2. Cell autonomous and non-cell autonomous regulations of excitotoxicity by N4-2

3.2.1. N4-2 KO neurons are resistant to neural death upon NMDA treatment

It was recently reported that Prr7 plays crucial roles in NMDA-mediated excitotoxicity at the PSD (Kravchick et al., 2016). We decided to measure excitotoxicity in N4-2 KO neurons. For this purpose, we prepared primary cultured cortical neurons using N4-2/f mice, and infected with lentivirus expressing only dsRed (N4-2 CTL) or dsRed together with Cre recombinase (N4-2 KO). At DIV16, we applied a fluorescence dye (Celltox green, Promega) that is integrated in nuclei of dead cells, followed by NMDA application (100 uM for 25 min). After washout of NMDA, we did live imaging on treated neurons using the Incucyte Live imaging system (Figure 3.19). We observed that in N4-2 CTL neurons, the high dose of NMDA caused excitotoxicity and killed the cells, whereas N4-2 KO neurons did not show NMDA-dependent cell death, indicating that N4-2 KO neurons were resistant to excitotoxicity upon NMDA treatment.

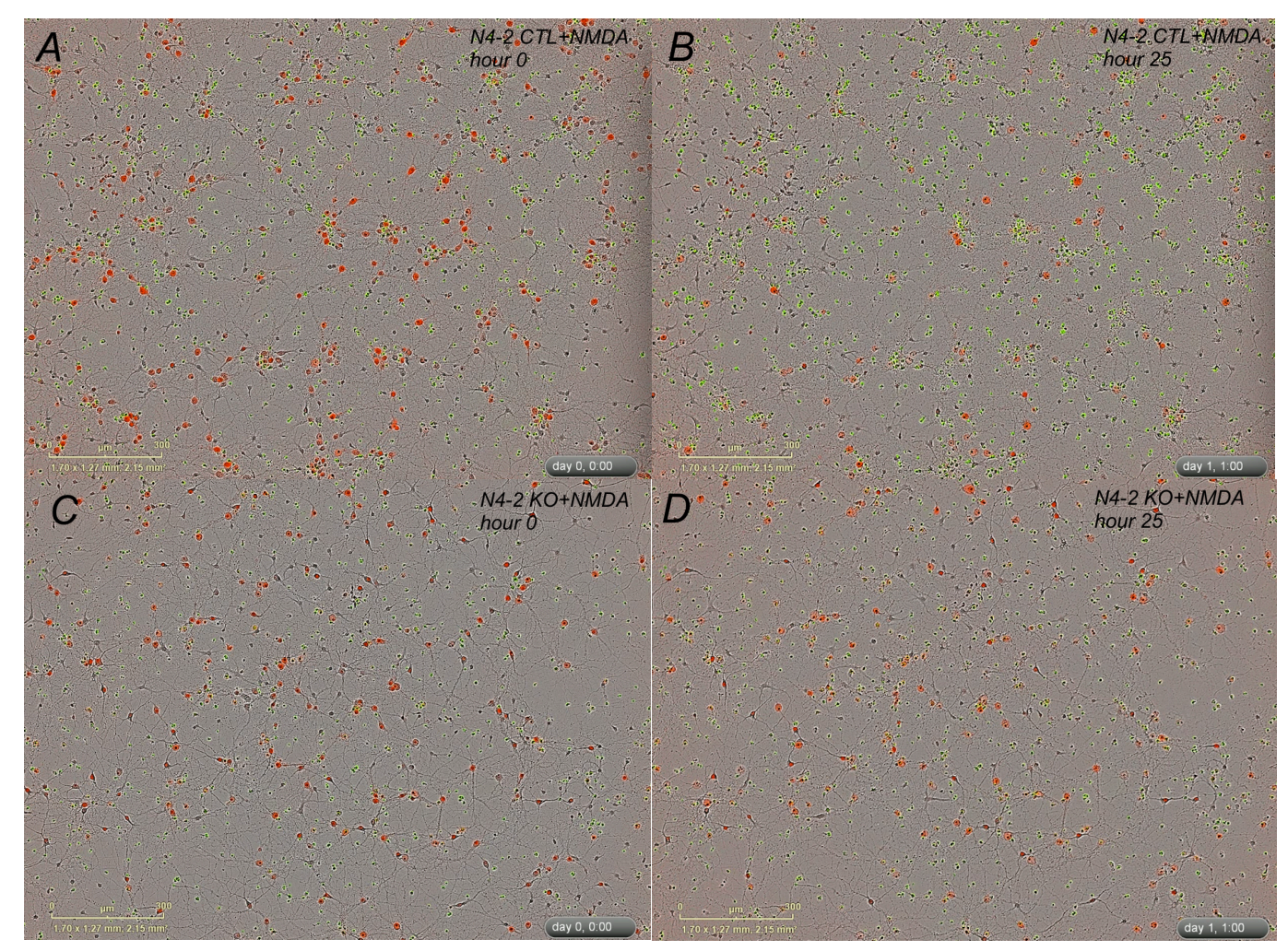




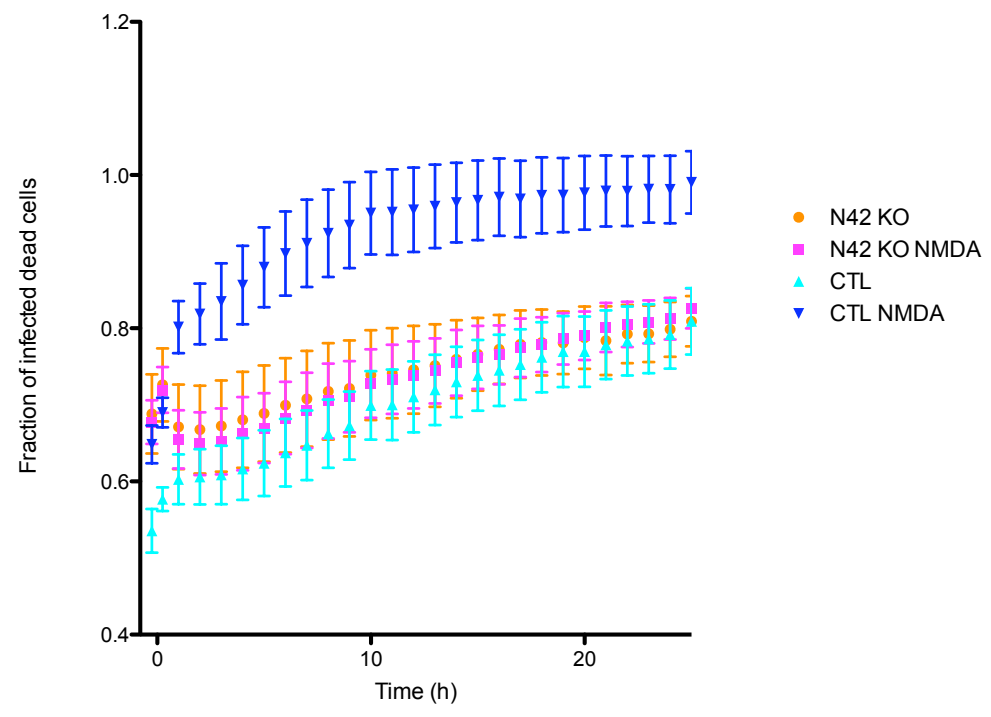

Figure 3.19. Resistance of N4-2 KO neurons to excitotoxicity upon NMDA treatment. Primary cultured cortical N4-2 CTL (A and B) and N4-2 $\mathrm{KO}(\mathrm{C}$ and $\mathrm{D})$ neurons were incubated with NMDA (100 uM for $25 \mathrm{~min}$ ) at DIV16. After washing out NMDA, uptake of Celltox green was monitored by live imaging using Incucyte Live imaging system with 10X objective lens for 25 hours. Representative images before ( $A$ and $C$ ) and after ( $B$ and $D)$ the NMDA treatment showed that there were significantly more dead green cells detected in N4-2 CTL cells than N4-2 KO (compare panels B and D). Represented as mean \pm SEM. $\mathrm{N}=5$ for each condition, Two way ANOVA, Tukey posthoc test, interaction $p<0.0001$, time $p<0.0001$, treatment $p=0.012$, subjects $p<0.0001$.

\subsubsection{Astroglial protein Connexin- 43 as a substrate of Nedd4-2 E3} ligase

Connexin-43 (Cnx-43) is another protein identified in the proteome screen of proteins upregulated in N4-1/2 bDKO. It has been reported previously that Cnx-43 is expressed mainly in astrocytes (Dere et al., 2012), and a binding assay revealed that the second WW domain of N4-1 binds to the PY motif of 
Cnx-43 (Kawabe et al., 2010; Leykauf et al., 2006). Moreover, it has been shown that in N4-1 knockdown cells, Cnx-43 levels were significantly increased (Girao et al., 2009). It has also been reported that glial $\mathrm{Cnx}-43$ is critical for neuroprotection after stroke (Nakase et al., 2004).

Like Prr7, we also verified the proteome screen results for $\mathrm{Cnx}-43$ by quantitative Western blotting with the anti-Cnx-43 antibody using N4-1/2 CTL and N4-1/2 bDKO P2C fractions (Figure $5.4 \mathrm{~A}$ ), and demonstrated that Cnx-43 level was altered. As shown in Figure 5.3 A, Cnx-43 level showed a 2-fold increase in N4-1/2 bDKO compared to N4-1/2 CTL. Unaltered Cnx-43 mRNA levels in N4-1/2 bDKO indicate that the enhancement in Cnx-43 protein was caused posttranscriptionally (Figure 3.19). We also did quantitative Western blotting using neuron-specific N4-1 and N4-2 double conditional KO (N4-1 $\left.1^{\mathrm{f} / \mathrm{f}} ; \mathrm{N} 4-2^{\mathrm{f} / \mathrm{f}} ; \mathrm{NEX}-\mathrm{Cre}^{+/-}, N 4-1 / 2 \mathrm{nDKO}\right)$ and demonstrated that there is no significant change in $\mathrm{Cnx}-43$ levels compared to control (Figure 5.4 B). We concluded that astroglial N4-1 and/or N4-2 are responsible for the downregulation of $\mathrm{Cnx}-43$.

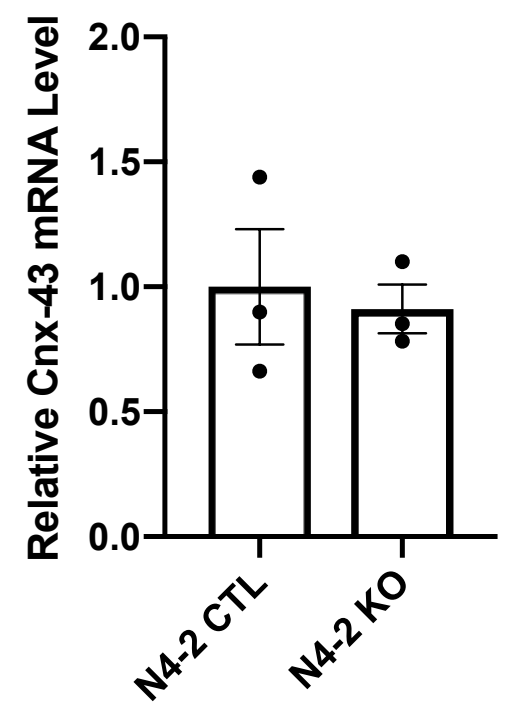

Figure 3.20. Cnx-43 mRNA levels in N4-1 and N4-2 conditional KO mouse lines. mRNA levels of Cnx-43 in from cortices of 6 weeks old N4-1/2 CTL $\left(N 4-1^{\mathrm{f} / \mathrm{f}} ; N 4-2^{\mathrm{f} / \mathrm{f}}\right)$ and N4-1/2 bDKO (N4-1/f; $; N 4-2^{\mathrm{f} / \mathrm{f}} ; E m \times 1$ Cre) mice (N41/2 bCTL, $1.00 \pm 0.0398, \mathrm{~N}=3 ; \mathrm{N} 4-1 / 2 \mathrm{bDKO}, 0.91 \pm 0.168 \mathrm{~N}=3 ; \mathrm{p}=0.741$. Represented as mean \pm SEM. 
We also observed that Cnx-43 level was not increased in N4-1 single brainspecific conditional KO (N4-1/ff; Emx1-Cre, N4-1 bKO), whereas N4-2 single brain-specific conditional KO (N4-2 f/f; Emx1-Cre, N4-2 bKO) showed significant increase in Cnx-43 (Figure 5.4 C and D). Taken all together, endogenous glial N4-2 is the relevant E3 ligase that suppresses $\mathrm{Cnx}-43$ at the posttranscriptional level.

\subsubsection{Ubiquitination of $\mathrm{Cnx}-43$ by $\mathrm{N} 4-2$}

We next studied if N4-1 and N4-2 ubiquitinate $\mathrm{Cnx}-43$ in vivo by doing a cellbased ubiquitination assay. C-terminally HA-tagged Cnx-43 (Connexin-43HA or Cnx-43-HA) was overexpressed in HEK293FT cells with or without the EGFP-tagged N4-1 (EGFP-N4-1) and N4-2 (EGFP-N4-2), followed by immunoprecipitation and subjected to Western blotting using anti-HA and anti-Ub antibodies (Figure 5.5). EGFP-N4-1- and EGFP-N4-2-dependent ubiquitination of Cnx-43-HA was observed with the anti-Ub antibody (Figure 5.5 third panel). More importantly, the level of the ubiquitin signal from was more pronounced upon EGFP-N4-2-overexpression than EGFP-N4-1 although very high expression of EGFP-N4-1 was seen (Figure 5.5 top panel), indicating that $\mathrm{N} 4-2$ has more prominent activity than N4-1 in ubiquitination of $\mathrm{Cnx}-43$. We also blotted the samples with antibodies to K48-linked polyUb and K63-linked polyUb (Figure 5.5 fourth and fifth panels), and loaded K48-linked and K63-linked tetra-Ub next to Cnx-43-HA samples to compare the titer of two anti-polyUb antibodies. As observed in the cell based ubiquitination assay done for Prr7, we detected strong signals from the anti-K48-linked polyUb antibody (the third lane in the fourth panel of Figure 5.5) in the absence of any EGFP-tagged Nedd4 proteins, probably because of the enhanced removal of $\mathrm{Cnx}-43-\mathrm{HA}$ by endoplasmic reticulumassociated protein degradation that involves K48-linked polyUb (Lemus and Goder, 2014; Zemoura et al., 2013). Western blotting using the anti-K63 polyUb antibody revealed similar results as anti-Ub antibody in Figure 5.5 third panel, indicating that N4-2 prominently conjugated Cnx-43 with K63linked polyUb for degradation. 


\section{DISCUSSION}

\subsection{Characterization of Prr7 as a substrate of N4-2}

Ubiquitination is a posttranslational protein modification involved in wide array of cellular functions, including proteasomal protein degradation, DNA damage response, and endocytosis. Substrate specificity of ubiquitination is determined by E3 ligases, which are encoded by $\sim 600$ genes in human genome. The loss- or gain-of-function of E3 ligase genes lead to neurological disorders, including neurodegenerative disease (e.g. Parkinson's and Alzheimer's diseases), autism spectrum disorders, and intellectual disabilities (George et al., 2018). Identification of N4-1 and N4-2 were done in a screening study to elucidate developmentally downregulated genes in the mouse brain (Kumar et al., 1992). N4-1, which was the first identified and most investigated member of the Nedd4 family has been linked to several potential substrates, showing its general function in vesicular trafficking and sorting (Yang and Kumar, 2010). N4-2 is of particular importance for neuronal development and function; loss of N4-2 causes familial heterotopia, which is a brain malformation caused by abnormal neuronal migration (Broix et al., 2016) and the gain-of-function N4-2 is a potential cause of familial epilepsy (Dibbens et al., 2007).

The present study demonstrates (i) a novel biological mechanism where a postsynaptic transmembrane protein Prr7 is regulated by N4-2 (Figure 3.4), (ii) the neuron-specific loss of N4-2 results in improved memory formation (Figure 3.12), as well as L-LTP (Figures 3.16-3.17).

\subsection{Identification of novel substrates of N4-2}

One of the well established substrates of N4-2 is the epithelial sodium channel, ENaC. ENaC is composed of alpha, beta, and gamma subunits, among which beta and gamma subunits have PY motifs at their C-termini. $\mathrm{ENaC}$ is highly expressed on the apical plasma membrane of the distal tube and collecting duct of the nephron of the kidney and is involved in 
reabsorption of sodium from the lumen into the epithelial cytoplasm. Eventually, ENaC increases the sodium level in the blood plasma, leading to the secondary reabsorption of water from the renal collecting duct. The regulation of $\mathrm{ENaC}$ is of particular importance to control of blood pressure. Upon activation of renin-angiotensin-aldosterone system in response to an acute decline of blood pressure, the steroid hormone aldosterone promotes the transcription of $\mathrm{ENaC}$, leading to the compensatory maintenance of blood pressure. In the pathological condition, Liddle syndrome patients with the deletion or missense mutation of the cytoplasmic C-terminus of ENaC suffer from hypertension caused by enhanced reabsorption of sodium in the nephron, indicating the gain-of-function of ENaC (Harvey et al., 2001; Kamynina et al., 2001; Rossier \& Schild, 2008). Indeed, in the mouse model of Liddle syndrome with a premature stop codon in beta-subunit of the $\mathrm{ENaC}$ gene, the reabsorption of sodium was increased without affecting the channel activity per se or the level of ENaC mRNA (Pradervand et al., 1999; Pradervand et al., 2003). Interestingly, mutations of C-terminus of ENaC disrupt a WW domain-binding PY motif. Originally, it was reported that N4-1 binds to this PY motif and ubiquitinates $\mathrm{ENaC}$ in vitro (Staub et al., 1996; Fotia et al., 2003). However, recent evidence has shown that N4-2 has more prominent E3 ligase activity for ENaC (Zhou et al., 2007) and levels of $\mathrm{ENaC}$ are increased in the kidney-specific N4-2 conditional KO mouse (Kimura et al., 2011). The history of studies of ENaC ubiquitination implies that comprehensive studies are required to identify and characterize the bona fide relationship between an E3 ligase and its substrates.

Besides ENaC, voltage-gated sodium channels Nav1.2, Nav1.3, Nav1.5 (van Bemmelen et al., 2004; Rougier et al., 2005), and potassium channels KCNQ1, KCNQ2/3 and KCNQ3/5 (Ekberg et al., 2007; Jespersen et al., 2007) have been reported as substrates of N4-2. However, the function of N4-2 remains to be explored. 
In our previous study, we screened for proteins upregulated in the synaptic plasma membrane fraction from N4-1/2 bDKO mice to identify potential substrates of N4-1 and N4-2. Among three identified transmembrane proteins, Kir4.1 and Cnx-43 were characterized as key substrates in astrocytes, whereby they control the neuronal network activity in a non-cell autonomous manner (Altas et al., 2019, manuscript in revision). In our present study, we characterized the third potential substrate protein, Prr7 with biochemical, cell biological, and behavioral methods. Prr7 was originally cloned as a postsynaptic transmembrane protein forming a complex with PSD-95 and NR2B (Murata et al., 2005). Given that PSD-95 binds to Prr7 through its PDZ domain, it is very likely that the C-terminal PDZ-binding motif of Prr7 is required for the interaction with PSD-95 and for the complex formation with NR2B. We demonstrated that the first or second PY motifs of Prr7 are essential for its binding to and ubiquitination by N4-2 (Figure 3.5 B). Despite highly homologous WW domains of N4-1 and N4-2 (i.e. 65 to $75 \%$ identity, Asher et al., 2003), only N4-2 has a prominent activity as an E3 ligase for Prr7 (Figure 5.2). Consistent with this result, Prr7 protein level was increased in N4-2 KO neurons while there were no changes in Prr7 protein expression in N4-1 KO neurons (Figure 5.1). We found that N4-2 has a potential to conjugate K63-polyUb to Prr7 in the cell-based ubiquitination assay (Figures $5.2 \mathrm{~B}$ and $3.5 \mathrm{C}$ ). K63-polyUb plays critical roles in endocytosis/lysosomal degradation, DNA damage response, and activation of NF-kappaB signaling (Erpapazoglou et al., 2014; Mattiroli et al., 2012; Chen, 2005). In our biotinylation assay (Figure 3.4), the level of Prr7 was more prominently upregulated in the plasma membrane than in the total lysate. This result indicates that Prr7 is regulated by N4-2 at the cell surface primarily, probably via endocytosis/lysosomal degradation, rather than in the cell body, e.g. transcriptionally. Indeed, the level of mRNA was not changed in N4-1/2 bDKO (Figure 3.2 A).

Developmentally, Prr7 level is upregulated in the brain from E18 till P42 (Murata et al., 2005). Such a temporal expression pattern resembles those of other postsynaptic proteins, including PSD-95 and Neuroligin-1 (Song et al., 1999). A number of proteins with this expression pattern promote 
synaptyogenesis of excitatory synapses. Prr7, on the other hand, impairs synapse formation by blocking the non-canonical Wnt pathway in a CamKIIdependent manner (Lee et al., 2018).

The level of N4-2 is downregulated developmentally in the brain from E13 (Hsia et al., 2014). This expression profile implies that N4-2 may play roles in the early phase of the neuronal development, including neuronal migration that may affect cortical circuit formation (Broix et al., 2016). Inversely proportional expression profiles of N4-2 and Prr7 may be accounted for by N4-2 dependent ubiquitination of Prr7. After P28, around the time that synapse elimination is completed, the level of N4-2 stays constant (Takeda, 2012, PhD thesis). N4-2 is localized to the synapse in mature primary cultured neurons (Figure 3.1). Our finding provides a novel insight for proteostasis at the postsynapse.

\subsection{Neuronal N4-2 enhances spatial reversal learning}

Behavior of mice as well as humans correlates with activity of certain neuronal pathways. It has been reported that KOs of genes involved in synaptic transmission, i.e. calcineurin, CamKIla, and NR2B show deficit in spatial learning in the MWM test (Zeng et al., 2001; Park et al., 2016). Similarly, several E3 ligase KO mice, including Ube3A KO, neuron specific chromodomain helicase DNA binding protein 1 (Chd1) conditional KO, and IDOL KO show impaired spatial learning (Jiang et al., 1998; Schoberleitner et al., 2019; Pick et al., 2013; Gao et al., 2017). Conversely, Cdk5 KO, polyadenylate-binding protein-interacting protein 2 (PAIP2A) KO, and $O R L_{1}$ $\mathrm{KO}$ mice show improved spatial learning and/or memory consolidation in MWM test (Hawasli et al., 2007; Khoutorsky et al., 2013; Plattner et al., 2014). Interestingly, Cdk5, PAIP2A, and ORL $\mathrm{L}_{1}$ promote the expression or activity of calcineurin or CamKIla, respectively, via conventional intracellular signaling, protein phosphorylation and calcium signaling. In order to test if N4-2 plays a role in spatial memory formation, we applied general behavioral analyses together with the MWM test and the MWM reversal test (Morris, 1984; Vorhees \& Williams, 2010). 
In our study, there was no anxiety phenotype in N4-2 KO mice in the elevated plus-maze and open field tests. Interestingly, in the open field test, N4-2 KO mice showed increased values both in velocity and path length, suggesting that these mice could be more curious of novel environments and also exhibit mild hyperactivity. However, we did not see the same outcome in holeboard exploration test. Moreover, these mice showed impaired motor learning in motor performance tests, such as rotarod and grip strength test, while sensory performances, such as vision and hearing were found to be intact. The hearing curve results might indicate reduced hearing at higher intensities, but that results would need to be confirmed by acoustic evoked potentials.

Very interestingly, despite the significant decrease in grip strength and motor coordination observed in $\mathrm{N4}-2 \mathrm{KO}$, we observed enhanced spatial memory and re-learning ability in N4-2 KO mice (Figure 3.12 and 3.13). The MWM test is known to be a strong and dependable test that is related to hippocampus-dependent learning and memory (Morris, 1984; Vorhees \& Williams, 2010). As the N4-2 KO mice showed decreased latency to find the hidden platform in comparison to the CTL mice during the learning trials, the N4-2 KO were therefore found to have enhanced hippocampal-dependent learning and memory compared to control mice. Moreover, the MWM reversal test, which is even more complicated since it is not only changing the position of the platform, but also removing the platform for some time and then changing the position of it. Additionally, only a limited time is given to mice to adapt to the changed situation and re-learn the task. It was observed that N4-2 KO mice have significantly higher visits to the new platform zone and path length in the new platform zone during the MWM reversal test, which indicates enhanced re-learning ability compared to the CTL mice.

Since the MWM test has been related with hippocampal LTP as well as NMDA receptor function (Morris et al., 1986; Bannerman et al., 1995), we harvested the hippocampi of mice subjected to behavior and did immunoblotting against NMDA receptor subunits, as well as several 
postsynaptic density proteins including Prr7. There was a significant increase was in Prr7 levels, which supports the role of Prr7 in memory enhancement. These findings also correlated with the changes of neuronal morphology regarding dendritic spine phenotype found in the CA1 region related with spatial memory, indicating a significant contribution of CA1 pyramidal neuron morphology to the circuitry for learning and memory (Tsien et al., 1996). Behavioral improvement in learning and memory in the neuron specific N4-2 mice provided novel insights into the molecular machinery of learning and memory.

\subsection{Neuronal N4-2 as a regulator for L-LTP}

Dendritic spines are small protrusions that form synaptic contacts with presynaptic boutons. There are huge varieties in the size and shape of spines. The morphology as well as the number of spines can be modified in response to the intensity and the number of afferent inputs. Spines are not commonly present in lower organisms such as Drosophila melanogaster and Caenorhabditis elegans, indicating that they might have evolved to process more complex information in the mammalian brain (Hering \& Sheng, 2001; Puram \& Bonni, 2013; Sala \& Segal, 2014). Spine head size correlates with the PSD size and also with vesicular pool size of its corresponding presynaptic bouton, which can lead to changes in synaptic transmission (Harris \& Stevens, 1989). Spine length, on the other hand, could affect the calcium distribution in the spine, and its increase can lead to a decrease in postsynaptic activation (Volfovsky et al., 1999; Araya et al., 2014). These changes could also modify electrophysiological characteristics of postsynaptic neurons, e.g. enlargement of spine heads results in stabilization of synapses harboring increased glutamate receptors (Fiala et al., 2002; Comery et al., 1997; Noguchi et al., 2005). Considering that Prr7 interacts with NMDA receptor subunits (Murata et al., 2005) and that Prr7 is accumulated on tip of spines (Figure 3.6), N4-2 might control the distribution of NMDA receptors by ubiquitinating Prr7. However, we did not see any 
significant changes in total and cell surface levels of glutamate receptor subunits such as GluN1, GluN2B, GluA1, and GluA2 in the absence of N4-2 (Figures 3.14 and 3.15).

Trommald and colleagues proposed a link between LTP and bifurcated spines by demonstrating an increase in bifurcated spines upon LTP induction (Trommald et al, 1996). However, involvement of bifurcated spines in memory formation and the molecular machinery of spine bifurcation are still unclear. Our morphometric analyses of spines demonstrate the critical role of N4-2 in spine bifurcation (Figure 5.3). The increased number of bifurcated spines observed in N4-2 KO mice might play a role in the maintenance of L-LTP. Indeed, we observed enhanced L-LTP in N4-2 KO mice, whereas there was no change in E-LTP or LTD, which supports our findings in increased learning and memory. Moreover, the change in L-LTP between the N42 KO and CTL was reversed by deleting one allele of Prr7, indicating that upregulation of Prr7 is the cause of enhanced L-LTP in N4-2 KO mice (Figure $3.17 \mathrm{C}$ ).

\subsection{Roles of N4-2 in neuronal apoptosis}

It was recently reported that Prr7 shuttles from the postsynapse to the nucleus to mediate excitotoxicity upon the stimulation of NMDA receptors (Kravchick et al., 2016). This process is required for the blockade of ubiquitination and proteasomal degradation of phospho-c-jun to promote neuronal death. Unexpectedly, our live imaging experiment resulted in neuroprotection upon the loss of neuronal N4-2. This result indicates that an alternative substrate of N4-2 is involved in the control of excitotoxicity in a cell autonomous manner. Interestingly, we identified Cxn-43 as a substrate of N4-2 and the protein level of Cnx-43 is increased in the absence of N4-2 in glial cells (Figure 5.4). Cnx-43 is dominantly expressed in the astrocyte and the glia cell-specific conditional deletion of Cnx-43 results in enlarged infarct volume after middle cerebral artery (MCA) occlusion and reperfusion (Nakase et al., 2004). MCA occlusion is the widely accepted model for the 
ischemic stroke, which is mediated by NMDA-dependent excitotoxicity. Overall, we hypothesize that the loss of N4-2 in neurons leads to an increase in an unknown substrate resulting in neuroprotection, while its loss in astrocytes results in an increase in Cnx-43 level, which protects neurons from excitotoxicity in a non-cell autonomous manner.

\subsection{Multiple layers of regulation of Prr7 level}

MicroRNAs (miRNAs) are small noncoding RNAs that act by interfering with the stability or translation of messenger RNAs (mRNAs). miRNAs are widely expressed in eukaryotic cells, and regulate several genes involved in cellular processes like inflammation, cell-cycle regulation, stress response, differentiation, apoptosis, and migration via ribonuclease-based degradation system. Ubiquitination, on the other hand, is a regulatory mechanism at the protein level through the degradation of cellular proteins by the ubiquitin proteasome system. The miRNA and ubiquitination systems have similarities in several aspects; however, ubiquitination is a more robust and specific system, while miRNA regulates multiple targets mildly to move the molecular balance to change a certain cell function (e.g. synaptogenesis) (Di Leva et al., 2014; Gebert \& MacRae, 2019).

Very recently, Prr7 protein levels were reported to be upregulated in the hippocampus of miR379-410 KO mice (Lackinger et al., 2019). They demonstrated that miR379-410 KO mice show hypersocial behavior together with increased excitatory neurotransmission and spine density, which partially goes in line with our findings of increased L-LTP and altered spine morphology, revealing another level of regulation of Prr7 in neurons. For future studies, mEPSCs in N4-2 KO mice could be measured for further characterization 


\subsection{Summary}

In the present study, Neuronal N4-2 is characterized as the E3 ligase for the regulation of Prr7 protein level. It has been further confirmed by demonstrating increased surface expression of Prr7 in N4-2 KO neurons, ubiquitination assays, and binding assays that N4-2 binds and ubiquitinates Prr7. Prr7 is found to be at the tip of the spine in vivo, and the morphological analysis of N4-2 KO mice demonstrating that N4-2 E3 ligase has a role in spine formation. Moreover, N4-2 KO mice showed improved memory formation and re-learning ability, as well as increased L-LTP; and this effect is rescued by N4-2 KO;Prr7 heterozygous mice, stating that Prr7 is responsible for this phenotype. All in all, this study provides a novel role of N4-2 in neurons. 


\section{APPENDIX}

A

Genotype:

N4-1 ${ }^{f / 7} ; N 4-2^{f / f}$

Cortical Lysate

\begin{tabular}{|l|l|l|}
\hline Emx1 & WT & Cre \\
\hline
\end{tabular}

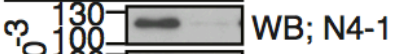

으 $130=2 \mathrm{WB}$; N4-2

$\times 100=-W \mathrm{WB}$; Prr7

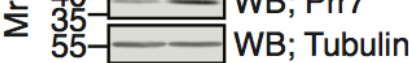

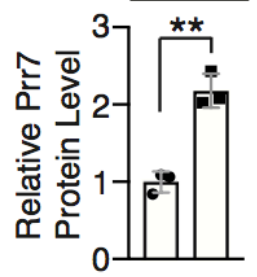

C

Genotype:

N4-1 ${ }^{\mathrm{f} / \mathrm{f}} ; \mathrm{N} 4-\mathrm{2}^{+/+}$

Cortical Lysate

\begin{tabular}{|c|c|}
\hline$\overline{E m \times 1}$ & WT Cre \\
\hline P130 & 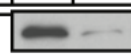 \\
\hline & \\
\hline & \\
\hline
\end{tabular}

WB; N4-1

WB; Prr7

WB; Tubulin
B

Genotype:

N4-1/f/f;N4-2/f

Cortical Lysate

\begin{tabular}{|l|l|l|}
\hline Nex & WT & Cre \\
\hline
\end{tabular}
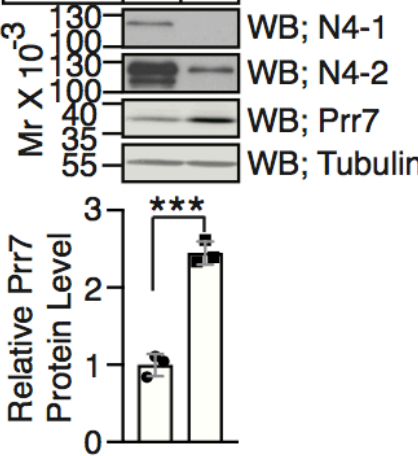

WB; Tubulin

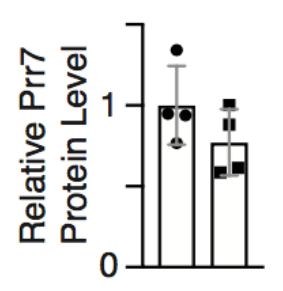

Genotype:

N4-1 ${ }^{+1+} ;$ N4-2 $\mathrm{f} / \mathrm{f}$

Cortical Lysate
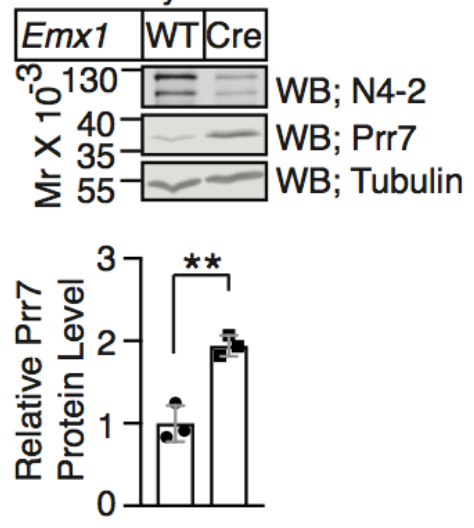

Figure 5.1. Prr7 levels in $\mathbf{N 4 - 1}$ and $\mathbf{N}$ 4-2 conditional KO mouse lines. (A) Protein levels of Prr7 in cortical brain lysates from 6 weeks old N4-1/2 CTL (Emx1 WT) and N4-1/2 bDKO (Emx1 Cre) animals. For the statistical analyses, Prr7 level was normalized to tubulin level. Prr7 protein showed a significant increase (N4-1/2 bCTL $1.00 \pm 0.078, N=3$; N4-1/2 bDKO, $2.18 \pm$ 0.13, $N=3 ; p=0.0014$ (B) Prr7 protein levels in N4-1/2 CTL (Nex WT) and N4-1/2 nDKO (Nex Cre) cortical homogenates (N4-1/2 CTL $1.00 \pm 0.082$, $\mathrm{N}=3 ; N 4-1 / 2 \mathrm{nDKO}, 2.45 \pm 0.085, \mathrm{~N}=3 ; \mathrm{p}=0.0003)$. Note that the fold change of Prr7 in N4-1/2 nDKO is comparable to that in N4-1/2 bDKO. (C) 
Prr7 levels in N4-1 CTL (Emx1 WT) and N4-1 bKO (Emx1 Cre) cortical homogenates (N4-1 CTL, $1.000 \pm 0.122 \mathrm{~N}=4$; N4-1 bKO, $0.77 \pm 0.102, \mathrm{~N}=4$; $\mathrm{p}=0.2011)$. (D) Prr7 levels in N4-2 CTL (Emx1 WT) and N4-2 bKO (Emx1 Cre) cortical homogenates (N4-2 CTL $1.000 \pm 0.127, \mathrm{~N}=3$; N4-2 bKO, $1.94 \pm$ $0.072, N=3 ; p=0.0030$ ). Represented as mean \pm SEM. (Modified from Altas, 2016, PhD thesis)
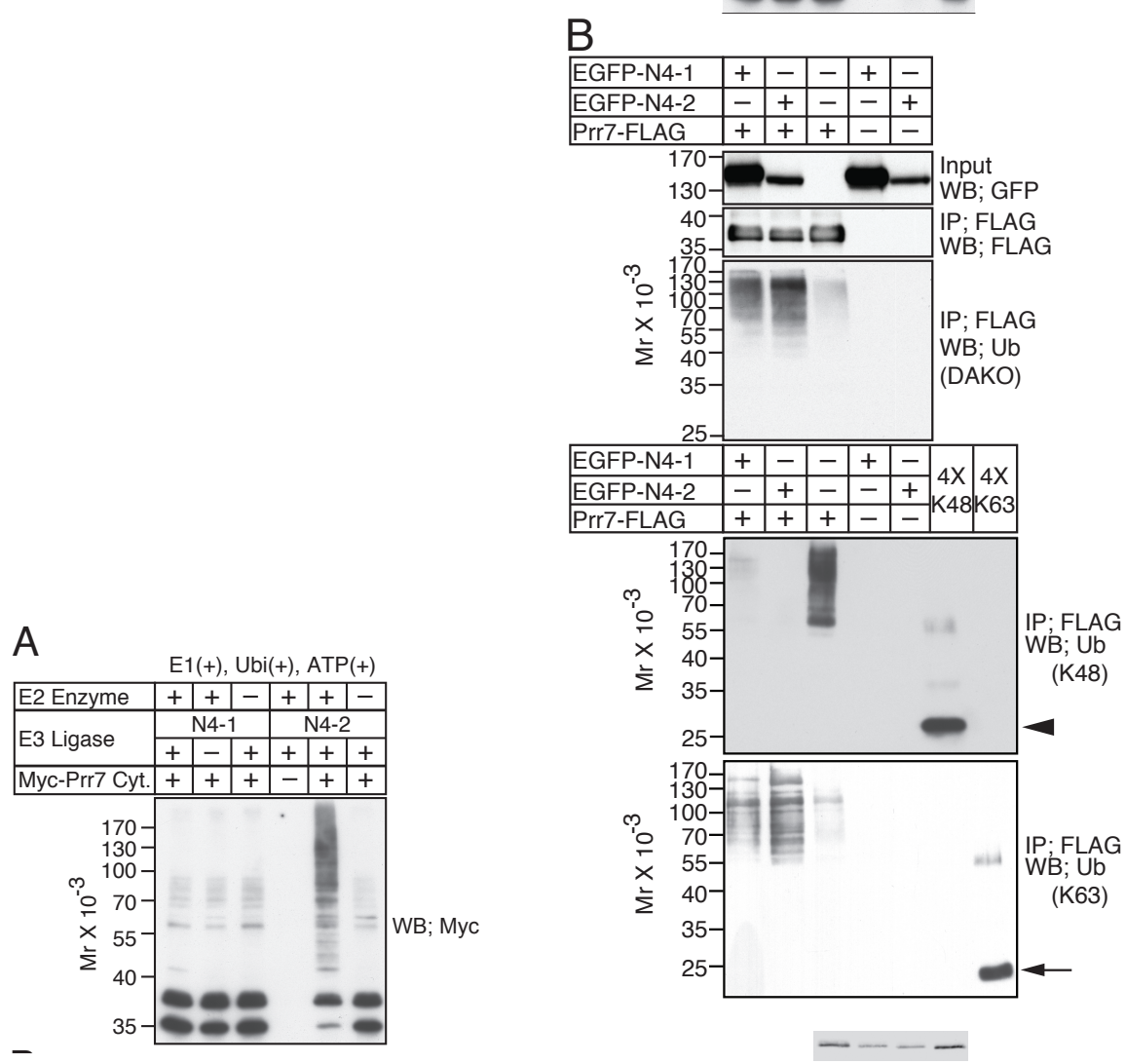

Figure 5.2 In vitro and in vivo ubiquitination of Prr7 by N4-2. (A) In vitro ubiquitination assay was performed with Myc-tagged cytoplasmic region of Prr7 (Myc-Prr7 Cyt), ATP, recombinant ubiquitin, and E1 enzyme in the presence or absence of E2, N4-1, and N4-2. Ubiquitination was detected by the shift of molecular weight of Myc-Prr7 Cyt with anti-Myc antibody. Note the increase in the molecular weight of Myc-Prr7 Cyt at the expense of protein detected around 37 and $35 \mathrm{kDa}$ in the presence of both E2 enzyme 
and N4-2. (B) FLAG-tagged Prr7 (Prr7-FLAG) was expressed in HEK293FT cells with or without EGFP-N4-1 or -N4-2. Immunoprecipitates using an antiFLAG antibody-coupled agarose beads were subjected to Western blotting using anti-FLAG (second panel) or anti-Ub antibody (third panel). Samples were blotted with anti-K48-linked polyUb (K48; fourth panel) or anti-K63linked polyUb (K63; fifth panel) antibodies. Note that signals from K48-linked (arrowhead) and K63-linked tetra-Ub (arrow) in fourth and fifth panels are comparable.

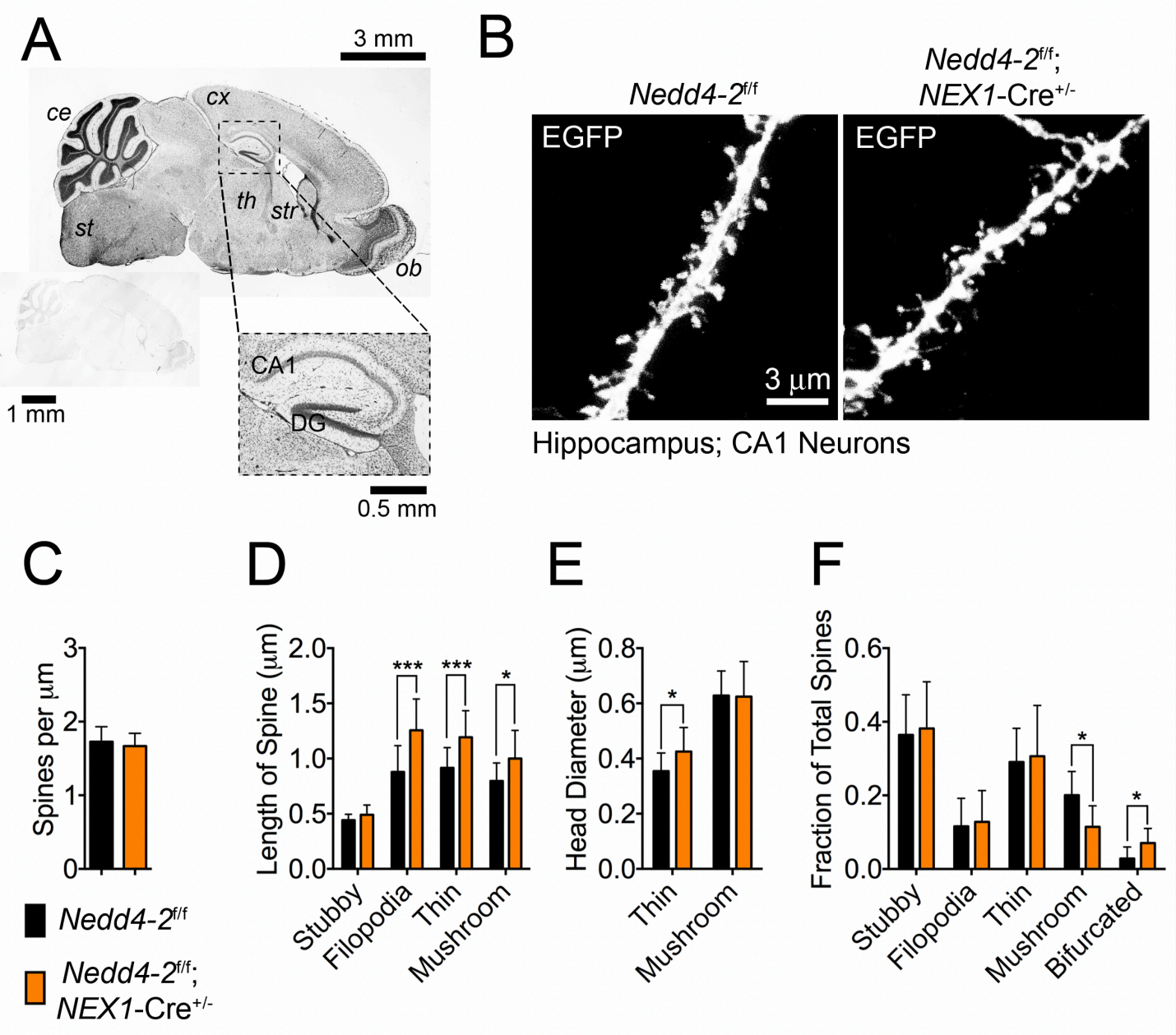

Figure 5.3. Spine analysis in neuron-specific N4-2 conditional KO mouse. (A) In situ hybridization using probes against N4-2 mRNA on sagittal sections in P20 murine brain and control reaction with sense probe (Figure A, bottom left). Note that dark signals show strong hybridization. Brain stem (st), cerebellum (ce), cortex (cx), thalamus (th), striatum (str), 
olfactory bulb (ob), Cornu Ammonis area 1 CA1, dentate gyrus (DG). N4-2 mRNA levels are elevated in CA1 and DG of hippocampus (Figure A, enlarged square). (B) Representative maximum projections images of antiGFP labeled dendrites of control (Nedd4-2 ${ }^{\mathrm{fff}}$, left panel) and neuron-specific N4-2 knockout (Nedd4-2 $2^{\mathrm{fff}} ; \mathrm{NEX}-\mathrm{Cre}^{+/}$, right panel) CA1 neurons. (C) Spine number quantification in control and N4-2 KO dendrites. (D) Spine length quantification in control and N4-2 KO (filopodia: N4-2 CTL, $0.88 \pm 0.24 \mu \mathrm{m}$; N4-2 KO, $1.26 \pm 0.28 \mu \mathrm{m}$, thin: N4-2 CTL, $0.92 \pm 0.19 \mu \mathrm{m} ; N 4-2 \mathrm{KO}, 1.19 \pm$ $0.24 \mu \mathrm{m}$, mushroom: N4-2 CTL, $0.80 \pm 0.16 \mu \mathrm{m} ; \mathrm{N} 4-2 \mathrm{KO}, 1.00 \pm 0.26 \mu \mathrm{m}$ ). ${ }^{*} p<0.05,{ }^{* * *} p<0.001$, unpaired t-test. (E) Head diameter measurement in control and N4-2 KO neurons (thin: N4-2 CTL $0.35 \pm 0.07 \mu \mathrm{m}$; N4-2 KO, $0.43 \pm 0.09 \mu \mathrm{m}) .{ }^{*} p<0.05$, unpaired t-test. $(F)$ Fraction of total spines showing significant decrease in mushroom spines, and increase in bifurcated spines (mushroom: N4-2 CTL $0.20 \pm 0.06$; N4-2 KO $0.11 \pm 0.06$, bifurcated: N4-2 CTL $0.03 \pm 0.03$; N4-2 KO $0.07 \pm 0.04$ ). Two way ANOVA with Bonferroni multiple comparisons test; ${ }^{*} p<0.05$. Bars represent averages \pm S.D. C, N4-2 CTL $N=2$ animals, $n=11$ cells, $n=288$ spines; $\mathrm{N} 4-2 \mathrm{KO}, \mathrm{N}=2$ animals, $\mathrm{n}=12$ cells, $\mathrm{n}=315$ spines (Ambrozkiewicz, 2015, $\mathrm{PhD}$ thesis). 
A
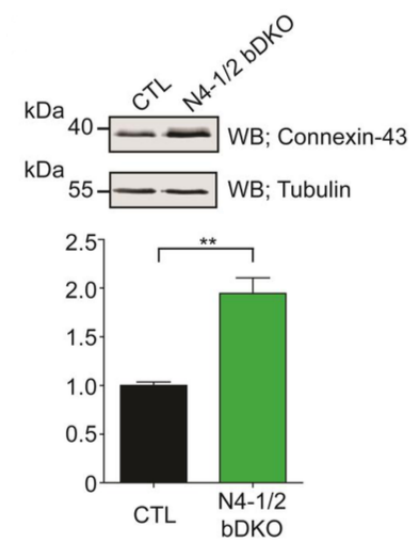

C
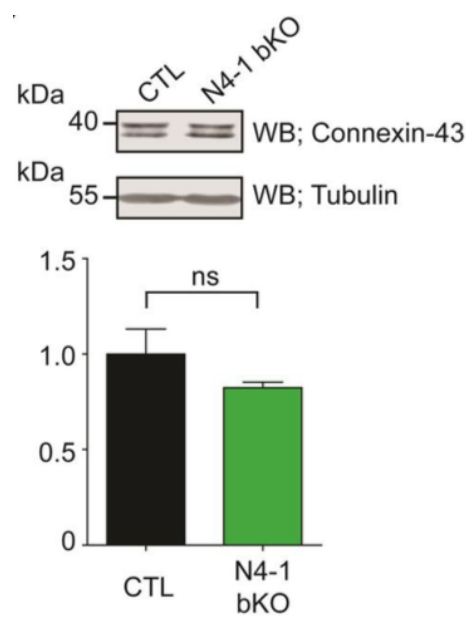

B
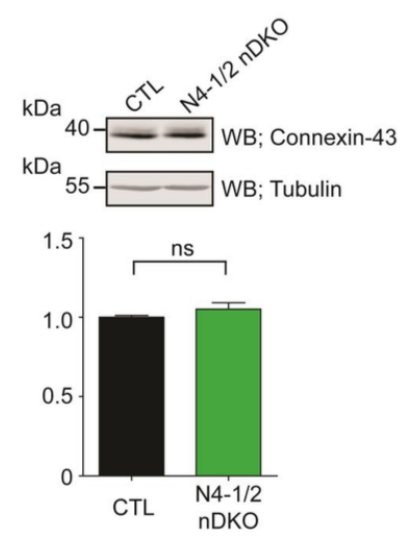

D

Figure 5.4. Cnx-43 levels in N4-1 and N4-2 conditional KO mouse lines.

(A) Protein levels of Cnx-43 in cortical brain lysates from 6 weeks old N4-1/2 CTL (Emx1 WT) and N4-1/2 bDKO (Emx1 Cre) animals. Cnx-43 level was normalized to tubulin level. Cnx-43 protein showed a significant increase in N4-1/2 bDKO (A) N4-1/2 bCTL, $1.00 \pm 0.035, \mathrm{~N}=3$; N4-1/2 bDKO, $1.95 \pm$ $0.16 \mathrm{~N}=3 ; \mathrm{p}=0.0044$ (B) Unchanged $\mathrm{Cnx}-43$ protein levels in N4-1/2 CTL (Nex WT) and N4-1/2 nDKO cortical homogenates (N4-1/2 nCTL $1.00 \pm$ 0.012, N=3; N4-1/2 nDKO, $1.051 \pm 0.040, N=3 ; p=0.2927$ ). (C) Cnx-43 levels in N4-1 CTL (Emx1 WT) and N4-1 bKO (Emx1 Cre) cortical homogenates (N4-1 bCTL, $1.00 \pm 0.13, \mathrm{~N}=4$; N4-1 bKO, $0.82 \pm 0.029, \mathrm{~N}=4$; $\mathrm{p}=0.2382)$. (D) Cnx-43 levels in N4-2 CTL $(E m \times 1 \mathrm{WT})$ and N4-2 bKO (Emx1 Cre) cortical homogenates (N4-2 bCTL $1.00 \pm 0.13, \mathrm{~N}=3$; N4-2 bKO, 
$1.55 \pm 0.068, N=3 ; p=0.0193$ ). Represented as mean \pm SEM. (Modified from Altas, 2016, PhD thesis).
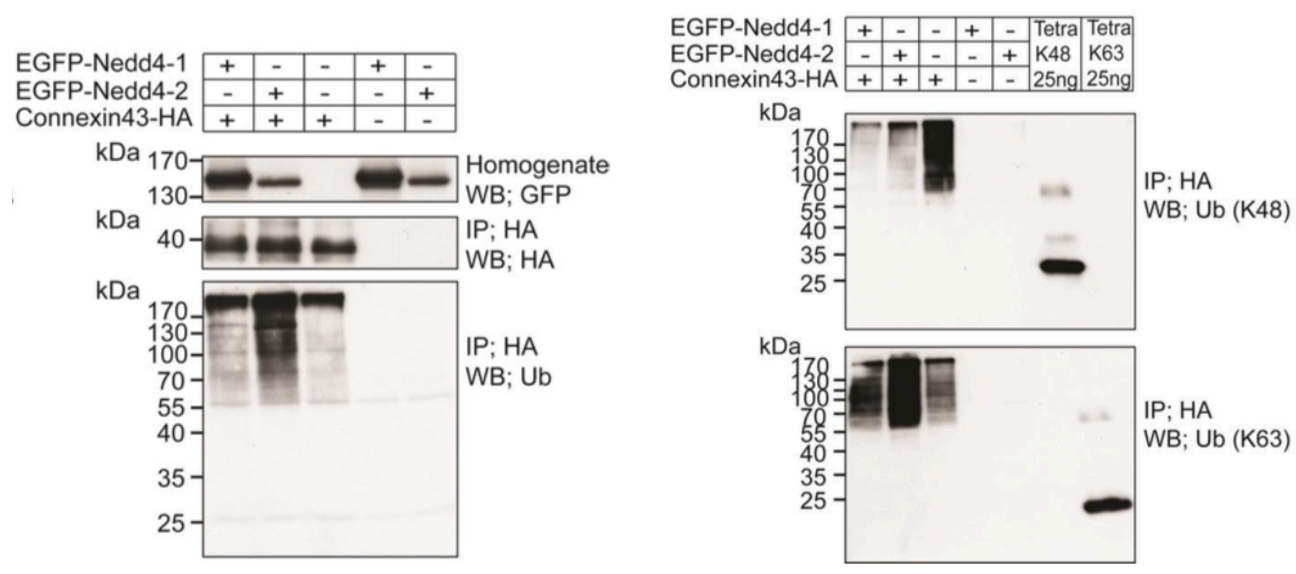

Figure 5.5. In vivo ubiquitination assay for Cnx-43 and Nedd4 E3s. Cterminally HA-tagged Connexin-43 (Connexin-43-HA or Cnx-43-HA) was expressed in HEK293FT cells in the presence or absence of EGFP-N4-1 or -N4-2. Immunoprecipitates were subjected to Western blotting using anti-HA (second panel) or anti-Ub antibody (third panel). Samples were blotted with anti-K48-linked polyUb (K48; fourth panel) or anti-K63-linked polyUb (K63; fifth panel) antibodies. Note the comparable signals from K48-linked (arrowhead) and K63-linked tetra-Ub (arrow) in fourth and fifth panels. 


\section{REFERENCES}

Akutsu, M., Dikic, I., \& Bremm, A. (2016). Ubiquitin chain diversity at a glance. Journal of Cell Science, 129(5), 875-880.

Alberts, B., Johnson, A., Lewis, J., Raff, M., Roberts, K., \& Walter, P. (2002). Molecular Biology of the Cell. Garland Science.

Altas, B. (2016). Roles of the Nedd4 Family E3 Ligases in Glial Function and Nerve Cell Development.

Ambrozkiewicz, M. (2015). HECT-type Ubiquitin Ligases in Nerve Cell Development.

Anan, T., Nagata, Y., Koga, H., Honda, Y., Yabuki, N., Miyamoto, C., Kuwano, A., Matsudo, I., Endo, F., Saya, H., \& Nakao, M. (1998). Human ubiquitin-protein ligase Nedd4: expression, subcellular localization and selective interaction with ubiquitin-conjugating enzymes. Genes to Cells, 3, 751-763.

Anindya, R., Aygun, O., \& Svejstrup, J. Q. (2007). Damage-induced ubiquitylation of human RNA polymerase II by the ubiquitin ligase Nedd4, but not Cockayne syndrome proteins or BRCA1. Molecular Cell, 28(3), 386-397.

Araya, R., Vogels, T. P., \& Yuste, R. (2014). Activity-dependent dendritic spine neck changes are correlated with synaptic strength. PNAS, 111(28), E2895-2934.

Arimura, N., \& Kaibuchi, K. (2007). Neuronal polarity: from extracellular signals to intracellular mechanisms. Nature Reviews Neuroscience, 8(3), 194-205.

Bach, I., \& Ostendorff, H. P. (2003). Orchestrating nuclear functions: Ubiquitin sets the rhythm. Trends in Biochemical Sciences, 28(4), 189195.

Bakkers, J., Camacho-Carvajal, M., Nowak, M., Kramer, C., Danger, B., \& Hammerschmidt, M. (2005). Destabilization of $\Delta \mathrm{Np63a}$ by Nedd4mediated ubiquitination and Ubc9-mediated sumoylation, and its implications on dorsoventral patterning of the zebrafish embryo. Cell Cycle, 4(6), 790-800.

Bannerman, D. M., Good, M. A., Butcher, S. P., Ramsay, M., \& Morris, R. G. 
M. (1995). Distinct components of spatial learning revealed by prior training and NMDA receptor blockade. Nature Letters, 378, 182-186.

Bird, C. M., \& Burgess, N. (2008). The hippocampus and memory: Insights from spatial processing. Nature Reviews Neuroscience, 9(3), 182-194. Bliss, T. V. P., Collingridge, G. L., Morris, R. G. M., \& Reymann, K. G. (2018). Long-term potentiation in the hippocampus: discovery, mechanisms and function. Neuroforum, 24(3), A103-A120.

Boase, N. A., Rychkov, G. Y., Townley, S. L., Dinudom, A., Candi, E., Voss, A. K., Tsoutsman, T., Semsarian, C., Melino, G., Koenten, F., Cook, D. I., \& Kumar, S. (2011). in Nedd4-2-deficient mice. Nature Communications, 2, 287-289.

Broix, L., Jagline, H., L Ivanova, E., Schmucker, S., Drouot, N., ClaytonSmith, J., Pagnamenta, A. T., Metcalfe, K. A., Isidor, B., Louvier, U. W., Poduri, A., Taylor, J. C., Tilly, P., Poirier, K., Saillour, Y., Lebrun, N., Stemmelen, T., Rudolf, G., Muraca, G., Saintpierre, B., Elmorjani, A., Deciphering Developmental Disorders study, Moïse, M., Weirauch, N. B., Guerrini, R., Boland, A., Olaso, R., Masson, C., Tripathy, R., Keays, D., Beldjord, C., Nguyen, L., Godin, J., Kini, U., Nischké, P., Deleuze, J. F., Bahi-Buisson, N., Sumara, I., Hinckelmann, M. V., \& Chelly, J. (2016). Mutations in the HECT domain of NEDD4L lead to AKT-mTOR pathway deregulation and cause periventricular nodular heterotopia. Nature Genetics, 48(11), 1349-1358.

Brose, N. (1999). Synaptic Cell Adhesion Proteins and Synaptogenesis in the Mammalian Central Nervous System. Naturwissenschaften, 86(11), 516-525.

Cao, X. R., Lill, N. L., Boase, N., Shi, P. P., Croucher, D. R., Shan, H., Qu, J., Sweezer, E. M., Place, T., Kirby, P. A., Daly, R. J., Kumar, S., \& Yang, B. (2008). Nedd4 controls animal growth by regulating IGF-1 signaling. Science Signaling, 1(38), 1-11.

Chen, Z. J. (2005). Ubiquitin signalling in the NF-kB pathway. Nature Cell Biology, 7(8), 758-765.

Chong, P. A., Lin, H., Wrana, J. L., \& Forman-Kay, J. D. (2010). Coupling of tandem Smad ubiquitination regulatory factor (Smurf) WW domains modulates target specificity. Proceedings of the National Academy of 
Sciences, 107(43), 18404-18409.

Citri, A., \& Malenka, R. C. (2008). Synaptic plasticity: Multiple forms, functions, and mechanisms. Neuropsychopharmacology, 33(1), 18-41. Comery, T. A., Harris, J. B., Willems, P. J., Oostra, B. A., Irwin, S. A., J, W. I., \& Greenough. (1997). Abnormal dendritic spines in fragile $X$ knockout mice: Maturation and pruning deficits. PNAS, 94(5), 54015404.

Dal Maschio, M., Ghezzi, D., Bony, G., Alabastri, A., Deidda, G., Brondi, M., Sato, S. S., Zaccario, R. P., Di Fabrizio, E., Ratto, C. M., \& Cancedda, L. (2012). High-performance and site-directed in utero electroporation by a triple-electrode probe. Nature Communications, 3, 911-960.

Dalton, H. E., Denton, D., Foot, N. J., Ho, K., Mills, K., Brou, C., \& Kumar, S. (2011). Drosophila Ndfip is a novel regulator of Notch signaling. Cell Death and Differentiation, 18(7), 1150-1160.

Deng, W., Aimone, J. B., \& Gage, F. H. (2010). New neurons and new memories: how does adult hippocampal neurogenesis affect learning and memory?, 11(5), 339-350.

Dere, E. (2012). Gap Junctions in the Brain: Physiological and Pathological Roles. Elsevier.

Dere, E., Dahm, L., Lu, D., Hammerschmidt, K., Ju, A., Tantra, M., Kästner, Chowdhury, K., A., \& Ehrenreich, H. (2014). Heterozygous Ambra1 Deficiency in Mice: A Genetic Trait with Autism-Like Behavior Restricted to the Female Gender. Frontiers in Behavioral Neuroscience, 8(5), 1-19.

Dere, E., Ronnenberg, A., Tampe, B., Arinrad, S., Schmidt, M., Zeisberg, E., \& Ehrenreich, H. (2018). Cognitive, emotional and social phenotyping of mice in an observer-independent setting. Neurobiology of Learning and Memory, 150 (9), 136-150.

Dibbens, L. M., Ekberg, J., Taylor, I., Hodgson, B. L., Conroy, S. J., Lensink, I. L., Kumar, S., Zielinski, M. A., Harkin, L. A., Sutherland, G. R., Adams, D. J., Berkovic, S. F., Scheffer, I. E., Mulley, J. C., \& Poronnik, P. (2007). NEDD4-2 as a potential candidate susceptibility gene for epileptic photosensitivity. Genes, Brain and Behavior, 6(8), 750-755.

Donovan, P., \& Poronnik, P. (2013). Nedd4 and Nedd4-2: Ubiquitin ligases 
at work in the neuron. International Journal of Biochemistry and Cell Biology, 45(3), 706-710.

Ekberg, J., Schuetz, F., Boase, N. A., Conroy, S. J., Manning, J., Kumar, S., Poronnik, P., \& Adams, D. J. (2007). Regulation of the voltage-gated $\mathrm{K}+$ channels $\mathrm{KCNQ} 2 / 3$ and $\mathrm{KCNQ3/5}$ by ubiquitination: Novel role for Nedd4-2. Journal of Biological Chemistry, 282(16), 12135-12142.

Erpapazoglou, Z., Walker, O., \& Haguenauer-Tsapis, R. (2014). Versatile Roles of K63-Linked Ubiquitin Chains in Trafficking. Cells, 3(4), 10271088.

Fiala, J. C., Spacek, J., \& Harris, K. M. (2002). Dendritic Spine Pathology:

Cause or Consequence of Neurological Disorders? Brain Research Reviews, 39, 29-54.

Fischer, A., Sananbenesi, F., Pang, P. T., Lu, B., \& Tsai, L. H. (2005). Opposing roles of transient and prolonged expression of p25 in synaptic plasticity and hippocampus-dependent memory. Neuron, 48(5), 825838.

Fotia, A. B., Dinudom, A., Shearwin, K. E., Koch, J. P., Korbmacher, C., Cook, D. I., \& Kumar, S. (2003). The role of individual Nedd4-2 (KIAA0439) WW domains in binding and regulating epithelial sodium channels. The FASEB Journal: Official Publication of the Federation of American Societies for Experimental Biology, 17(1), 70-72.

Frotscher, M. (1998). Cajal-Retrius cells, Reelin, and the formation of layers. Current Opinion in Neurobiology, 8(5), 570-575.

Galan, J. M., \& Haguenauer-Tsapis, R. (1997). Ubiquitin Lys63 is involved in ubiquitination and endocytosis of a yeast plasma membrane protein. Embo J., 16(19), 5847-5854.

Gao, J., Marosi, M., Choi, J., Achiro, J. M., Kim, S., Li, S., Otis, K., Martin, K. J., Portera-Cailliou, C., \& Tontonoz, P. (2017). The E3 ubiquitin ligase IDOL regulates synaptic ApoER2 levels and is important for plasticity and learning. ELife, 6, 1-24.

García-Tardón, N., González-González, I. M., Martínez-Villarreal, J., Fernández-Sánchez, E., Giménez, C., \& Zafra, F. (2012). Protein kinase C (PKC)-promoted endocytosis of glutamate transporter GLT-1 requires ubiquitin ligase Nedd4-2-dependent ubiquitination but not 
phosphorylation. Journal of Biological Chemistry, 287(23), 1917719187.

Garner, C. C., Zhai, R. G., Gundelfinger, E. D., \& Ziv, N. E. (2002). Molecular mechanisms of CNS synaptogenesis. Trends in Neurosciences, 25(5), 243-250.

Gebert, L. F. R., \& Macrae, I. J. (2019). Regulation of microRNA function in animals. Nature Reviews Molecular Cell Biology, 20(1), 21-37.

George, A. J., Hoffiz, Y. C., Charles, A. J., Zhu, Y., \& Mabb, A. M. (2018). A comprehensive atlas of E3 ubiquitin ligase mutations in neurological disorders. Frontiers in Genetics, 9(2), 1-17. https://doi.org/10.3389/fgene.2018.00029

Girão, H., Catarino, S., \& Pereira, P. (2009). Eps15 interacts with ubiquitinated $\mathrm{C} \times 43$ and mediates its internalization. Experimental Cell Research, 315(20), 3587-3597.

Goebbels, S., Bormuth, I., Bode, U., Hermanson, O., Schwab, M. H., \& Nave, K.-A. (2006). Genetic Targeting of Principal Neurons in Neocortex and Hippocampus of NEX-Cre Mice. Genesis, 44, 611-621.

Götz, M., \& Huttner, W. B. (2005). The Cell Biology of Neurogenesis, 6(10), $777-788$.

Harris, M., \& Stevens, J. K. (1989). Dendritic Spines of CA1 Pyramidal Cells in the Rat Hippocampus: Serial Electron Microscopy with Reference to Their Biophysical Characteristics, (8), 2982-2997.

Harvey, K. F., Dinudom, A., Cook, D. I., \& Kumar, S. (2001). The Nedd4-like Protein KIAA0439 is a Potential Regulator of the Epithelial Sodium Channel. Journal of Biological Chemistry, 276(11), 8597-8601.

Hawasli, A. H., Benavides, D. R., Nguyen, C., Kansy, J. W., Hayashi, K., Chambon, P., Greengard, P., Powell, C. M., Cooper, D. J., \& Bibb, J. A. (2007). Cyclin-dependent kinase 5 governs learning and synaptic plasticity via control of NMDAR degradation. Nature Neuroscience, 10(7), 880-886.

Hayashi, K., Ishikawa, R., Ye, L. H., He, X. L., Takata, K., Kohama, K., \& Shirao, T. (1996). Modulatory role of drebrin on the cytoskeleton within dendritic spines in the rat cerebral cortex. The Journal of Neuroscience: The Official Journal of the Society for Neuroscience, 
16(22), 7161-70.

Hell, J. W. (2014). CaMKII: Claiming Center Stage in Postsynaptic Function and Organization. Neuron, 1542(9), 33-36.

Hering, H., \& Sheng, M. (2001). DENDRITIC SPINES: STRUCTURE , DYNAMICS AND REGULATION. Nature Reviews Neuroscience, 2(12), 880-888.

Hershko, A., \& Ciechanover, A. (1998). THE UBIQUITIN SYSTEM. Annual Review of Biochemistry, 67, 425-79.

Honda, T., Kobayashi, K., Mikoshiba, K., \& Kazunori, N. (2011). Regulation

of Cortical Neuron Migration by the Reelin Signaling Pathway. Neurochemistry Research, 36(7), 1270-1279.

Hrdinka, M., Sudan, K., Just, S., Drobek, A., Stepanek, O., Schlüter, D., Reinhold, D., Jordan, B. A., Gintschel, P., Schraven, B., \& Kreutz, M. R. (2016). Normal development and function of T cells in proline rich 7 (Prr7) deficient mice. PLoS ONE, 11(9), 1-15.

Hsia, H.-E., Kumar, R., Luca, R., Takeda, M., Courchet, J., Nakashima, J., Wu, S., Goebels, S., An, W., Eickholt, B. J., Polleux, F., Rotin, D., Wu, H., Rossner, M. J., Bagni, C., Rhee, J. S., Brose, N., \& Kawabe, H. (2014). Ubiquitin E3 ligase Nedd4-1 acts as a downstream target of PI3K/PTEN-mTORC1 signaling to promote neurite growth. Proceedings of the National Academy of Sciences, 111(36), 13205-13210.

Huysse, J. W. Van, Amin, S., Yang, B., \& Leenen, F. H. H. (2012). SaltInduced Hypertension in a Mouse Model of Liddle Syndrome Is Mediated by Epithelial Sodium Channels in the Brain. Hypertension, 60, 691-696. https://doi.org/10.1161/HYPERTENSIONAHA.112.193045 Janova, H., Arinrad, S., Balmuth, E., Mitjans, M., Hertel, J., Habes, M. H., Bittner, R. A., Pan, H., Goebbels, S., Begemann, M., Gerwig, U. C., Langner, S., Werner, H. B., Kittel-Schneider, S., Homuth, G., Davatzikos, C., Völzke, H., West, B. L., Reif, A., Grabe, J., Boretius, S., Ehrenreich, H., \& Nave, K. A. (2017). Microglia ablation alleviates myelin-associated catatonic signs in mice. Journal of Clinical Investigation, 128(2), 734-745.

Jeon, D., Song, I., Guido, W., Kim, K., Kim, E., Oh, U., \& Shin, H. S. (2008). Ablation of $\mathrm{Ca} 2+$ channel $\beta 3$ subunit leads to enhanced N-methyl-D- 
aspartate receptor-dependent long term potentiation and improved long term memory. Journal of Biological Chemistry, 283(18), 12093-12101. Jespersen, T., Membrez, M., Nicolas, C. S., Pitard, B., Staub, O., Olesen, S. P., Baró, I., \& Abriel, H. (2007). The KCNQ1 potassium channel is down-regulated by ubiquitylating enzymes of the Nedd4/Nedd4-like family. Cardiovascular Research, 74(1), 64-74.

Jiang, Y. hui, Armstrong, D., Albrecht, U., Atkins, C. M., Noebels, J. L., Eichele, G., Sweatt, J. D., \& Beaudet, A. L. (1998). Mutation of the Angelman ubiquitin ligase in mice causes increased cytoplasmic p53 and deficits of contextual learning and long-term potentiation. Neuron, 21(4), 799-811.

Kamynina, E., Debonneville, C., Bens, M., Vandewalle, A., \& Staub, O. (2002). A novel mouse Nedd4 protein suppresses the activity of the epithelial $\mathrm{Na}+$ channel. The FASEB Journal, 15(1), 204-214.

Kandel, E. R., Schwartz, T. M., \& M, J. T. (2000). Principles of Neural Science. McGraw-Hill.

Kane, L. A., Lazarou, M., Fogel, A. I., Li, Y., Yamano, K., Sarraf, S. A., Banerjee, S., \& Youle, R. J. (2014). PINK1 phosphorylates ubiquitin to activate parkin E3 ubiquitin ligase activity. Journal of Cell Biology, 205(2), 143-153.

Kanelis, V., Rotin, D., \& Forman-kay, J. D. (2001). ISolution structure of a Nedd4 WW domain - ENaC peptide complex. Nature Structural Biology, 8(5), 407-412.

Kato, S., Funakoshi, H., Nakamura, T., Kato, M., Nakano, I., Hirano, A., \& Ohama, E. (2003). Expression of hepatocyte growth factor and c-Met in the anterior horn cells of the spinal cord in the patients with amyotrophic lateral sclerosis (ALS): Immunohistochemical studies on sporadic ALS and familial ALS with superoxide dismutase 1 gene mutation. Acta Neuropathologica, 106(2), 112-120.

Kawabe, H., \& Brose, N. (2011). The role of ubiquitylation in nerve cell development. Nature Reviews Neuroscience, 12(5), 251-268.

Kawabe, H., Neeb, A., Dimova, K., Young, S. M., Takeda, M., Katsurabayashi, S., Mitkovski, M., Malakhova, O. A., Zhang, D., Umikawa, M., Kariya, K., Goebels, S., Nave, K. A., Rosenmund, C., 
Jahn, O., Rhee, J. S., \& Brose, N. (2010). Regulation of Rap2A by the Ubiquitin Ligase Nedd4-1 Controls Neurite Development. Neuron, 65(3), 358-372.

Kazlauskaite, A., Kondapalli, C., Gourlay, R., Campbell, D. G., Ritorto, M. S., Hofmann, K., Alessi, D. R., Knebel, A., Trost, M., \& Muqit, M. M. K. (2014). Parkin is activated by PINK1-dependent phosphorylation of ubiquitin at Ser ${ }^{65}$. Biochemical Journal, 460(1), 127-141.

Khoutorsky, A., Yanagiya, A., Gkogkas, C. G., Fabian, M. R., Pragerkhoutorsky, M., Cao, R., Gamache, Bouthiette, F., Parsyan, A., Sorge, R. E., Mogil, J. S., Nader, K., Lacaille, J., \& Sonenberg, N. (2010). Article Control of Synaptic Plasticity and Memory via Suppression of Poly ( A ) -Binding Protein. Neuron, 78(2), 298-311.

Kim, E., \& Sheng, M. (2004). PDZ domain proteins of synapses. Nature Reviews Neuroscience, 5(10), 771-781.

Kimura, T., Kawabe, H., Jiang, C., Zhang, W., Xiang, Y.-Y., Lu, C., Salter, M. W., Brose, N., Lu, W., \& Rotin, D. (2011). Deletion of the ubiquitin ligase Nedd4L in lung epithelia causes cystic fibrosis-like disease. Proceedings of the National Academy of Sciences, 108(8), 3216-3221. Komander, D. (2009). The emerging complexity of protein ubiquitination. Biochemical Society Transactions, 37(5), 937-953.

Komander, D., \& Rape, M. (2012). The Ubiquitin Code. Annual Review of Biochemistry, 81(1), 203-229.

Koyano, F., Okatsu, K., Kosako, H., Tamura, Y., Go, E., Kimura, M., Tsuchiya, H., Yoshihara, H., Hirokawa, T., Endo, T., Fon, E. A., Trempe, J., Saeki, Y., Tanaka, K., \& Matsuda, N. (2014). Ubiquitin is phosphorylated by PINK1 to activate parkin. Nature, 510(7503), 162166.

Kravchick, D. O., Karpova, A., Hrdinka, M., Lopez-Rojas, J., lacobas, S., Carbonell, A. U., lacobas, D. A., Kreutz, M. R., \& Jordan, B. A. (2016). Synaptonuclear messenger PRR7 inhibits c-Jun ubiquitination and regulates NMDA-mediated excitotoxicity. The EMBO Journal, 35(17), 1923-1934.

Kuczera, T., Stilling, R. M., Hsia, H. E., Bahari-Javan, S., Irniger, S., 
Nasmyth, K., Sananbenesi, F., \& Fischer, A. (2011). The anaphase promoting complex is required for memory function in mice. Learning and Memory, 18(1), 49-57.

Kumar, S., Harvey, K. F., Kinoshita, M., Copeland, N. G., Noda, M., \& Jenkins, N. A. (1997). cDNA Cloning, Expression Analysis, and Mapping of the MouseNedd4Gene. Genomics, 40(3), 435-443.

Kumar, S., Tomooka, Y., \& Noda, M. (1992). IDENTIFICATION OF A SET OF GENES WITH DEVELOPMENTALLY DOWN-REGULATED EXPRESSION IN THE MOUSE BRAIN Sharad. Biochemical and Biophysical Research Communications, 185(3), 1155-1161.

Lackinger, M., Sungur, A. Ö., Daswani, R., Soutschek, M., Bicker, S., Stemmler, L., Wüst, T., Fiore, R., Dieterich, C., Schwarting, R. K. W., Wöhr, M., \& Schratt, G. (2019). A placental mammal-specific microRNA cluster acts as a natural brake for sociability in mice, 1-11.

Lackovic, J., Howitt, J., Callaway, J. K., Silke, J., Bartlett, P., \& Tan, S. S. (2012). Differential regulation of Nedd4 ubiquitin ligases and their adaptor protein Ndfip1 in a rat model of ischemic stroke. Experimental Neurology, 235(1), 326-335.

Laemelli, U. K. (1970). Cleavage of Structural Proteins during the Assembly of the Head of Bacteriophage T4. Nature, 227(5259), 680-685.

Lee, S. H., Shin, S. M., Zhong, P., Kim, H., Kim, D., Kim, J. M., Heo, W. D., Kim, D., Yeo, C., Kim, C., \& Liu, Q. (2018). by Wnt and Wnt inhibitor PRR7 secreted on. Nature Communications, 9(3434), 1-15.

Lee, Y. S. (2014). Genes and signaling pathways involved in memory enhancement in mutant mice. Molecular Brain, 7(1), 1-14.

Lemus, L., \& Goder, V. (2014). Regulation of Endoplasmic ReticulumAssociated Protein Degradation (ERAD) by Ubiquitin. Cells, 3(3), 824847.

Leva, G. Di, Garofalo, M., \& Croce, C. M. (2014). MicroRNAs in Cancer, 9:287-314.

Leykauf, K., Salek, M., Bomke, J., Frech, M., Lehmann, W.-D., Dürst, M., \& Alonso, A. (2006). Ubiquitin protein ligase Nedd4 binds to connexin43 by a phosphorylation-modulated process. Journal of Cell Science, 119(17), 3634-3642. 
Lin, A., Hou, Q., Jarzylo, L., Amato, S., Gilbert, J., Shang, F., \& Man, H. Y. (2011). Nedd4-mediated AMPA receptor ubiquitination regulates receptor turnover and trafficking. Journal of Neurochemistry, 119(1), 27-39.

Lip, P. Z. Y., Demasi, M., \& Bonatto, D. (2017). The role of the ubiquitin proteasome system in the memory process. Neurochemistry International, 102, 57-65.

Livak, K. J., \& Schmittgen, T. D. (2001). Analysis of relative gene expression data using real-time quantitative $\mathrm{PCR}$ and the 2- $\Delta \triangle \mathrm{CT}$ method. Methods, 25(4), 402-408.

Lynch, M. A. (2004). Long-Term Potentiation and Memory. Physiological Reviews, 84(1), 87-136.

Maekawa, M., Watanabe, M., Yamaguchi, S., Konno, R., \& Hori, Y. (2005). Spatial learning and long-term potentiation of mutant mice lacking Damino-acid oxidase. Neuroscience Research, 53(1), 34-38.

Mamiya, T., Yamada, K., Miyamoto, Y., König, N., Watanabe, Y., Noda, Y., \& Nabeshima, T. (2003). Neuronal mechanism of nociceptin-induced modulation of learning and memory: Involvement of N-methyl-Daspartate receptors. Molecular Psychiatry, 8(8), 752-765.

Maspero, E., Valentini, E., Mari, S., Cecatiello, V., Soffientini, P., Pasqualato, S., \& Polo, S. (2013). Structure of a ubiquitin-loaded HECT ligase reveals the molecular basis for catalytic priming. Nature Structural and Molecular Biology, 20(6), 696-701.

Matsui, A., Yoshida, A. C., Kubota, M., Ogawa, M., \& Shimogori, T. (2011). Mouse in Utero Electroporation: Controlled Spatiotemporal Gene Transfection. Journal of Visualized Experiments, (54), 1-6.

Mattiroli, F., Vissers, J. H. A., Van Dijk, W. J., Ikpa, P., Citterio, E., Vermeulen, W., Martejin, J. A., \& Sixma, T. K. (2012). RNF168 ubiquitinates $\mathrm{K} 13-15$ on $\mathrm{H} 2 \mathrm{~A} / \mathrm{H} 2 \mathrm{AX}$ to drive DNA damage signaling. Cell, 150(6), 1182-

Mizoguchi, A., Ueda, T., Ikeda, K., Shiku, H., Mizoguti, H., \& Takai, Y. (1989). Localization and subcellular distribution of cellular ras gene products in rat brain. Brain Research. Molecular Brain Research, 5(1), $31-44$. 
Morris, R. (1984). Developments of a water-maze procedure for studying spatial learning in the rat. Journal of Neuroscience Methods, 11, 47-60.

Nakamura, Y., Yamamoto, K., He, X., Otsuki, B., Kim, Y., Murao, H., Soeda, T., Tsumaki, N., Deng, J. M., Zhang, Z., Behringer, R. R., de Crombrugghe, B., Postlethwait, J. H., Warman, M. L., Nakamura, T., \& Akiyama, H. (2011). Wwp2 is essential for palatogenesis mediated by the interaction between Sox9 and mediator subunit 25. Nature Communications, 2, 251.

Nakase, T., Fushiki, S., \& Naus, C. C. G. (2003). Astrocytic gap junctions composed of connexin 43 reduce apoptotic neuronal damage in cerebral ischemia. Stroke, 34(8), 1987-1993.

Nakase, T., So, G., Theis, M., Willecke, K., \& Naus, C. C. G. (2004). Increased Apoptosis and Inflammation after Focal Brain Ischemia in Mice Lacking Connexin43 in Astrocytes. American Journal of Pathology, 164(6), 2067-2075.

Netrakanti, P. R., Cooper, B. H., Dere, E., Poggi, G., Winkler, D., Brose, N., \& Ehrenreich, H. (2015). Fast Cerebellar Reflex Circuitry Requires Synaptic Vesicle Priming by Munc13-3. Cerebellum, 14(3), 264-283.

Neves, G., Cooke, S. F., \& Bliss, T. V. P. (2008). Synaptic plasticity, memory and the hippocampus: A neural network approach to causality. Nature Reviews Neuroscience, 9(1), 65-75.

Noguchi, J., Matsuzaki, M., Ellis-davies, G. C. R., \& Kasai, H. (2005). SpineNeck Geometry Determines NMDA Receptor-Dependent Ca $2+$ Signaling in Dendrites. Neuron, 46, 609-622.

Ohtake, F., Saeki, Y., Sakamoto, K., Ohtake, K., Nishikawa, H., Tsuchiya, H., Ohta, T., Tanaka, K., \& Kanno, J. (2015). Ubiquitin acetylation inhibits polyubiquitin chain elongation. EMBO Reports, 16(2), 192-201.

Ordureau, A., Sarraf, S. A., Duda, D. M., Heo, J. M., Jedrychowski, M. P., Sviderskiy, V. O., Olszewski, J. L., Koerber, J. T., Xie, T., Beausoleil, S. A., Wells, \& J. A., Gygi, S. P., Schulman, B. A., \& Harper, J. W. (2014). Quantitative proteomics reveal a feedforward mechanism for mitochondrial PARKIN translocation and ubiquitin chain synthesis. Molecular Cell, 56(3), 360-

Paoletti, P., Bellone, C., \& Zhou, Q. (2013). NMDA receptor subunit 
diversity: Impact on receptor properties, synaptic plasticity and disease. Nature Reviews Neuroscience, 14(6), 383-400.

Park, J., Chavez, A. E., Mineur, Y. S., Morimoto-tomita, M., Lutzu, S., Kim, K. S., Picciotto, M. R., Castillo, P. E \& Susumu, T.. (2016). CaMKII phosphorylation of TARPY-8 is a mediator of LTP and learning and memory. Neuron, 92(1), 75-83.

Persaud, A., Alberts, P., Hayes, M., Guettler, S., Clarke, I., Sicheri, F., Dirks, P., Ciruna, B., \& Rotin, D. (2011). Nedd4-1 binds and ubiquitylates activated FGFR1 to control its endocytosis and function. EMBO Journal, 30(16), 3259-3273.

Pick, J. E., Malumbres, M., \& Klann, E. (2013). The E3 ligase APC / C Cdh1 is required for associative fear memory and long-term potentiation in the amygdala of adult mice. Learning and Memory, 20(1), 11-20.

Piper, R. C., Dikic, I., \& Lukacs, G. L. (2016). Ubiquitin-dependent sorting in endocytosis . PubMed Commons. Cold Spring Harbor Perspectives in Biology, 6(1), 24384571.

Plattner, F., Hernandéz, A., Kistler, T. M., Pozo, K., Zhong, P., Yuen, E. Y., Tan, C., Hawasli, A. H., Cooke, S. F., Nishi, A., Guo, A., Wiederhold, T., Yan, Z., \& Bibb, J. A. (2014). Memory Enhancement by Targeting Cdk5 Regulation of NR2B. Neuron, 81(5), 1070-1083.

Pradervand, S., Vandewalle, A., Bens, M., Gautschi, I., Loffing, J., Hummler, E., Schild, L., \& Rossier, B. C. (2003). Dysfunction of the epithelial sodium channel expressed in the kidney of a mouse model for Liddle syndrome. Journal of the American Society of Nephrology, 14(9), 22192228.

Pradervand, S., Wang, Q., Burnier, M., Beermann, F., Horisberger, J. D., Hummler, E., \& Rossier, B. C. (1999). A mouse model for Liddle's syndrome. Journal of the American Society of Nephrology: JASN, 10(12), 2527-33.

Puram, S. V, \& Bonni, A. (2013). Cell-intrinsic drivers of dendrite morphogenesis. Development, 140, 4657-4671.

Rape, M. (2018). Post-Translational Modifications: Ubiquitylation at the crossroads of development and disease. Nature Reviews Molecular Cell Biology, 19(1), 59-70. 
Ross, P. L., Huang, Y. N., Marchese, J. N., Williamson, B., Parker, K., Hattan, S., Khainovski, N., Pillai, S., Dey, S., Daniels, S., Purkayastha, S., Juhasz, P., Bartlet-Jones, M., He, F., Jacobson, A., \& Pappin, D. J. (2004). Multiplexed protein quantitation in Saccharomyces cerevisiae using amine-reactive isobaric tagging reagents. Molecular \& Cellular Proteomics : MCP, 3(12), 1154-1169.

Rossi, M., De Laurenzi, V., Munarriz, E., Green, D. R., Liu, Y.-C., Vousden, K. H., Cesareni, G., \& Melino, G. (2005). The ubiquitin-protein ligase Itch regulates p73 stability. The EMBO Journal, 24(4), 836-848.

Rossier, B. C., \& Schild, L. (2008). Epithelial sodium channel: Mendelian versus essential hypertension. Hypertension, 52(4), 595-600.

Rotin, D., \& Kumar, S. (2009). Physiological functions of the HECT family of ubiquitin ligases, 10(5), 398-409.

Rougier, J.-S., Bemmelen, M. X. Van, Bruce, M. C., Jespersen, T., Gavillet, B., Apothéloz, F., Cordonier, S., Staub, O., Rotin, D., \& Abriel, H. (2005). Molecular determinants of voltage-gated sodium channel regulation by the Nedd4 / Nedd4-like proteins. Am J Physiol Cell Physiol, 208, 692-701.

Rougier, J. S., Albesa, M., Abriel, H., \& Viard, P. (2011). Neuronal precursor cell-expressed developmentally down-regulated 4-1 (NEDD4-1) controls the sorting of newly synthesized CaV1.2 calcium channels. Journal of Biological Chemistry, 286(11), 8829-8838.

Rouvroit, C. L. De, \& Goffinet, A. M. (2001). Neuronal migration. Mechanisms of Development, 105(1-2), 47-56.

Saito, T. (2006). In vivo electroporation in the embryonic mouse central nervous system. Nature Protocols, 1(3), 1552-1558.

Sakata, T., Sakaguchi, H., Tsuda, L., Higashitani, A., Aigaki, T., Matsuno, K., \& Hayashi, S. (2004). Drosophila Nedd4 Regulates Endocytosis of Notch and Suppresses Its Ligand-Independent Activation. Current Biology, 14, 2228-2236.

Sala, C., \& Segal, M. (2014). DENDRITIC SPINES: THE LOCUS OF STRUCTURAL AND FUNCTIONAL PLASTICITY METHODOLOGICAL CONSIDERATIONS. Physiological Reviews, 94, 141-188.

Sang, Q., Kim, M. H., Kumar, S., Bye, N., Morganti-Kossman, M. C., 
Gunnersen, J., Fuller, S., Howitt, J., Hyde, L., Beissbarth, T., Scott, H. S., Silke, J., \& Tan, S.-S. (2006). Nedd4-WW Domain-Binding Protein 5 (Ndfip1) Is Associated with Neuronal Survival after Acute Cortical Brain Injury. Journal of Neuroscience, 26(27), 7234-7244.

Scannevin, R. H., \& Huganir, R. L. (2000). Postsynaptic organisation and regulation of excitatory synapses. Nature Reviews Neuroscience, 1(2), $133-141$.

Schmidt, C., Hesse, D., Raabe, M., Urlaub, H., \& Jahn, O. (2013). An automated in-gel digestion/iTRAQ-labeling workflow for robust quantification of gel-separated proteins. Proteomics, 13(9), 1417-1422. Schoberleitner, I., Mutti, A., Sah, A., Wille, A., Gimeno-valiente, F., Piatti, P., Kharitonova, M., Torres, L., López-Rodas, G., Liu, J. J., Singewald, N., Schwarzer, N., \& Lusser, A. (2019). Role for Chromatin Remodeling Factor Chd1 in Learning and Memory. Frontiers in Molecular Neuroscience, 12(January), 1-13.

Shi, P. P., Cao, X. R., Sweezer, E. M., Kinney, T. S., Williams, N. R., Husted, R. F., Nair, R., Weiss, R. M., Williamson, R. A., Sigmund, C. D., Snyder, P. M., Staub, O., Stokes, J. B., \& Yang, B. (2008). Saltsensitive hypertension and cardiac hypertrophy in mice deficient in the ubiquitin ligase Nedd4-2. American Journal of Physiology Renal Physiology, 52242, 462-470.

Song, J.-Y., Ichtchenko, K., Sudhof, T. C., \& Brose, N. (2002). Neuroligin 1 is a postsynaptic cell-adhesion molecule of excitatory synapses. Proceedings of the National Academy of Sciences, 96(3), 1100-1105.

Sopjani, M., Alesutan, I., Dërmaku-Sopjani, M., Fraser, S., Kemp, B. E., Föller, M., \& Lang, F. (2010). Down-regulation of Na+-coupled glutamate transporter EAAT3 and EAAT4 by AMP-activated protein kinase. Journal of Neurochemistry, 113(6), 1426-1435.

Staub, O., Dho, S., Henry, P., Correa, J., Ishikawa, T., McGlade, J., \& Rotin, D. (1996). WW domains of Nedd4 bind to the proline-rich PY motifs in the epithelial $\mathrm{Na}+$ channel deleted in Liddle's syndrome. The EMBO Journal, 15(10), 2371-80.

Staub, O., Gautschi, I., Ishikawa, T., Breitschopf, K., Ciechanover, A., Schild, L., \& Rotin, D. (1997). Regulation of stability and function of the 
epithelial $\mathrm{Na}+$ channel $(\mathrm{ENaC})$ by ubiquitination. EMBO Journal, 16(21), Südhof, T. C., \& Malenka, R. C. (2008). Understanding Synapses: Past, Present, and Future. Neuron, 60(3), 469-476.

Summers, D. F., Maizel, J. V, \& Darnell, J. E. (1965). Evidence for virusspecific noncapsid proteins in poliovirus-infected HeLa cells. Proceedings of the National Academy of Sciences of the United States of America, 54(2), 505-13.

Swaney, D. L., Rodriguez-Mias, R. A., \& Villen, J. (2015). Phosphorylation of ubiquitin at Ser65 affects its polymerization, targets, and proteomewide turnover. EMBO Rep, 16(9), 1131-1144.

Tai, H. C., \& Schuman, E. M. (2008). Ubiquitin, the proteasome and protein degradation in neuronal function and dysfunction. Nature Reviews Neuroscience, 9(11), 826-838.

Tang, Y. P., Liu, G., Rampon, C., Dube, G. R., Shimizu, E., Zhuo, M., Lio, G., \& Tsien, J. Z. (1999). Genetic enhancement of learning and memory in mice. Nature, 401(6748), 63-69.

Tantra, M., Hammer, C., Kastner, A., Dahm, L., Begemann, M., Bodda, C., Hammerschmidt, K., Giegling, I., Stepniak, B., Venzor, A. C., Konte, B., Erbaba, B., Hartmann, A., Tarami, A., Schulz-Schaeffer, W., Rujescu, D., Mannan, A. U., \& Ehrenreich, H. (2014). Mild expression differences of MECP 2 influencing aggressive social behavior. EMBO Molecular Medicine, 6(5), 1-22.

Towbin, H., Staehelint, T., \& Gordon, J. (1979). 1979 Towbin Electrophoretic transfer of proteins from polyacrylamide gels to nitrocellulose sheets, 76(9), 4350-4354.

Trommald, M., Hulleberg, G., \& Andersen, P. (1996). Long-term potentiation is associated with new excitatory spine synapses on rat dentate granule cells. Learning Memory, 3(2-3), 218-228.

Tsien, J. Z., Huerta, P. T., \& Tonegawa, S. (1996). The Essential Role of Hippocampal CA1 NMDA Receptor - Dependent Synaptic Plasticity in Spatial Memory. Cell, 87(7), 1327-1338.

Turvy, D. N., \& Blum, J. S. (2004). Biotin Labeling and Quantitation of CellSurface Proteins. Current Protocols in Immunology, 1-12.

Van Bemmelen, M. X., Rougier, J. S., Gavillet, B., Apothéloz, F., Daidié, D., 
Tateyama, M., Rivolta, I., Thomas, M. A., Kass, R. S., Staub, O., \& Abriel, H. (2004). Cardiac voltage-gated sodium channel $\mathrm{Na} \vee 1.5$ is regulated by Nedd4-2 mediated ubiquitination. Circulation Research, 95(3), 284-291.

Vanli-yavuz, E. N., Ozdemir, O., Demirkan, A., Ctal, S., Bebek, N., Ozbek, U., \& Baykan, B. (2015). Investigation of the possible association of NEDD4 - 2 ( NEDD4L ) gene with idiopathic photosensitive epilepsy. Acta Neurologica Belgica, 2(115), 241-245.

Vina-vilaseca, A., \& Sorkin, A. (2010). Lysine 63-linked Polyubiquitination of the Dopamine Transporter Requires WW3 and WW4 Domains of Nedd4-2 and UBE2D Ubiquitin-conjugating Enzymes, 285(10), 76457656.

Volfovsky, N., Parnas, H., Segal, M., \& Korkotian, E. (2018). Geometry of Dendritic Spines Affects Calcium Dynamics in Hippocampal Neurons: Theory and Experiments. Journal of Neurophysiology, 82(1), 45-62.

Wang, D., Cui, Z., Zeng, Q., Kuang, H., Wang, L. P., Tsien, J. Z., \& Cao, X. (2009). Genetic enhancement of memory and long-term potentiation but not CA1 long-term depression in NR2B transgenic rats. PLoS ONE, 4(10), 1-8.

Wang, Y. A., Yu, X., Silverman, P. M., Harris, R. L., \& Edward, H. (2010). NIH Public Access, 385(1), 22-29.

Williams, M. T., \& Vorhees, C. V. (2006). Morris water maze: procedures for assessing spatial and related forms of learning and memory. Nature Protocols, 1(2), 848-858.

Winkler, D., Daher, F., Wüstefeld, L., Hammerschmidt, K., Poggi, G., Seelbach, A., Krueger-Burg, D., Vafadari, B., Ronnenberg, A., Liu, Y., Kaczmarek, L., Schlüter, O. M., Ehrenreich, H., \& Dere, E. (2018). Hypersocial behavior and biological redundancy in mice with reduced expression of PSD95 or PSD93. Behavioural Brain Research, 352, 3545.

Woelk, T., Sigismund, S., Penengo, L., \& Polo, S. (2007). The ubiquitination code: A signalling problem. Cell Division, 2, 1-12.

Wong, R. W.-C., Setou, M., Teng, J., Takei, Y., \& Hirokawa, N. (2002). Overexpression of motor protein KIF17 enhances spatial and working 
memory in transgenic mice. Proceedings of the National Academy of Sciences, 99(22), 14500-14505.

Yang, B., \& Kumar, S. (2009). Nedd4 and Nedd4-2: closely related ubiquitin-protein ligases with distinct physiological functions. Cell Death and Differentiation, 17(1), 68-77.

Zemoura, K., Schenkel, M., Acuña, M. A., Yévenes, G. E., Zeilhofer, H. U., \& Benke, D. (2013). Endoplasmic reticulum-associated degradation controls cell surface expression of $\mathrm{Y}$-aminobutyric acid, type $\mathrm{B}$ receptors. Journal of Biological Chemistry, 288(48), 34897-34905.

Zeng, H., Chattarji, S., Barbarosie, M., Rondi-Reig, L., Philpot, B. D., Miyakawa, T., Bear, M. F., \& Tonegawa, S. (2001). Forebrain-specific calcineurin knockout selectively impairs bidirectional synaptic plasticity and working/episodic-like memory. Cell, 107(5), 617-629.

Zhou, R., Patel, S. V., \& Snyder, P. M. (2007). Nedd4-2 catalyzes ubiquitination and degradation of cell surface ENaC. Journal of Biological Chemistry, 282(28), 20207-20212.

Zhu, J., Lee, K. Y., Jewett, K. A., Man, H., \& Chung, H. J. (2017). Epilepsyassociated gene Nedd4-2 mediates neuronal activity and seizure susceptibility through AMPA receptors. Plos Genetics, 13(2), 1-24. 


\section{ACKNOWLEDGEMENTS}

I would like to express my gratitude toward all the people who made this work possible. First, I would like to express my sincere gratitude towards Dr. Hiroshi Kawabe for giving me the opportunity to achieve my doctoral studies in his group, and work on very interesting projects, for his support, guidance, training in experimental skills, long scientific discussions, and all the time that devoted for my scientific growth.

I am also deeply grateful to Prof. Dr. Nils Brose, head of the Molecular Neurobiology Department, Max Planck Institute of Experimental Medicine, and my thesis committee. I would like to thank him for giving me the opportunity to join his department and providing constant support, guidance, and critical input. It was indeed an amazing experience becoming a part of such a big family.

I would like to thank my thesis committee members, Prof. Dr. Thomas Dresbach and Prof. Dr. Tiago Fleming Outeiro, for their critical evaluation and valuable input on my projects during the regular meetings.

I would like to express my gratitude towards every single member of Department of Molecular Neurobiology for an interactive scientific environment during my doctorate. First, I would like to thank Dr. Bekir Altas for his huge help and sharing invaluable expertise with me during numerous experiments. I would like to specifically thank Manuela Schwark for helping me to master in utero electroporation as well as her great assist during the methods courses. I would also like to thank Klaus-Peter Hellmann for his excellent assistance in biochemical experiments. I would like to thank all members of AGCT lab for their hard work on genotyping, DNA sequencing and oligonucleotide synthesis. I am also thankful to the staff of the MPI-EM Animal House Facility for the maintenance of the mouse lines. Even though the group is not there anymore, I would like to thank former Kawabe group: Bekir, Manu, Mohamed, Sonja, Rashi; as well as Ubiquitin/SUMO/Postsynapse subgroup for fruitful discussions. 
This work would not be completed without the collaborators. I sincerely thank Prof. Dr. Hannelore Ehrenreich, Sahab Arinrad and Anja Ronnenberg for characterization of Nedd4-2 mice behavior, without which this study would be incomplete. I am sincerely grateful to Dr. Jeong Seop Rhee and Dr. Erinn Gideons for their great work on electrophysiology using Nedd4-2 mice. I would like to thank Dr. Katrin Willig for introducing me with STED nanoscopy, and her helpful comments and discussions. I am also thankful to Prof. Dr. Michael Kreutz and Mohamed Raafet Ammar for their help with sharing Prr7 KO mice with us.

I want to thank all the colleagues in the Max Planck Institute of Experimental Medicine, and all my friends in Göttingen, who made my life colorful and gave me unforgettable memories. I also appreciate Dr. Erinn Gideons and Lydia Maus for proofreading this manuscript.

I would like to exceptionally thank Efe Arabaci for his unconditional support and strong belief in me. Last, but not least, I am indebted to my family, who has been always there for me, for their invaluable encouragements and support throughout my whole life. 